Check for updates

Cite this: J. Mater. Chem. C, 2021, 9, 9042

Received 31st March 2021

Accepted 25th June 2021

DOI: $10.1039 / \mathrm{d} 1 \mathrm{tc} 01477 \mathrm{c}$

rsc.li/materials-c

\section{A review on electrospun magnetic nanomaterials: methods, properties and applications}

\author{
Yifan Jia, $\dagger^{\mathrm{a}}$ Congyi Yang, $\dagger^{\mathrm{a}}$ Xueyang Chen, ${ }^{a}$ Wenqing Xue, ${ }^{a}$ \\ Helena J. Hutchins-Crawford, (DD ${ }^{b}$ Qianqian Yu, ${ }^{* a}$ Paul D. Topham (DD*b and \\ Linge Wang (D) *a
}

\begin{abstract}
Magnetic materials display attractive properties for a wide range of applications. More recently, interest has turned to significantly enhancing their behaviour for advanced technologies, by exploiting the remarkable advantages that nanoscale materials offer over their bulk counterparts. Electrospinning is a high-throughput method that can continuously produce nanoscale fibres, providing a versatile way to prepare novel magnetic nanomaterials. This article reviews 20 years of magnetic nanomaterials fabricated via electrospinning and introduces their two primary production methods: electrospinning polymer-based magnetic fibres directly from solution and electrospinning fibrous templates for posttreatment. Continual advances in electrospinning have enabled access to a variety of morphologies, which has led to magnetic materials having desirable flexibility, anisotropy and high specific surface area. Post-treatment methods, such as surface deposition, carbonization and calcination, further improve or even create unique magnetic properties in the materials. This renders them useful in broad ranging applications, including electromagnetic interference shielding (EMS), magnetic separation, tissue engineering scaffolding, hyperthermia treatment, drug delivery, nanogenerators and data storage. The processing methods of electrospun magnetic nanofibres, their properties and related applications are discussed throughout this review. Key areas for future research have been highlighted with the aim of stimulating advances in the development of electrospun magnetic nanomaterials for a wide range of applications.
\end{abstract}

\section{Introduction}

Materials that possess magnetic character often exhibit specific desirable properties. This has led to the inclusion of magnetic materials in an ever-growing range of applications, including hard magnetic materials within magneto-biology, ${ }^{1}$ magnetic medicine, ${ }^{2}$ magnetic separation ${ }^{3}$ and electrical machinery and soft magnetic materials in stator or rotator parts of generators and motors. ${ }^{4}$ In addition to the various types of magnetic materials, there is also a variety of magnetic functional materials with various niche functions and applications such as giant magnetic resistors, magneto-strictive materials, magnetic fluids and magnetic refrigeration materials. For these applications pure

\footnotetext{
${ }^{a}$ South China Advanced Institute for Soft Matter Science and Technology, School of Molecular Science and Engineering, Guangdong Provincial Key Laboratory of Functional and Intelligent Hybrid Materials and Devices, South China University of Technology, Guangzhou 510640, China.E-mail: yuqianqian@scut.edu.cn, lingewang@scut.edu.cn

${ }^{b}$ Chemical Engineering and Applied Chemistry, School of Infrastructure and Sustainable Engineering, College of Engineering and Physical Sciences, Aston University, Birmingham, B4 7ET, UK. E-mail: p.d.topham@aston.ac.uk

$\dagger$ Y. Jia and C. Yang contributed equally to this work.
}

organic, pure inorganic and hybrid organic-inorganic composite materials have become of increasing interest.

Within the past few decades many classic bulk materials (such as magnetic materials) have been processed into shapes with one or more dimensions at the nanoscale, rendering the materials with desirable properties that nanotechnology delivers. Among these magnetic nanomaterials, materials with two-dimensional scale constraints such as nanofibres (NFs) achieve incredible advances due to their anisotropic nature. NFs exhibit great enhancement and control of many properties with the most notable being flexibility, large specific surface area, porosity and coercivity $\left(H_{\mathrm{c}}\right)$.

Electrospinning is a simple means of processing materials to form NFs, where polymer chains align themselves under an electrostatic force to form elongated, thin, filamentous nanostructures. During the process, a polymer solution (or melt) is stretched and deformed by the electrostatic force and a droplet forms at the tip of needle. The shape of the droplet is determined by gravity, viscosity, surface tension and electric field. In the process of electrospinning, the most common droplet shape is a cone, referred to as the Taylor cone. ${ }^{5,6}$ When charge repulsion exceeds surface tension the polymer is pulled from the end of the Taylor cone. The modes of flow are also determined by the 
aforementioned forces. The withdrawn flow initially experiences stable motion and is then forced into an unstable stage where the polymer solidifies in the air to form fibres, which are then received by the collector.

The final properties of the fibres are influenced by three key factors:

(i) solution properties (such as the viscosity, concentration, polymer molecular weight and dielectric properties of the solution);

(ii) processing parameters (such as applied voltage, needleto-collector distance and feeding rate) and

(iii) environmental conditions (such as temperature, humidity and air flow around the system).

These factors demonstrate the diverse range of magnetic electrospun NFs that can be produced from a single chemical composition; as the structure of a single NF and the fibre assembly can be manipulated by other means. Indeed, advances in the control over electrospun NFs is envisioned to vastly benefit the magnetic material field. For example, electrospinning is the only known method used to prepare continuous ultra-long, thin NFs. ${ }^{7}$

To the best of our knowledge, there are no comprehensive reviews of electrospun magnetic NFs that evaluate their methods of production, properties and applications. Herein, we have reviewed articles from 20 years of research on electrospun magnetic fibres. The review is divided into three main parts (as shown in Fig. 1): (i) electrospinning organic-inorganic hybrid magnetic materials (summarised in Table 1); (ii) using electrospun fibres as templates for the creation of both hybrid and solely inorganic magnetic materials (summarised in Table 2); and (iii) applications of magnetic nanofibrous materials. As explained in this review, organic-inorganic composite magnetic nanomaterials can be prepared via a one-step method and the resulting nanofibrous matrix can provide magnetic nanoparticles (MNPs) with mechanical support, protection against oxidation and favourable dispersion (Section 2). Alternatively, for pure inorganic

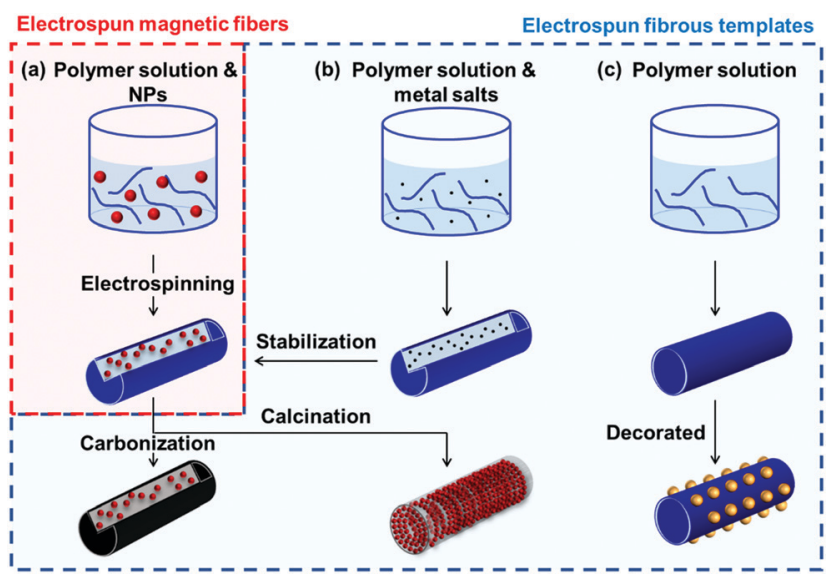

Fig. 1 General methods to prepare electrospun magnetic fibres, where the area process highlighted in red is discussed in Section 2 (a) and the processes highlighted in blue are discussed in Section 3 (b and c). (a) Direct method for producing magnetic nanofibres; (b) templating procedure of MNFs from a magnetic pre-cursor solution and (c) templating procedure of MNFs where the magnetic component is deposited upon them. magnetic NFs (Section 3), electrospinning is a simple, available tool used in the fabrication of fibrous templates with different morphological structures enabling the user to manipulate the magnetic properties of the final product. The major difference between these two strategies is that organic matter is removed in the latter to create the final inorganic product. In the final section (Section 4), we explore the various applications of these advanced materials from electromagnetic interference (EMI) shielding and pollutant treatment, to biomedical devices in drug delivery and tissue engineering. In short, this review focuses on the processing methods of electrospun magnetic composite NFs and pure inorganic NFs from templates, their properties and related applications.

Finally, as aforementioned, we summarise the complete literature of magnetic NFs in two comprehensive tables, where Table 1 covers systems in the category described in Section 2 [i.e. organic-inorganic hybrid magnetic nanofibrous materials created directly from electrospinning solution(s)] and Table 2 lists those systems created from electrospun fibrous templates, as described in Section 3. Both tables describe the methodological approaches used, properties obtained and potential applications, where relevant. We anticipate that these tables will serve as a useful repository for researchers, in addition to those new to the field, looking to study such advanced materials.

\section{Electrospinning magnetic materials: reagents, methods and morphologies}

Electrospun polymer-magnetic material composite fibres have been widely reported across the literature. This section discusses the various electrospinning methods and parameters used to manipulate the creation of magnetic NFs, before reviewing the variety of magnetic materials that have been used. Table 1 serves as a comprehensive summary of this section, listing the various systems that have been explored, the magnetic reagent(s), polymer(s), electrospinning approach, major magnetic property and applications (where relevant) in each case.

\subsection{Electrospinning methods and fibre structures}

Electrospinning is a primary method used to prepare continuous nanofibrous materials with advantages such as simple device manufacture, material compatibility and controllable fibre morphology. Fibres produced by electrospinning have high surface area-to-volume ratios, tuneable surface morphology and controlled alignment. The specific morphology of the fibre can control the distribution of nanoparticles (NPs). ${ }^{8}$ In this section, we discuss the various electrospinning parameters that can be used to create an array of NFs, specifically focusing on magnetic NFs.

2.1.1 Materials. NFs can be produced by electrospinning from a solution or melt of a variety of materials. Adequate entanglement is the key for the material to be suitable for electrospinning. Most polymeric materials produce enough entanglement to perform both solution and melt electrospinning. The extent of entanglement is related to the polymer molecular weight, the concentration and the solvent system. Sufficiently low molecular weight, low 


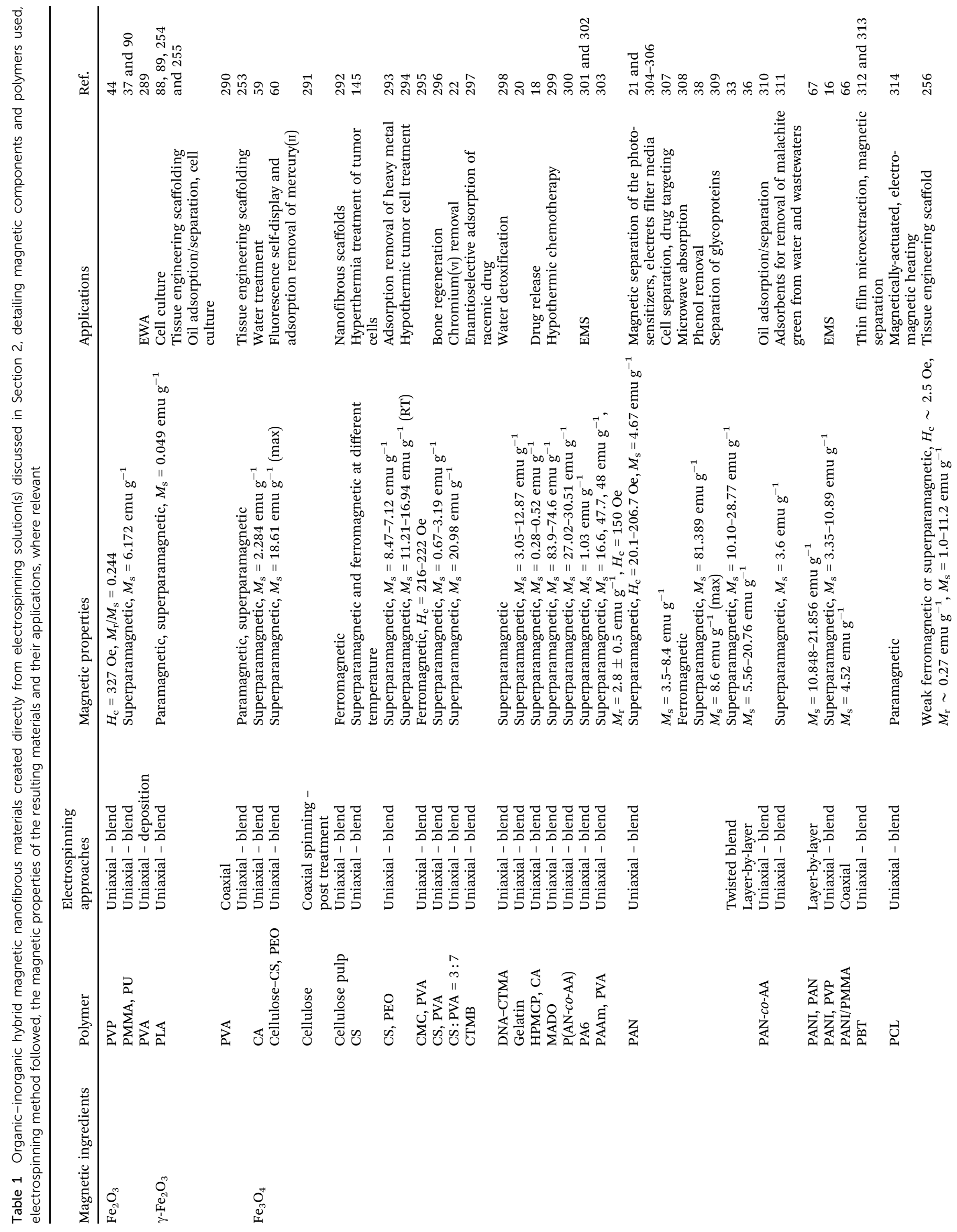


$\sqrt{8}$

8

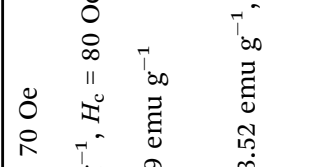

i.

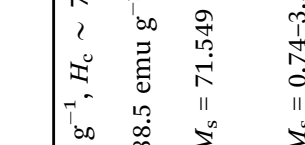

$\sum \quad \sum^{n}$

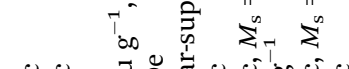

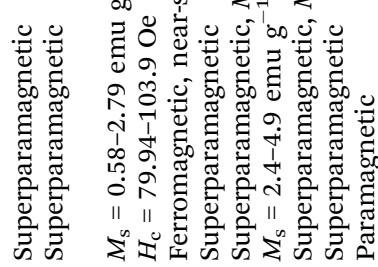

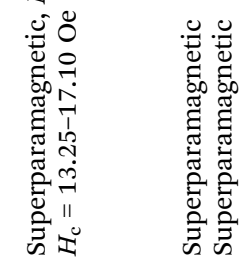

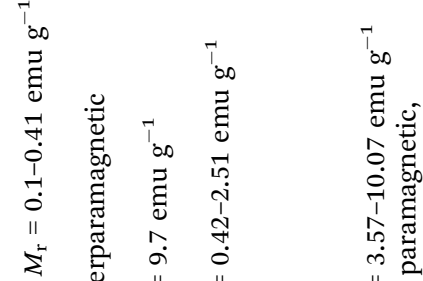

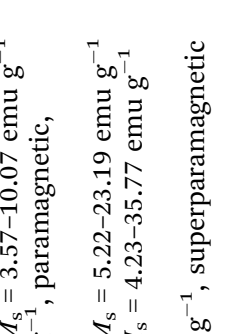

Ton $\sum^{n+1} \sum_{0}^{n} \sum^{n}$

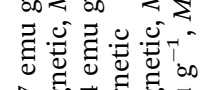

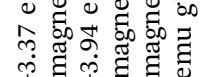

记

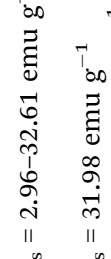

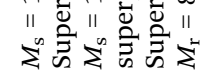

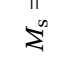
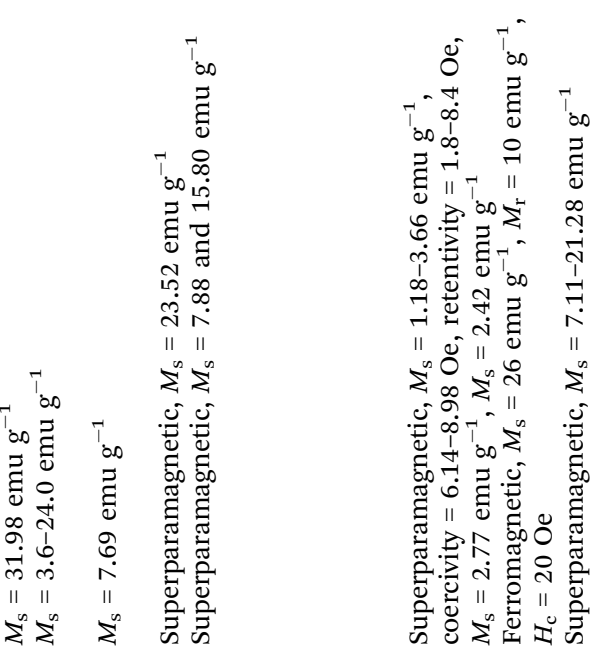

్ㅗㅁ
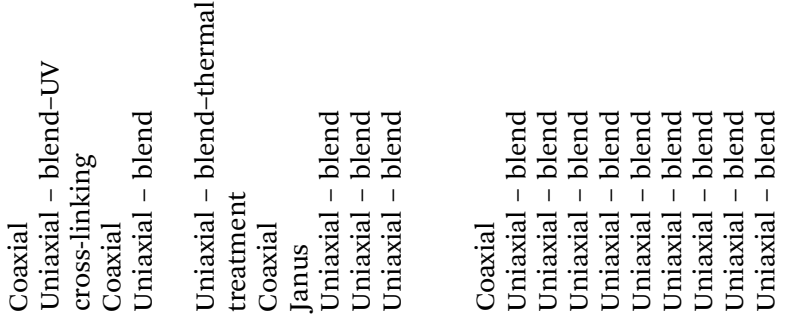

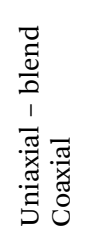
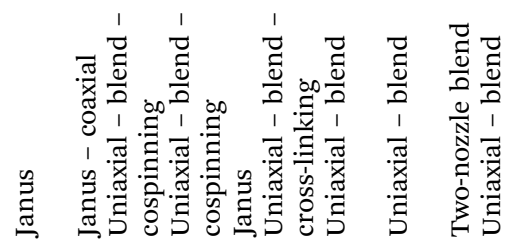

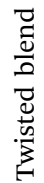

$\ddot{0}$
$\| 1$
$\tilde{0}$
$\ddot{0}$
$\ddot{0}$

离

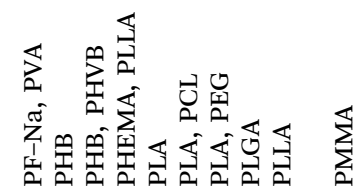

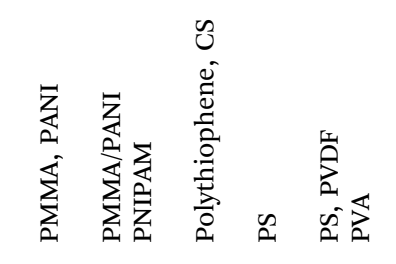

\section{$\sqrt{1}$}




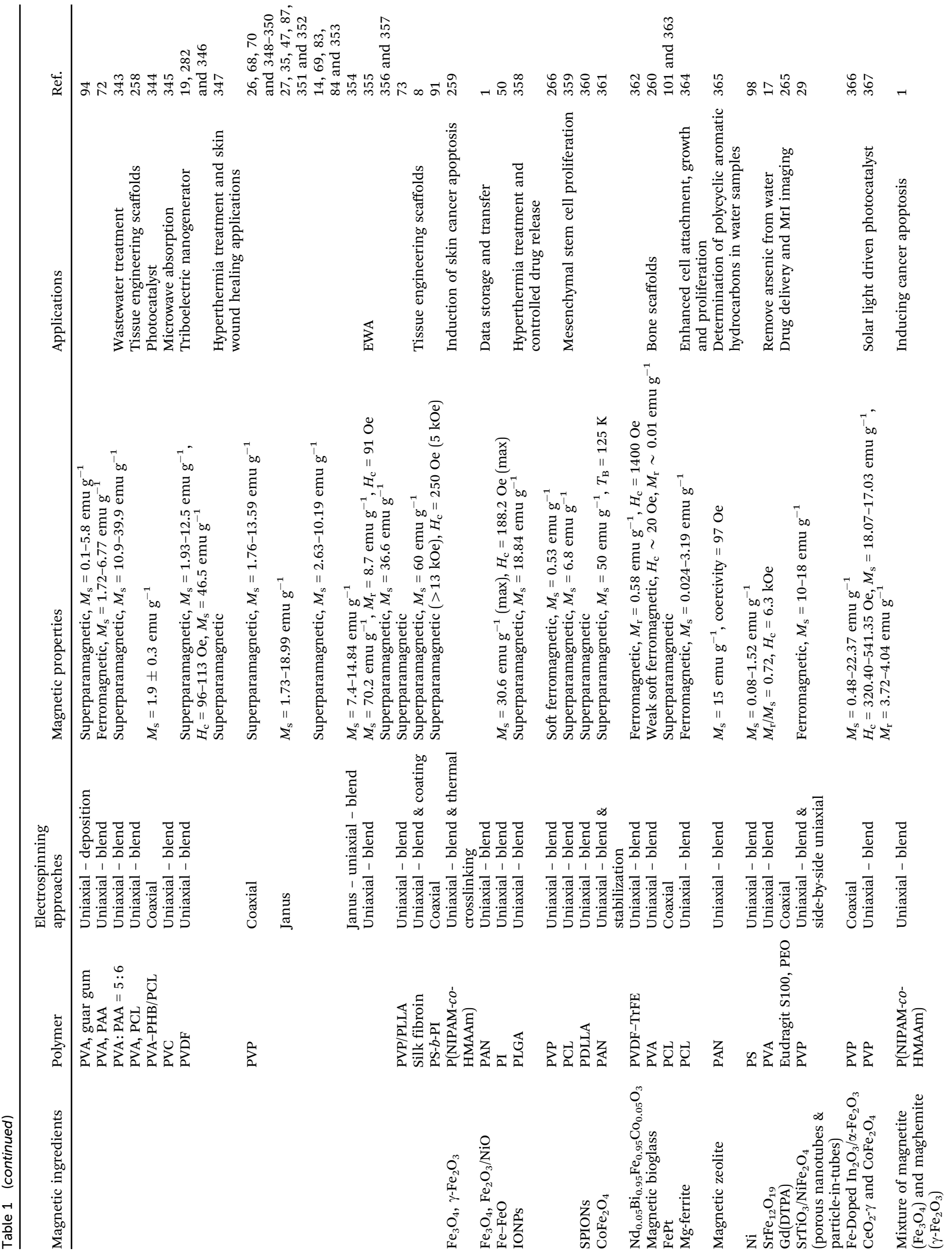




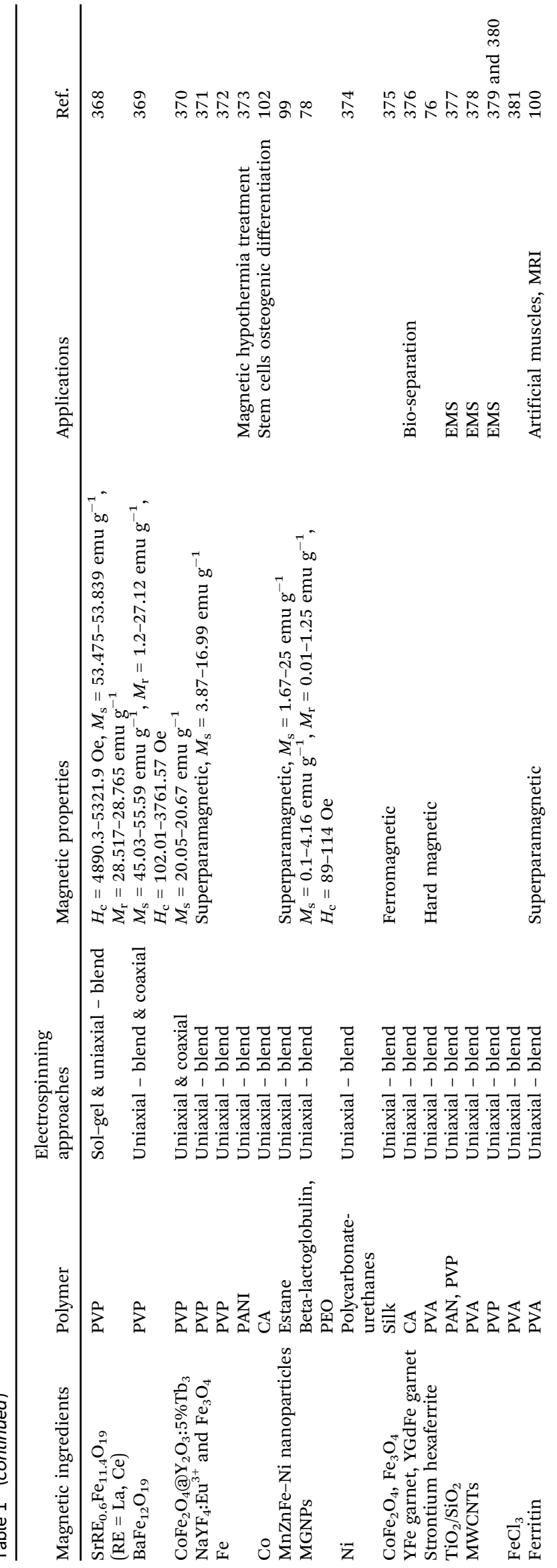

concentration or poor solubility typically result in beaded structures (beaded fibres or discrete microspheres) rather than long defect-free fibres. Wang et al. ${ }^{9}$ studied the effect of solvent on the preparation of fibres and beads and found that decreasing the compatibility between the solvent and the polymer decreased the intermolecular entanglement, thus producing beads.

Nanoparticles can also be electrospun by adding nanoscale components into the polymer carrier. However, in order to form uniform nanoparticles some materials require pre-treatment. Common examples of pre-treatment include sol-gel treatment of the polymer solution and dispersive pre-treatment of composite nanoparticles, such as ultrasonic dispersion ${ }^{10-13}$ or coating with oleic acid (or grafting with a coupling agent) to prevent undesirable aggregation. ${ }^{14-17}$

2.1.2 Electrospinning rigs. Fig. 2 shows the wide range of electrospinning rigs that have been used to create various nanofibrous fabrics. The most commonly used electrospinning rig is relatively simple and is comprised of a power supply, a liquid supply device and a collector (Fig. 2(a)). The power supply provides sufficient electric field force to create liquid filaments. Adjustment of the liquid supply parameters such as; flow rate of solution, needle structure and mode of liquid supply, allow for continuous and uniform fibres to be formed. In addition to common single and multiple needle set-ups, there are also needleless devices such as silk thread, bulged roller and liquid pool. In these cases, the collector is usually a flat plate and the morphology of the fibre mat can be regulated by changing the collection method. ${ }^{11}$

2.1.2.1 Uniaxial electrospinning. Uniaxial electrospinning is the most simplistic device design (Fig. 2(a)). The liquid supply uses a solitary nozzle to prepare a single component of solid micro/nanofibre. ${ }^{18}$ Fibres have been prepared, via uniaxial electrospinning, with different morphologies including; nanobelt (Fig. 3(c)), bead-on-string (Fig. 3(d)), and connected fibre mesh structures. ${ }^{19-22}$ The various morphologies provide different characteristics, such as hydrophobicity and mechanical properties. Superhydrophobicity is caused by the huge specific surface area of the fibrous mesh membrane. The large surface area of the membrane can greatly reduce the contact area between the fibrous membrane surface and the liquid. Additionally, the micro- and nanoscale voids on the surface of the specimen can easily trap air, and when water droplets come into contact with the material the air holds the droplets up in accordance with the typical CassieBaxster contact model. ${ }^{23}$ Additionally, it has been shown that electrospinning can be used to construct a composite structure of electrospun nanofibres decorated with microspheres to provide the superhydrophobic character. On this basis it becomes easier to design and control the micro-nano structure of the surface, allowing the perfect realisation of superhydrophobic structures. ${ }^{24,25}$

2.1.2.2 Coaxial electrospinning. Coaxial electrospinning (Fig. 2(b and c)) can be used to produce continuous, singlechannel, or multi-channel core-shell and hollow fibres. The fibres are prepared by using two or more coaxial nozzles of 


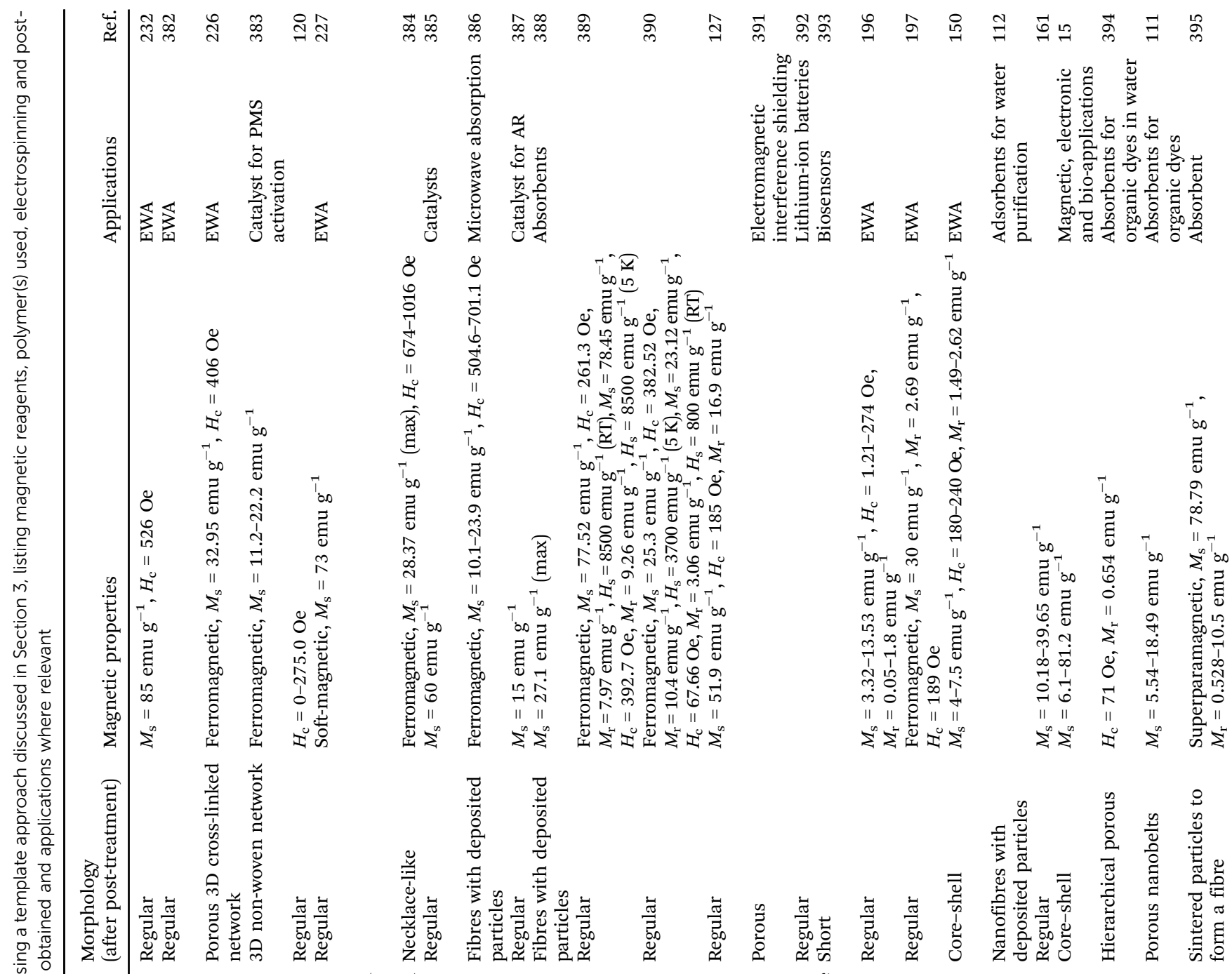

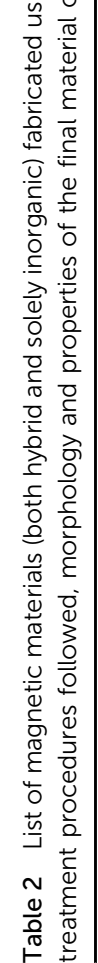<smiles>[CH][C@H]1C[C@@H]1C</smiles><smiles>CCC</smiles><smiles>[CH][CH][CH]</smiles> 


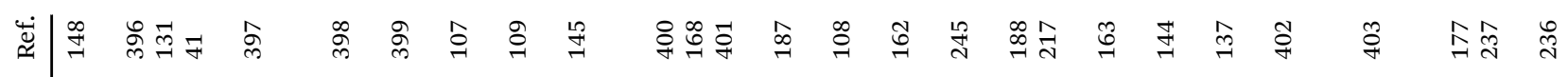

$\stackrel{0}{\circ}$

$$
\text { 苛 }
$$

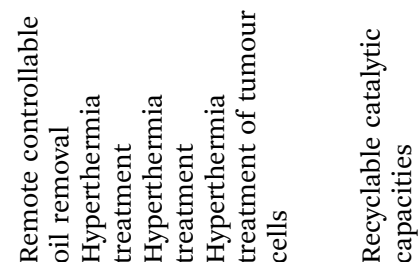

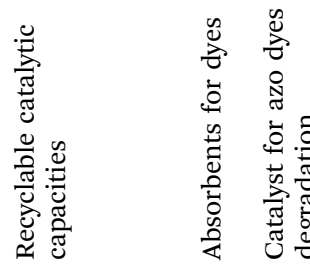

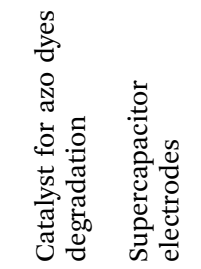

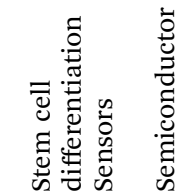
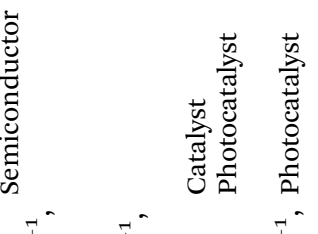

垔

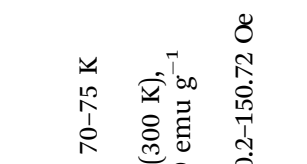

西

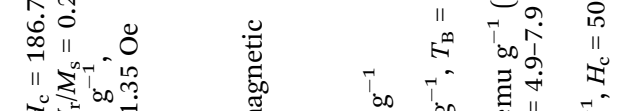

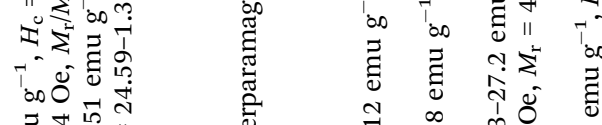

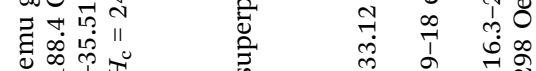

com

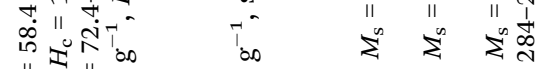

$\sum^{n-1}$ "no

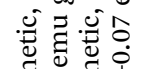

(5)

苟 in है

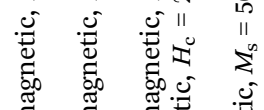

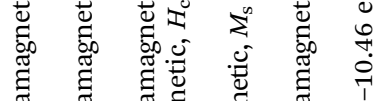

芯

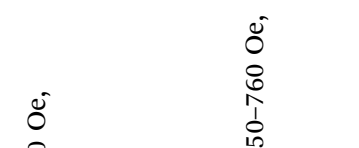

חু

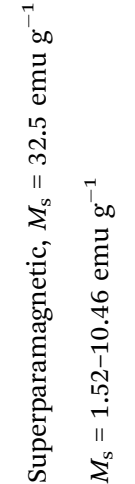

i.

它

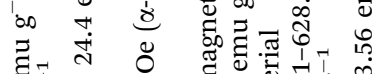

क्षा कo "

我 $=\sum^{\infty}$

$$
\text { 政 }
$$

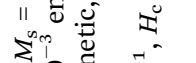

i을

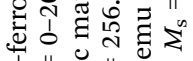

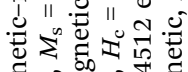

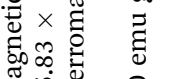

कृ.

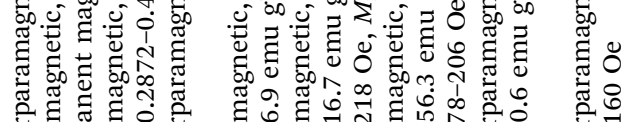

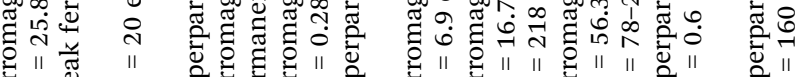

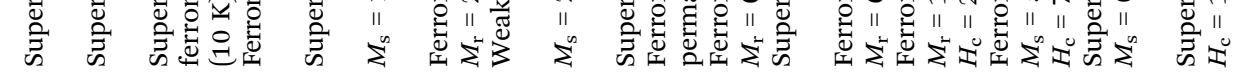

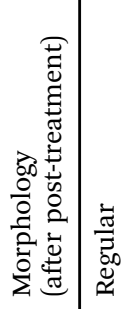

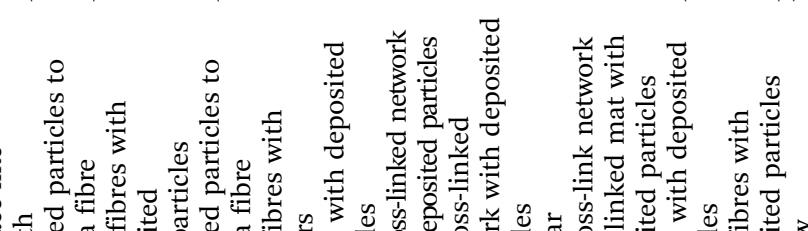

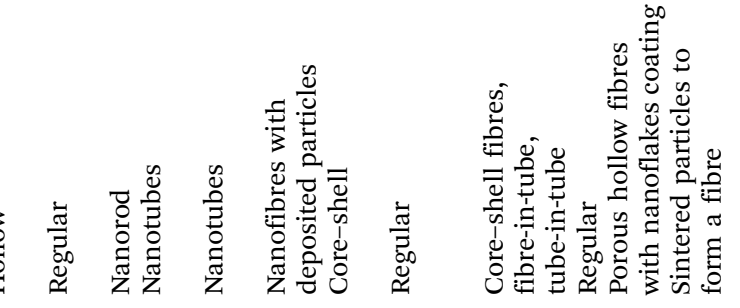
응 모

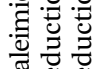

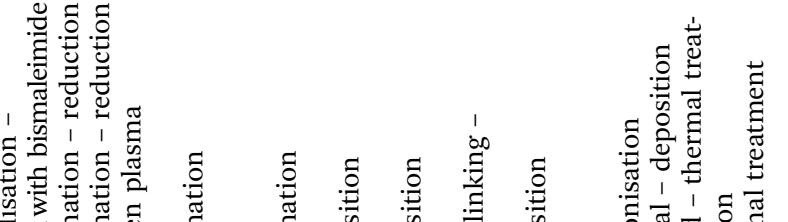

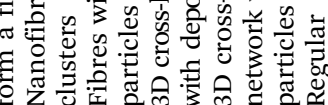

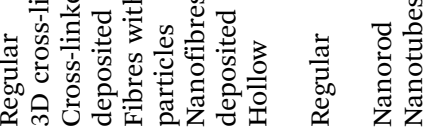

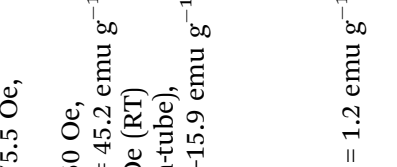

10

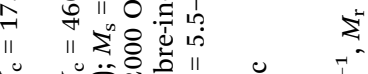

.

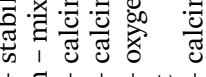

苞

离

吾

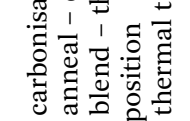

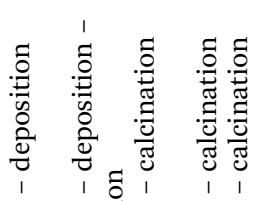

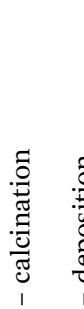

量

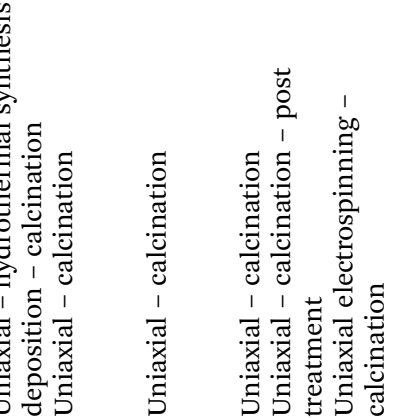

悹

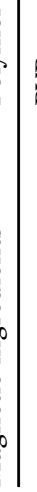

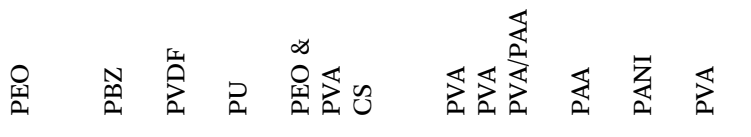

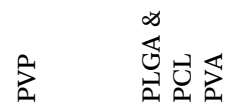

点

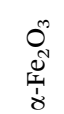

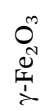

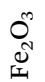



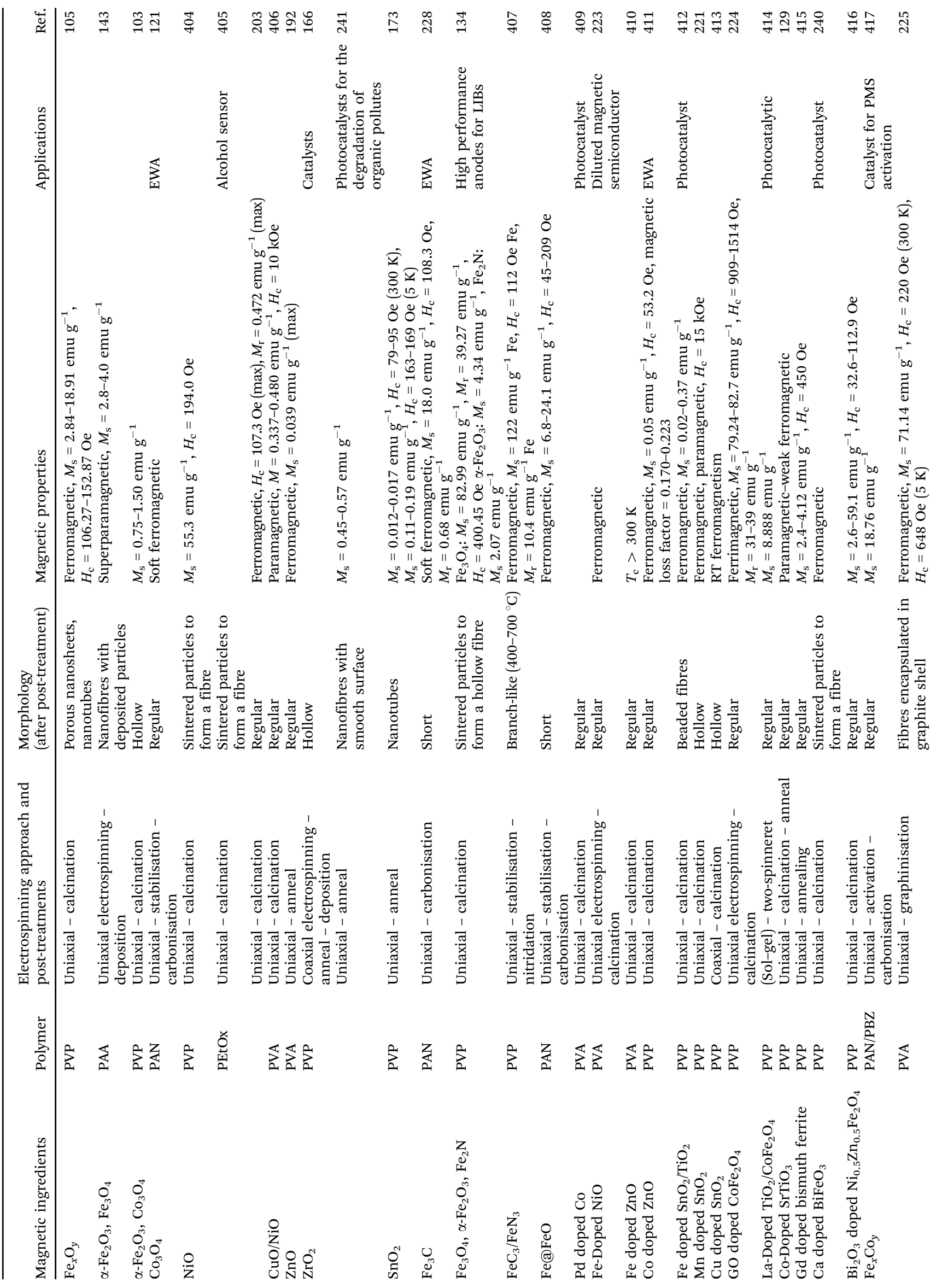

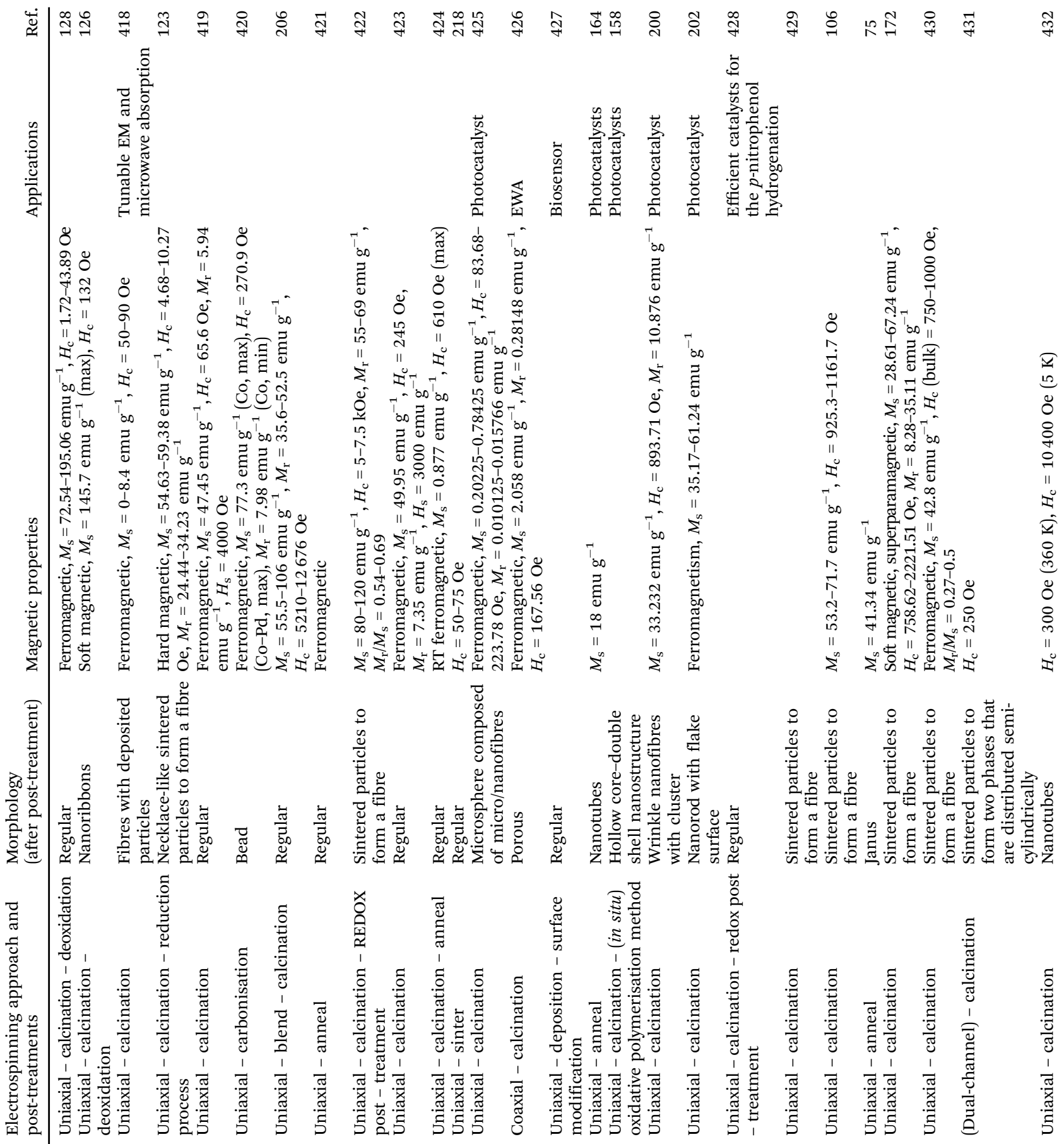

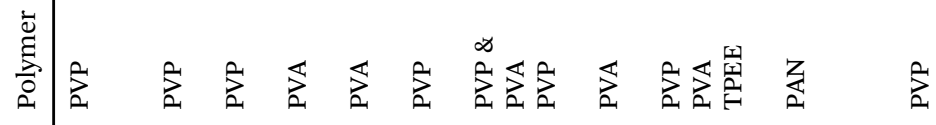

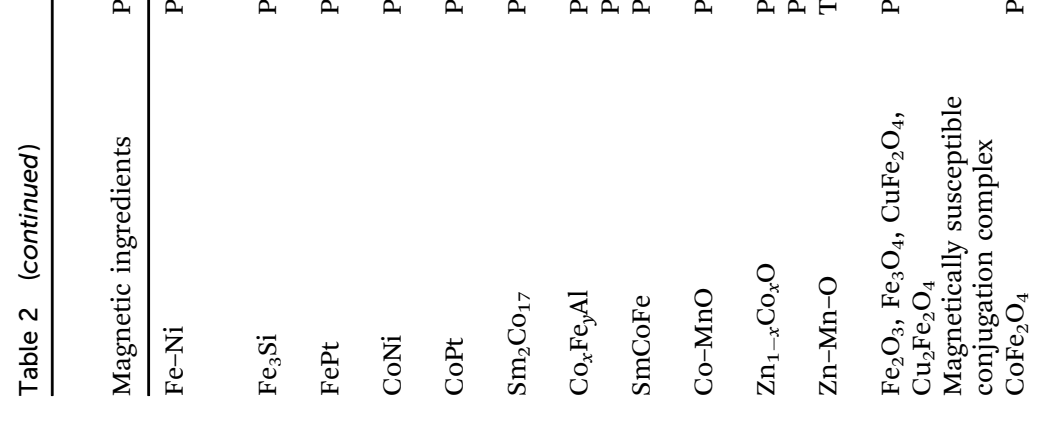




\begin{tabular}{|c|c|c|c|c|c|c|c|c|c|c|c|c|c|c|c|}
\hline$\ddot{\widetilde{u}}$ & $\stackrel{\infty}{\mathscr{F}} \quad \exists \underset{F}{\exists}$ & 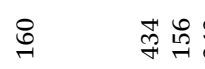 & 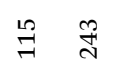 & హ゙ & $\underset{d}{J}$ & 㫄品 & $\underset{\mathscr{F}}{\mathscr{F}}$ & 骂导 & $\underset{\Im}{\stackrel{J}{J}} \stackrel{\infty}{\dddot{q}}$ & $\stackrel{\mathscr{F}}{F}$ & $\stackrel{9}{\forall}$ & సె & $\underset{\sim}{\mathscr{\gamma}}$ & $\underset{\sim}{\mathcal{F}}$ & $\stackrel{1}{\subseteq}$ 孚 \\
\hline 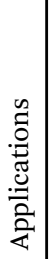 & & & 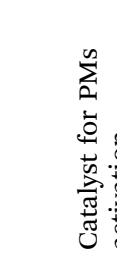 & & 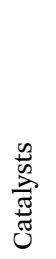 & & 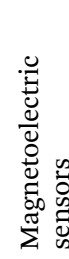 & & & & & & & 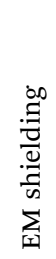 & 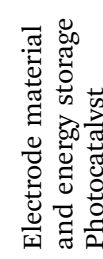 \\
\hline 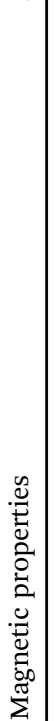 & 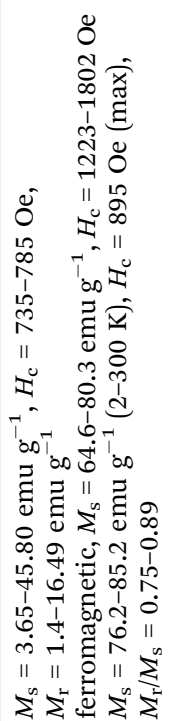 & 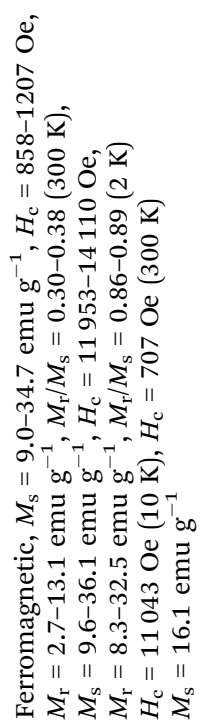 & 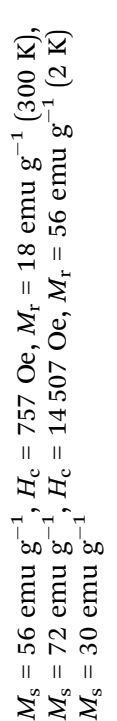 & 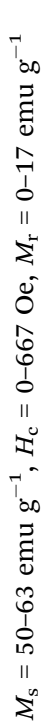 & 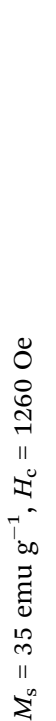 & 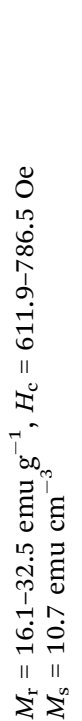 & 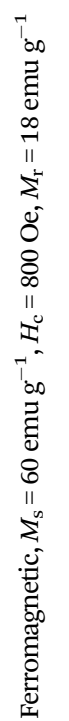 & 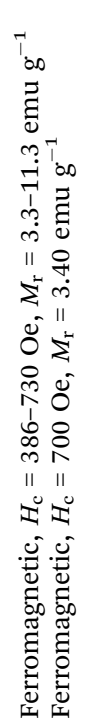 & 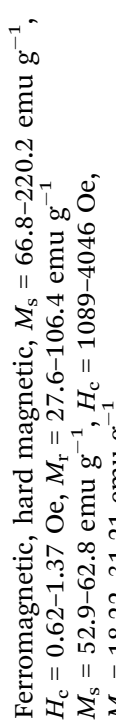 & 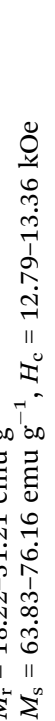 & 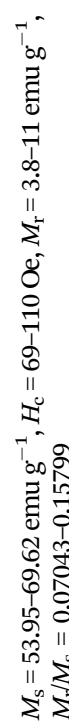 & 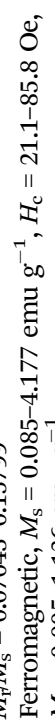 & 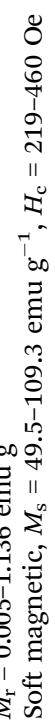 & 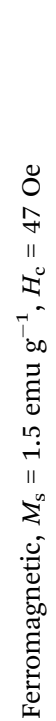 & 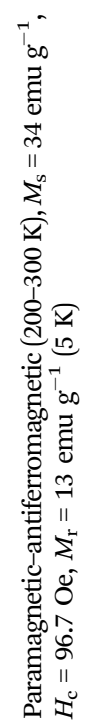 \\
\hline
\end{tabular}
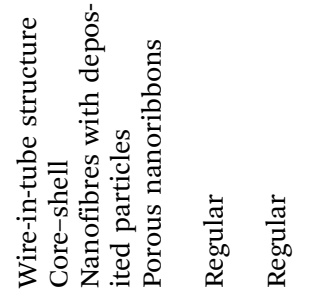

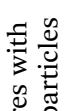

里
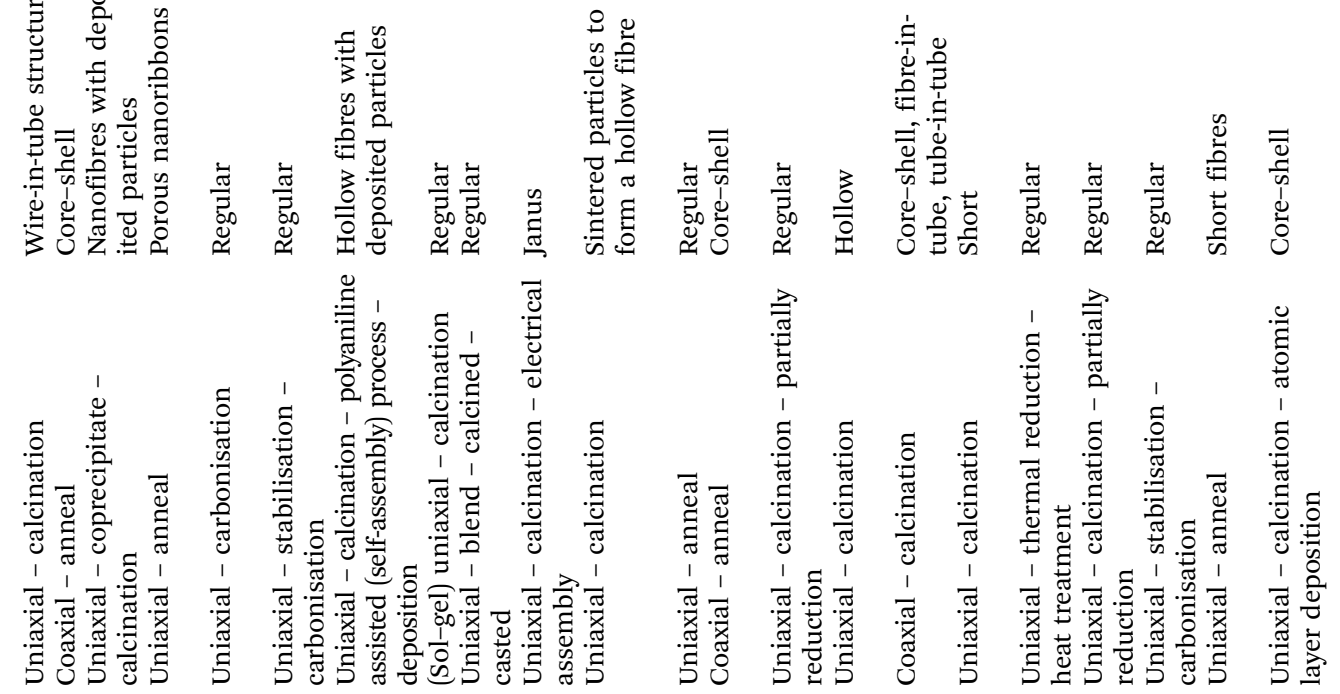

㝌

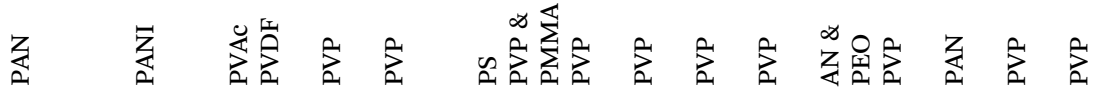
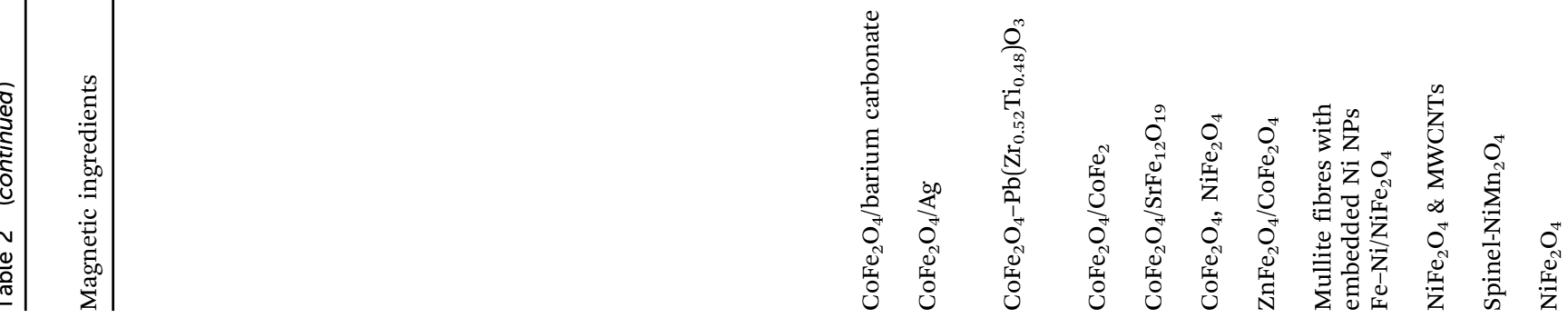


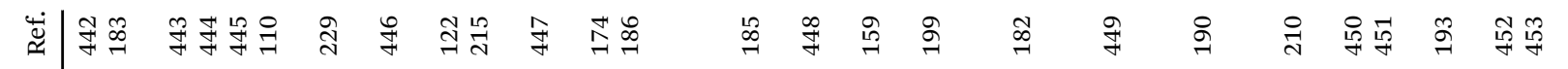



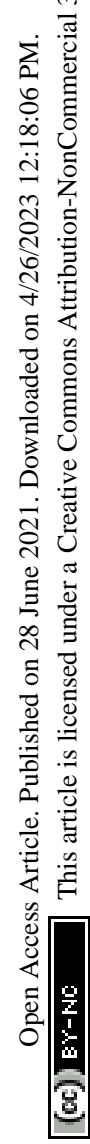

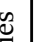

范

¿.

总

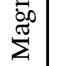

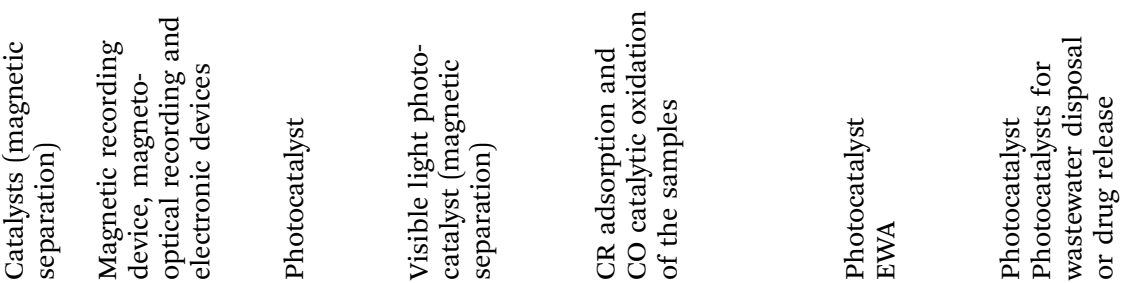

s.

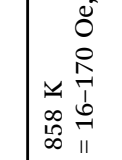

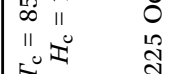

वृ कo

远

II 0 की

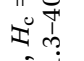

ल- শ.

घ 11 ले

रा

11111 号

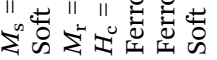

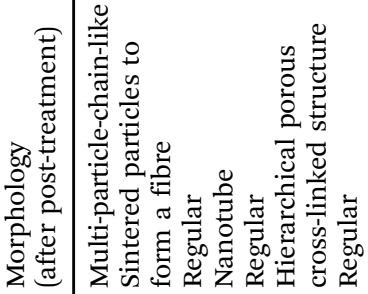

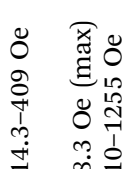

$\begin{array}{lll}\exists & \infty & 0 \\ \| & \| & \|\end{array}$

I

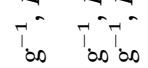

芩

म.

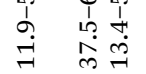

II 1111

$\sum \sum \sum^{n}$

5
5
8
0
0
0
0 


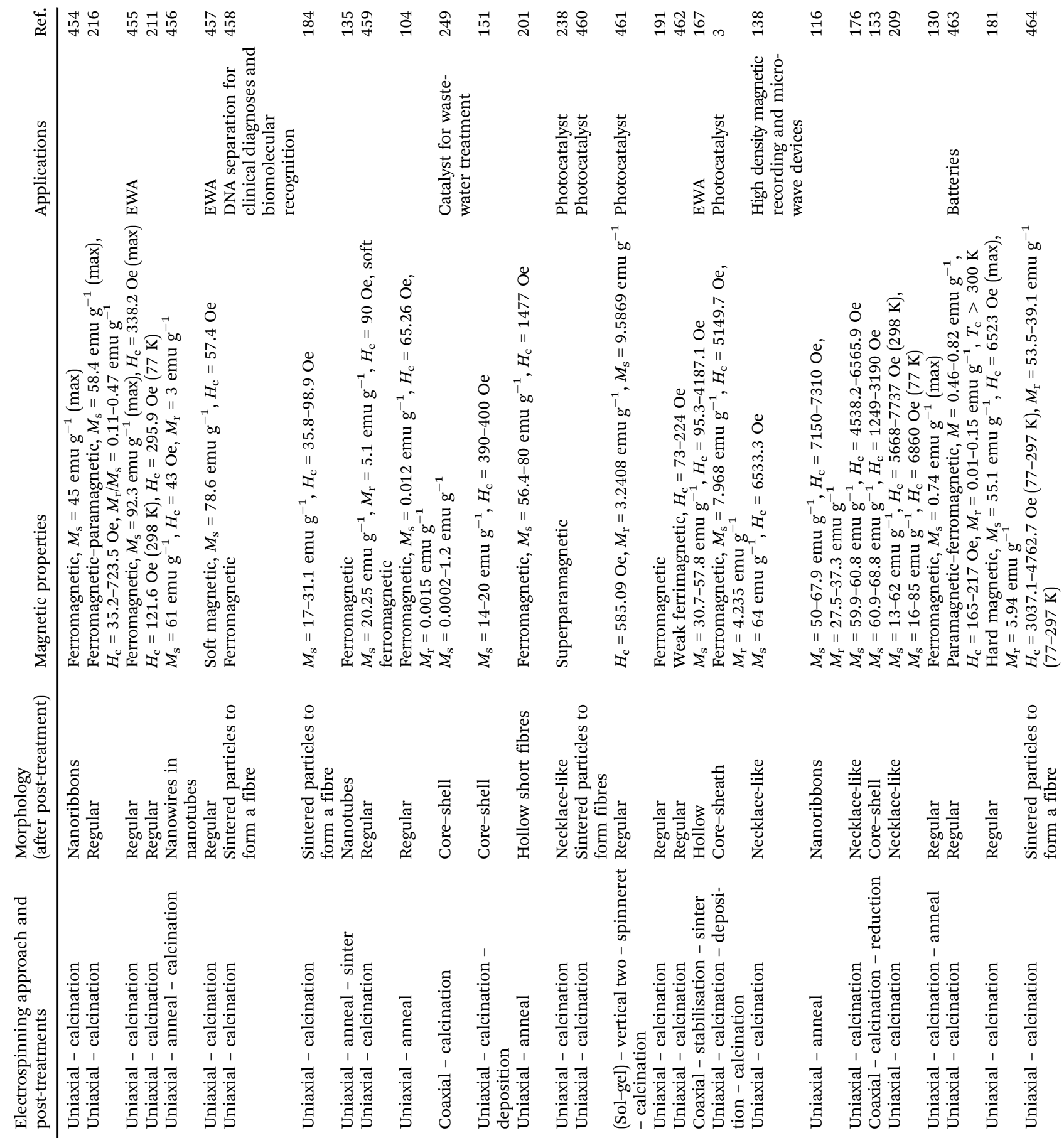

离

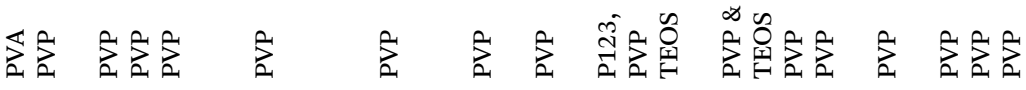

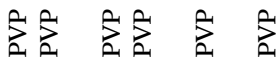

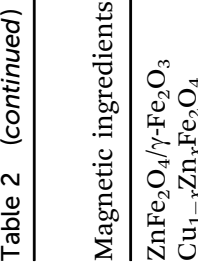

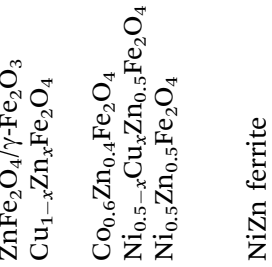
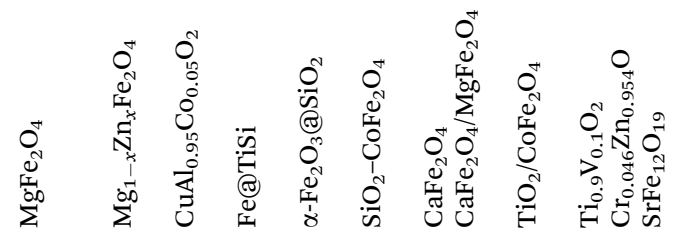

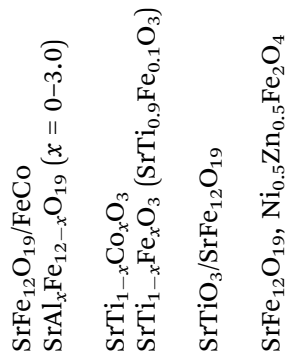




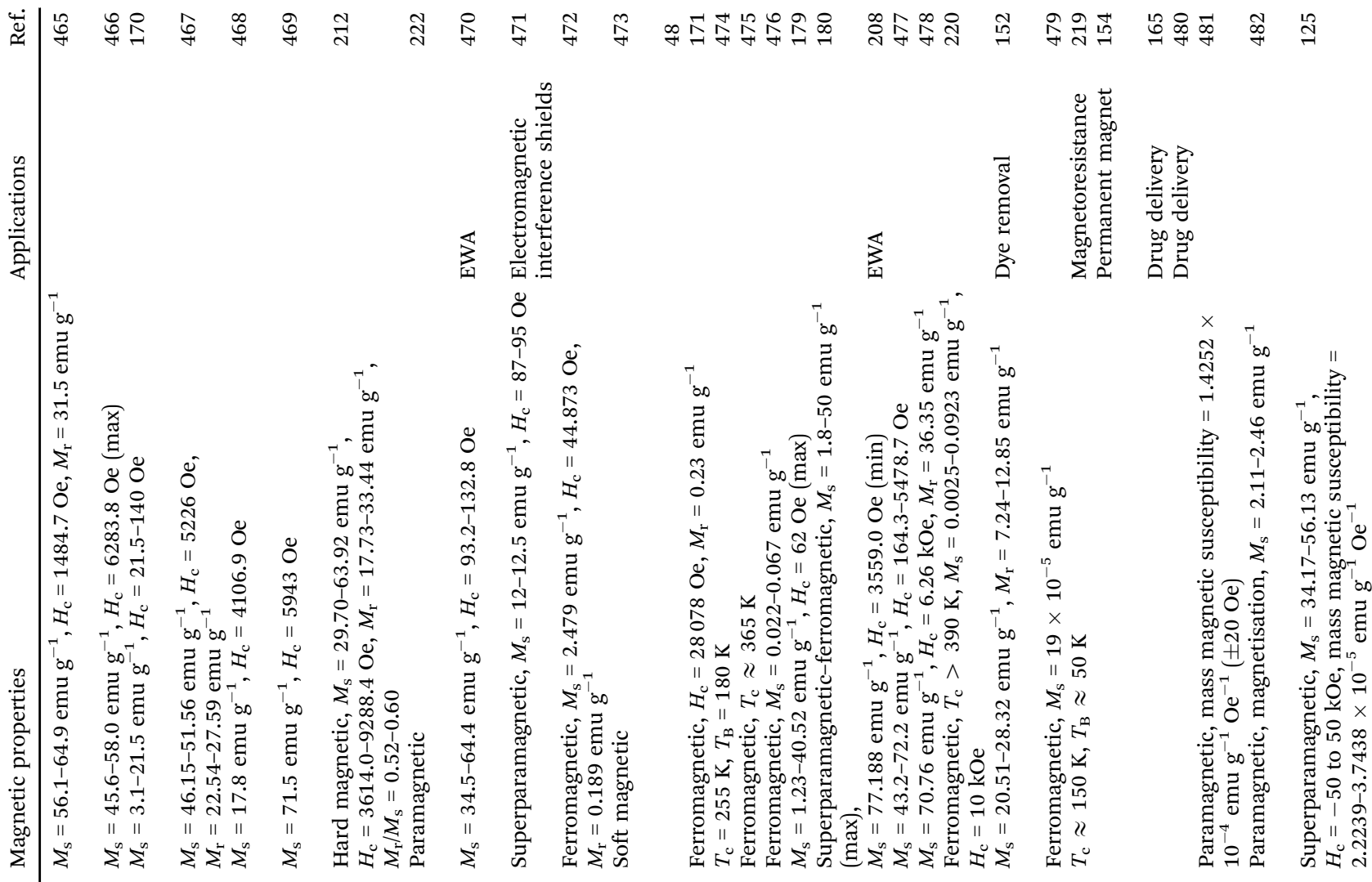

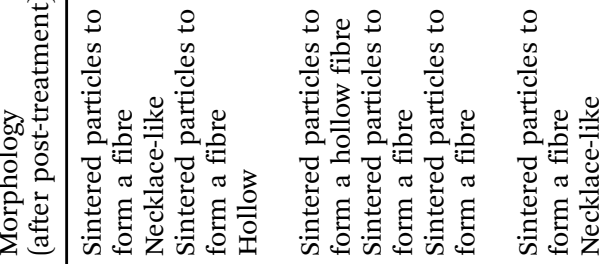

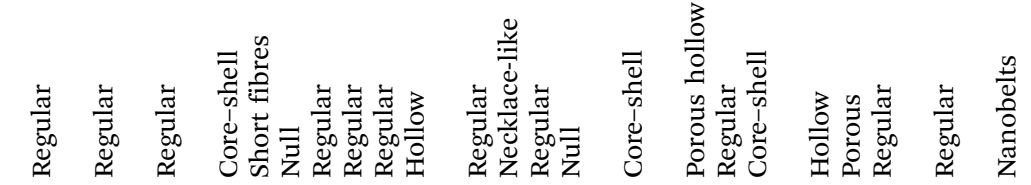

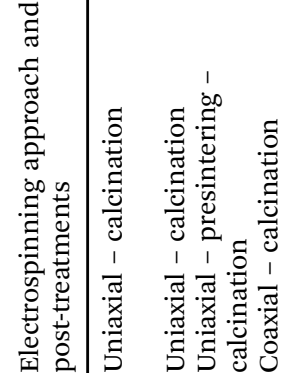
离

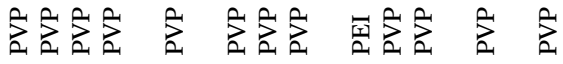




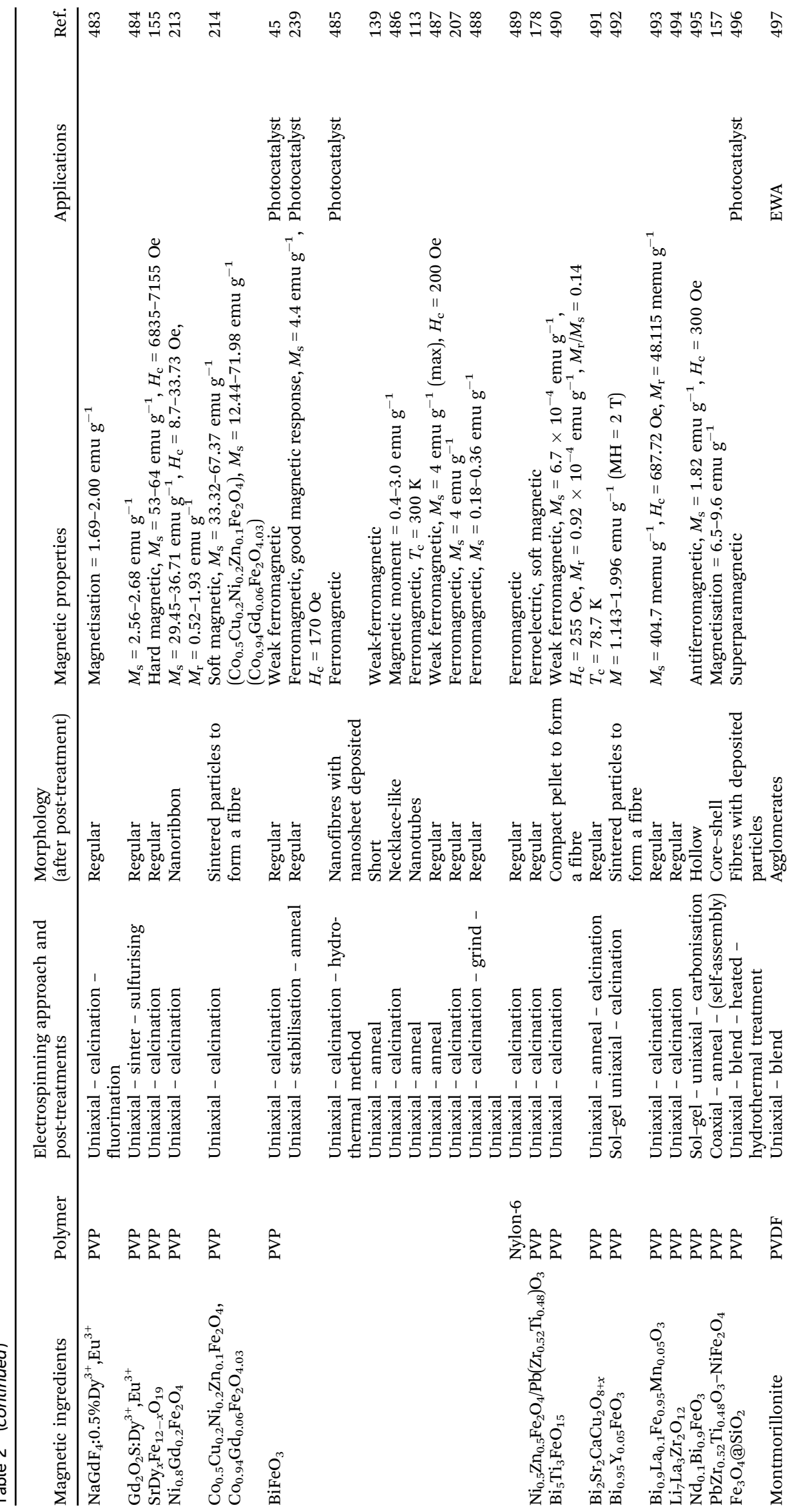


(a)

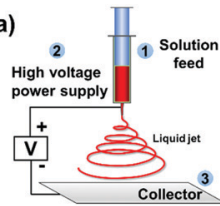

(b)

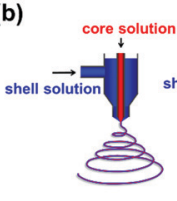

(e)

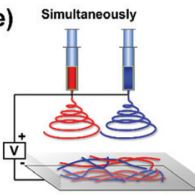

(f) Layer by layer

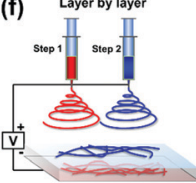

(c)

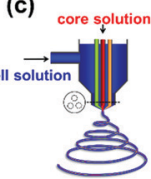

(d)
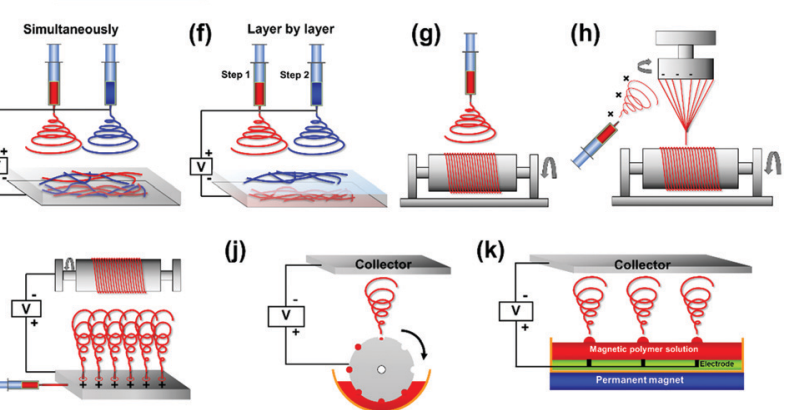

Fig. 2 Variety of different electrospinning apparatus including: (a) three basic parts, (b) core-shell needle, (c) multi-channel needle, (d) Janus fibre needle, (e) fibre blend, (f) layer-by-layer fibre, (g) drum collector, (h) twisted fibre collector, (i) multi-needle electrospinning, (j) drum electrospinning and (k) magnetically assisted electrospinning.
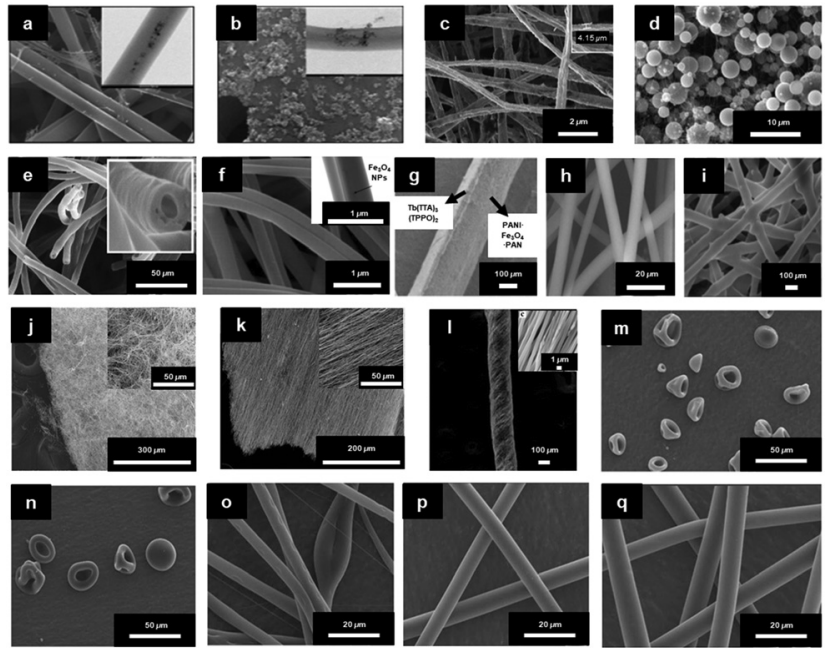

Fig. 3 SEM images of electrospun fibres and particles: (a) NFs with encapsulated MNPs; ${ }^{8}$ (b) NFs with dip-coated MNPs; ${ }^{8}$ (c) nanobelts; ${ }^{55}$ (d) beaded fibres; ${ }^{19}$ (e) hollow fibres; ${ }^{26}$ (f) Janus NFs; ${ }^{14}(\mathrm{~g})$ cross section of a bi-layered composite nanofibrous film; ${ }^{36}$ (h) the fibre of left layer containing the terbium complex $\mathrm{Tb}(T \mathrm{TA})_{3}(\mathrm{TPPO})_{2}$ (where TTA is thenoyltrifluoroacetone and TPPO is triphenylphosphine oxide); ${ }^{36}$ (i) the fibre of right layer containing PANI. $\mathrm{Fe}_{3} \mathrm{O}_{4} \cdot \mathrm{PAN} ;{ }^{36}$ reproduced from ref. 36 with permission from the PCCP Owner Societies; (j) random fibre mat; ${ }^{45}(\mathrm{k})$ oriented fibre mat; ${ }^{45}$ reproduced from ref. 45 with permission from the PCCP Owner Societies $(l)$ yarn twist fibres ${ }^{56}$ (Published by The Royal Society of Chemistry); and $(\mathrm{m}-\mathrm{q})$ electrosprayed and electrospun fibres of styrene(ethylene-co-butylene)-styrene from neat tetrahydrofuran (THF) solutions at varying polymer concentration (8 wt\%, $10 \mathrm{wt} \%, 12 \mathrm{wt} \%, 14 \mathrm{wt} \%$ and $18 \mathrm{wt} \%$ for $\mathrm{m}-\mathrm{q}$, respectively). ${ }^{9}$

differing diameter, which are loaded with the shell and core materials, respectively. The high speed of the jets prevents the disparate materials from mixing, resulting in a distinct boundary between the core and shell materials. Coaxial electrospinning is a useful method for separating the material of the inner and outer layers whilst protecting the load material (typically contained within the core). Yu et al. ${ }^{26}$ loaded air into the inner syringe to prepare hollow NFs (Fig. 3(e)) to be applied in targeted drug delivery applications.

2.1.2.3 Janus structure electrospinning. Janus nanostructures consist of two segregated materials with distinct physical and chemical properties to create a single nanostructure with two 'faces'. Commonly, the two materials exhibit antagonistic properties, such as being hydrophilic/hydrophobic (polar/nonpolar), which forms an important area of research in materials science. To create Janus NFs, two different fibres are produced from separate nozzles that have opposite charges. The two different fibres attract one another to form the final Janus structure (Fig. 3(f)). The Janus structure stops the two parts of the material interfering with one another to prevent the loss of dual performance. This technology has been utilised to produce materials with superior properties in catalysis, sensing, biomedicine and display technology. ${ }^{27-30}$

2.1.2.4 Collecting methods and collectors. In addition to nozzle design, and the whip and curing stages of the electrospinning process, the overall morphology of the fibre can be controlled by changing the method of collection. In addition to a stationary plate, common collection methods include (but are not limited to) additional magnetic field, ${ }^{13,31,32}$ mechanical traction, ${ }^{33}$ spinning $^{34}$ and layer-by-layer blending ${ }^{35,36}$ (Fig. 2). For example, Yang et al. ${ }^{35}$ prepared a novel sandwich-structured pellicle via layer-by-layer blending where the electric, magnetic and luminous layers could be effectively isolated from each other.

The arrangement of fibres can also be controlled by using different collectors. Again, compared to the more traditional flat plate, other collectors include the $\operatorname{drum}^{37-41}$ (Fig. 2(g)), parallel roller $^{11,42-44}$ (Fig. 2(h)) and slit collector. These collectors allow NF membranes to be obtained with intricate patterns (Fig. 3(j-l)) for more innovative applications. ${ }^{38,45}$ Among these collectors, the drum is the most common for preparing oriented fibre fabrics and membranes. ${ }^{46}$

2.1.2.5 Combinations. The aforementioned methods (discussed in Sections 2.1.2.1-2.1.2.4) are often combined to achieve enhanced control over the process. Such combinations have been exploited to access morphologies such as the yarn twist (Fig. 2(i)), Janus array fibre films ${ }^{28,35,47}$ and oriented coaxial fibres. ${ }^{48}$ Wang et al. ${ }^{36}$ fabricated highly fluorescent membranes made up of Janus NFs composed of magnetic $\left[\mathrm{Fe}_{3} \mathrm{O}_{4} /\right.$ polyvinylpyrrolidone (PVP)] and fluorescent terbium ligand complex $\mathrm{Tb}(\mathrm{BA})_{3}$ phen/PVP (where BA is benzoic acid and phen is phenanthroline) NFs. The trifunctional bi-layered composite nanofibrous film was produced using layerby-layer electrospinning and by systematically altering the process parameters during the electrospinning process.

2.1.2.6 Industrial production. In order to improve production efficiency, and to allow scale-up from the laboratory to industrial manufacture, modifications to the electrospinning equipment are often made. Most commonly the liquid supply device is adjusted commonly to; the use of densely packed needle arrays ${ }^{49}$ (Fig. 2(j)), separate silk threads used as spinnerets, ${ }^{50}$ a drum with grooves 
that rotates in a liquid pool to fill the hole for the supply of liquid (Fig. 2(k)) or a feedstock pool mounted with columns of magnets to directly supply the magnetic liquid ${ }^{51}$ (Fig. 2(l)).

Generally, the development of electrospinning rigs has been based on the design and combination of the two main components: the solution feeding system and collector. The development of industrial mass production equipment has also contributed to the commercialisation of electrospinning fibres.

2.1.3 Morphology and parameters. The processing parameters that affect the structure and morphology of an electrospun fibre include the applied voltage, liquid flow rate and the distance between nozzle and collector. The applied voltage determines the electric field intensity and charge density of the droplet, which directly influence the diameter of the fibres produced. Generally, a simple increase in voltage, without changing any other parameters, results in a decrease in fibre diameter. However, special cases still exist. For example, beaded fibres can be produced at low polymer solution concentration and at increasing (but low) voltages, the diameter initially increases with decreasing bead density. It is only at significantly higher voltages that a reversal is observed; the fibre diameter decreases and the beads reappear. ${ }^{52}$ Additionally, a voltage increase can also decrease the uniformity and length of the fibres produced. ${ }^{53}$ Conversely, increasing the flow rate of the liquid results in an increase in fibre diameter. Sufficient time is required for the solvent to fully evaporate during the fibre forming process, which corresponds directly to the distance between the nozzle and collector. If the distance between the nozzle and collector is too short there is insufficient time for the solvent to evaporate and fused fibres are formed. Similarly, fused fibres are formed when the distance is too large, this is attributed to the reduced electrostatic field strength experienced by the fibres meaning they are not stretched appropriately. In this latter case, the fibres formed often have large diameters which is a result of solvent being trapped within. ${ }^{54}$

System properties such as polymer molecular weight, concentration, solution viscosity, solvent type and solution electroconductivity also affect the fibre morphology. Electrospinning relies on chain entanglement to produce fibres. The level of chain entanglement is directly related to the solution viscosity, which is intrinsically linked to the polymer molecular weight and sufficiently high solution concentration. Insufficient chain entanglement causes bead-like morphologies instead of continuous fibres. Wang et al. ${ }^{9}$ studied the effect of co-solvent and polymer concentration on fibre morphology and the phenomenon of microphase separation during solution fibrillation (Fig. 3(m-q)). They found a morphological transition from fibres to beads occurred when increasing the concentration of dimethylformamide (DMF) in the THF/DMF co-solvent system. However, for the polymer system to self-assemble (microphase separate) the quantity of THF present had to be between 65-90 wt\%. In another example, Doepke et al. ${ }^{50}$ investigated nanoparticle concentration when preparing polymer bead/fibre mats for data storage. In this case they found that mechanical dispersion by ultrasonic treatment allowed for higher quantities of nanoparticles to be incorporated in both mats and bead formation without unwanted agglomeration effects.
MNPs or their constituent components (e.g. inorganic metal salts, alloys and oxides) are typically added into solution. These materials are highly electroconductive and alter the solution permittivity and conductivity, which in turn affects the creation of the local electrical field, improves the fibre morphology and decreases the fibre diameter. ${ }^{52}$ Additionally, environmental factors such as humidity and temperature can also influence the fibre structure. Typically, these conditions relate to the speed of solvent volatilisation and thus affect the overall fibre morphology.

In order to obtain the desired morphology or functionality for the target application, the electrospun fibrous membrane is often post treated. The surface of the NFs can be coated with functional entities (e.g. collagen ${ }^{57}$ ) or heat treated to chemically crosslink the polymer to improve mechanical strength and/or prevent dissolution (e.g. for temperature-controlled drug release). ${ }^{1}$ Sandwich structure fibrous membranes have also been prepared by thermally treating the electrospun sample post-deposition. ${ }^{58}$ The magnetic mat is sandwiched between two non-magnetic mats before an alternating magnetic field is used to induce magnetic heating, which in turn thermally bonds the nanofibrous mats together.

Overall, the development of solution supply systems has provided a rich and varied internal structure of individual fibres and the development of the collector has resulted in a diverse range of inter-fibre structures.

\subsection{Magnetic materials and properties}

Magnetic nanomaterials such as $\mathrm{Fe}_{3} \mathrm{O}_{4}, \alpha / \gamma-\mathrm{Fe}_{2} \mathrm{O}_{3}$ (hematite/ maghemite $)$ and $\mathrm{MFe}_{2} \mathrm{O}_{4}(\mathrm{M}=$ metal $)$ have received considerable attention due to their properties and potential applications. Herein, we review the magnetic materials that have been used in electrospun polymer-based NFs and how this relates to their final structure and properties.

2.2.1 $\mathrm{Fe}_{3} \mathrm{O}_{4} \cdot \mathrm{Fe}_{3} \mathrm{O}_{4}$ (magnetite) is one of the most commonly used magnetic materials due to its ease of preparation, biocompatibility, high surface area, catalytic activity, electrical conductivity, low toxicity and almost full spin polarisation at room temperature (RT). Superparamagnetic ${ }^{38,59,60}$ and ferrimagnetic ${ }^{58,61} \mathrm{Fe}_{3} \mathrm{O}_{4}$ NPs have been prepared with varying saturation magnetisation $\left(M_{\mathrm{s}}\right)$ values. The surface of $\mathrm{Fe}_{3} \mathrm{O}_{4}$ nanoparticles can also be modified to alter or enhance given properties. Song et al. ${ }^{21}$ prepared $\mathrm{Fe}_{3} \mathrm{O}_{4}$-polyhedral oligomeric silsesquioxane (POSS) particles using a hydrosilylation reaction whilst maintaining an $M_{\mathrm{S}}$ value of the $\mathrm{Fe}_{3} \mathrm{O}_{4}$-POSS at $18.77 \mathrm{emu}^{-1}$. The POSS was used in the system to improve the stability of the surface potential and charge retention of the mats. Gong et al. ${ }^{62}$ synthesised $\mathrm{Fe}_{3} \mathrm{O}_{4}$-loaded multi-walled carbon nanotubes (MWCNTs) (as a template for the $\mathrm{Fe}_{3} \mathrm{O}_{4} \mathrm{NPs}$ ), achieving $M_{\mathrm{s}}$ as high as $71.549 \mathrm{emu}^{-1}$. $\mathrm{Fe}_{3} \mathrm{O}_{4}$ NPs can also be mixed with a variety of polymer materials to increase their stability, introduce stimuliresponsiveness and manipulate the interparticle distance and magnetic interactions (Fig. 4). Additionally, polymers can guide the assembly of $\mathrm{Fe}_{3} \mathrm{O}_{4}$ NPs to form novel structures. ${ }^{14,33,63-70}$

Since polymeric materials can encapsulate and bind the nanoparticles as a matrix, research groups mix polymer materials with $\mathrm{Fe}_{3} \mathrm{O}_{4}$ NPs by uniaxial electrospinning, coaxial electrospinning 
(a)

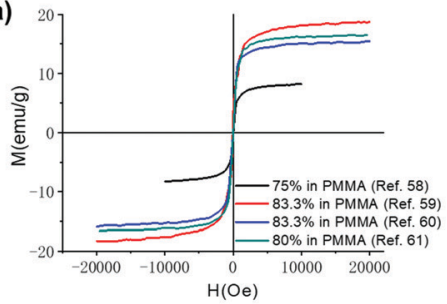

(b)

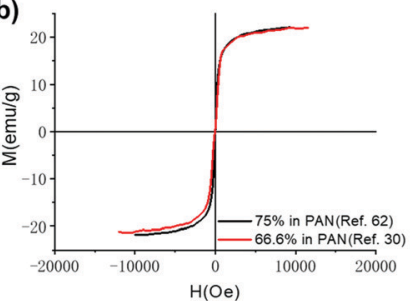

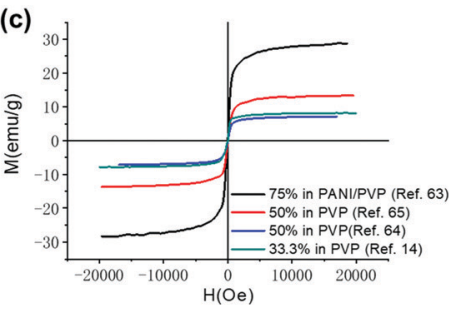

Fig. 4 Magnetization curves produced when mixing $\mathrm{Fe}_{3} \mathrm{O}_{4}$ NPs with different polymeric materials (a) $\mathrm{Fe}_{3} \mathrm{O}_{4} \mathrm{NPs}$ in $\mathrm{PMMA}^{63-66}$ (b) $\mathrm{Fe}_{3} \mathrm{O}_{4} \mathrm{NPs}^{6}$ in PAN, ${ }^{33,67}$ and (c) $\mathrm{Fe}_{3} \mathrm{O}_{4}$ NPs in PVP. ${ }^{14,68-70}$

and parallel-plate electrospinning. The method of electrospinning used affects the structure and properties of the composite material. The $M_{\mathrm{S}}$ of fibres prepared by uniaxial electrospinning increases with increasing mass of $\mathrm{Fe}_{3} \mathrm{O}_{4} \cdot{ }^{71,72}$ Savva et al. ${ }^{73}$ prepared oleic acidcoated magnetite nanoparticles, which show lower saturation magnetisation $\left(\sim 40 \mathrm{emu}^{-1}\right)$ due to the presence of the organic, nonmagnetic oleic acid coating. However, no significant agglomeration phenomena occur during the electrospinning process as exhibited in Fig. 5(a).

Fluorescent magnetic NFs have been targeted in research owing to their suitability in a wide range of applications such as;

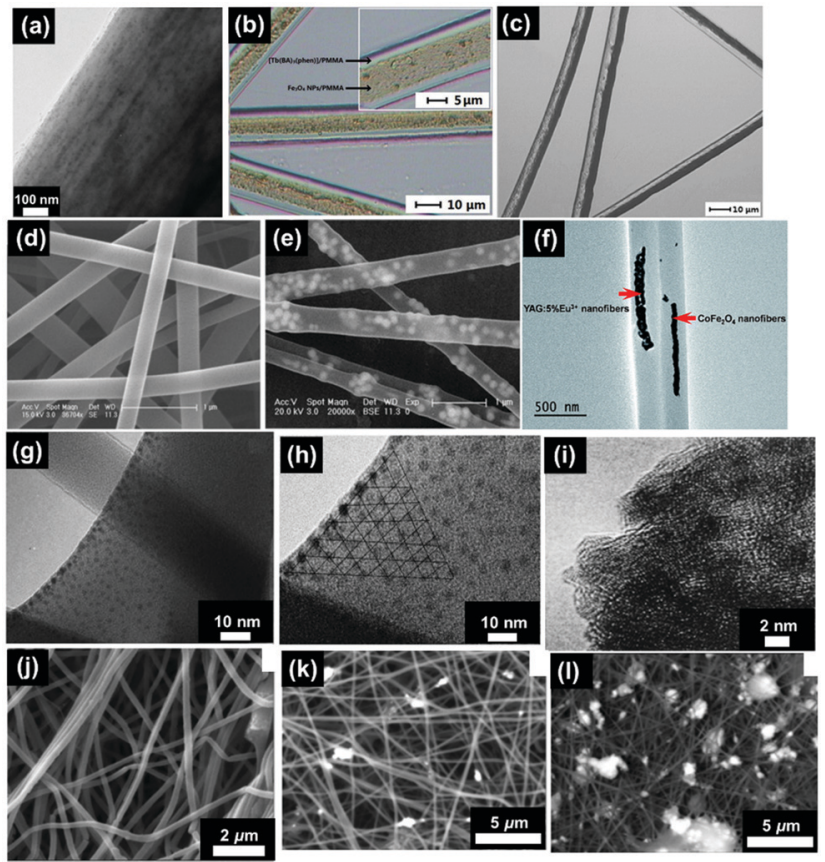

Fig. 5 (a) TEM bright field image of a PVP/PLLA/OA- $\mathrm{Fe}_{3} \mathrm{O}_{4}$ nanocomposite membrane; ${ }^{73}$ (b) BM image of $\left[\mathrm{Fe}_{3} \mathrm{O}_{4} / \mathrm{PMMA}\right]$ coaxial nanobelts; ${ }^{74}$ (c) $\mathrm{BM}$ image of $\left[\mathrm{Fe}_{3} \mathrm{O}_{4} / \mathrm{PANI} / \mathrm{PMMA}\right] / /\left[\mathrm{Tb}(\mathrm{BA})_{3}\right.$ phen/PMMA] Janus nanoribbons; ${ }^{28}$ (d) FESEM image of PVP NFs; ${ }^{44}$ (e) TEM image of $\alpha-\mathrm{Fe}_{2} \mathrm{O}_{3}$ /europium complex $\left[\mathrm{Eu}(\mathrm{DBM})_{3}(\right.$ Bath), where DBM is dibenzoylmethanate and Bath is bathophenanthroline]/PVP composite NFs; ${ }^{44}$ (f) TEM image of $\mathrm{CoFe}_{2} \mathrm{O}_{4} /$ yttrium aluminium garnet (YAG):5\% $\mathrm{Eu}^{3+} / \mathrm{PVP}$ composite $\mathrm{NFs} ;{ }^{75}$ reproduced from ref. 75 with permission from The Royal Society of Chemistry; (g) TEM image of strontium hexaferrite nanoparticles (SrM-NPs) embedded in a PVA matrix; $^{76}$ (h) TEM image of SrM-NPs; ${ }^{76}$ (i) TEM image of NiZn ferrite nanoparticles; $; 7$ (j) SEM image of $1 \%$ MGNPs-polymer; ${ }^{78}$ (k) SEM image of $3 \%$ MGNPs-polymer; ${ }^{78}$ and (l) SEM images of $7 \%$ MGNPS-PEO. ${ }^{78}$ light-emitting diodes, ${ }^{79}$ sensors, ${ }^{80}$ resonators ${ }^{81}$ and full-colour displays. ${ }^{82}$ However, heavy losses in fluorescent intensity is observed when $\mathrm{Fe}_{3} \mathrm{O}_{4}$ NPs are in direct contact with luminescent compounds. ${ }^{69}$ In order to circumnavigate this problem, coreshell and Janus structures have been produced as they offer the opportunity to incorporate both components in disparate zones of the material; minimising the direct interactions that would typically occur between them. Shao et al. ${ }^{64}$ reported the fabrication of tuneable fluorescent colour-electrical-magnetic trifunctional coaxial nanoribbons using coaxial electrospinning. These coaxial nanoribbons exhibited similar magnetic properties $\left(M_{\mathrm{s}}\right.$ of $18.58 \mathrm{emu}^{-1}$ ) to the corresponding composite nanoribbons (where all components were mixed within the ribbons). Most significantly, the fluorescent intensity and electrical conductivity of the coaxial nanoribbons were considerably higher than those of the composite nanoribbons, demonstrating the importance of architecture derived properties. Fig. 5(b) demonstrates the coaxial nanobelt structure, revealing that the core contains large quantities of dark-coloured $\mathrm{Fe}_{3} \mathrm{O}_{4}$ NPs whilst the shell of the coaxial nanobelts appears transparent. ${ }^{74}$

Another effective method to create the Janus structure is via parallel-plate electrospinning. Gai et al. ${ }^{83,84}$ prepared Janus nanobelts from $\mathrm{Fe}_{3} \mathrm{O}_{4} / \mathrm{PVP}$ and rare earth complex/PVP which demonstrated desired magnetism-luminescence bifunctionality. The $M_{\mathrm{S}}$ ranged from $3.16 \mathrm{emu} \mathrm{g}^{-1}$ to $10.19 \mathrm{emu} \mathrm{g}^{-1}$ and the results suggest that the magnetism can be tuned via different $\mathrm{Fe}_{3} \mathrm{O}_{4} \mathrm{NP}$ loadings. The Janus nanobelts exhibited superparamagnetic behaviour using $\mathrm{Fe}_{3} \mathrm{O}_{4}$ nanoparticles of approximately $15 \mathrm{~nm}$ diameter. When the dimensions of the magnetic component, such as magnetite, drop to less than 20 nanometres, its magnetisation direction can flip randomly under the influence of temperature. However, in this circumstance, magnetite becomes superparamagnetic with only one magnetism domain. ${ }^{85}$ In another example, Ma et al. ${ }^{86}$ fabricated Janus NFs with $\mathrm{Fe}_{3} \mathrm{O}_{4} /$ poly(methyl methacrylate) (PMMA) as the magnetic component and the $M_{\mathrm{S}}$ reached $32.61 \mathrm{emu} \mathrm{g}^{-1}$ when the mass ratio of $\mathrm{Fe}_{3} \mathrm{O}_{4}$ to PMMA was $6: 1$. This is similar to $\mathrm{Fe}_{3} \mathrm{O}_{4} /$ rare earth complex/PMMA composite nanobelts $\left(32.15 \mathrm{emu} \mathrm{g}^{-1}\right)$ that have also been produced. ${ }^{86}$ However, the fluorescent intensity of the Janus nanobelts is considerably higher than that of the composite nanobelts. Additionally, luminescent-electrical-magnetic trifunctional materials are also a popular target structure in multifunctional nanocomposites. $\mathrm{Lv}$ et $a .^{87}$ added polyaniline (PANI) to the magnetic half of the Janus structure and the electrical conductivity 
values of the Janus NFs increased with increasing PANI loading. However, the conductivity of the Janus NFs decreased with increasing amounts of $\mathrm{Fe}_{3} \mathrm{O}_{4}$ NPs due to the influence of $\mathrm{Fe}_{3} \mathrm{O}_{4}$ on the polymerisation process of aniline. The inner structure of the Janus nanoribbons can be revealed by the transmission light of a biological microscope (BM). As shown in the Fig. 5(c), one side of the Janus nanoribbon contains large quantities of dark coloured PANI and $\mathrm{Fe}_{3} \mathrm{O}_{4}$ NPs and, by contrast, the other side is transparent. ${ }^{28}$

2.2.2 $\alpha-\mathrm{Fe}_{2} \mathrm{O}_{3}$ and other iron oxides. $\alpha-\mathrm{Fe}_{2} \mathrm{O}_{3}$ is another popular choice of magnetic material due to its high stability, ease of fabrication, appropriate saturation magnetisation and increased acid resistance compared with $\mathrm{Fe}_{3} \mathrm{O}_{4}$. Additionally, $\alpha-\mathrm{Fe}_{2} \mathrm{O}_{3}$ also has excellent adsorption ability of heavy metal ions and organic pollutants. ${ }^{88}$ Wang et al. ${ }^{44}$ fabricated NFs based on $\alpha-\mathrm{Fe}_{2} \mathrm{O}_{3}$ nanoparticles and a europium complex to achieve magnetic-photoluminescent bifunctionality. The coercivity of the sample was 327 Oe with a remanent magnetisation $\left(M_{\mathrm{r}}\right) / M_{\mathrm{S}}$ ratio of 0.244 . Wang et al. ${ }^{44}$ found that the ${ }^{5} \mathrm{D}_{0}-{ }^{7} \mathrm{~F}_{2}$ transition was higher in the pure complex than in the composites. This was due to the addition of $\alpha-\mathrm{Fe}_{2} \mathrm{O}_{3}$ nanoparticles decreasing the symmetry of the coordination environment for the $\mathrm{Eu}^{3+}$ ions. As shown in Fig. 5(d), the pure poly(vinyl alcohol) (PVA) NFs are relatively smooth. After incorporation of europium complexes and $\alpha-\mathrm{Fe}_{2} \mathrm{O}_{3}$ nanoparticles into the polymer matrix the average diameter increased; this was due to an increase in viscosity of the feed solution.

Hematite is also often blended with polymeric materials via uniaxial electrospinning. Meng et $a .^{89}$ produced a paramagnetic nanofibrous composite film with polylactide (PLA), hydroxyapatite and $\gamma-\mathrm{Fe}_{2} \mathrm{O}_{3}$ nanoparticles. The $M_{\mathrm{s}}$ of $\gamma-\mathrm{Fe}_{2} \mathrm{O}_{3}$ NPs was $67.6 \mathrm{emu} \mathrm{g}^{-1}$ whilst the $M_{\mathrm{s}}$ of the film was $0.0492 \mathrm{emu}^{-1}$, achieved at a mass ratio of $8.3 \% \gamma-\mathrm{Fe}_{2} \mathrm{O}_{3}$ NPs within the film. Alternatively, Khanlou et $a l^{90}$ prepared $\gamma-\mathrm{Fe}_{2} \mathrm{O}_{3}$ NPs through a chemical co-precipitation process with an $M_{\mathrm{S}}$ of $12.19 \mathrm{emu}^{-1}$. Following the chemical co-precipitation, at $5 \mathrm{wt} \% \gamma-\mathrm{Fe}_{2} \mathrm{O}_{3} \mathrm{NPs}$, the NPs were added to a PMMA solution. The $M_{\mathrm{s}}$ of the composite produced was then

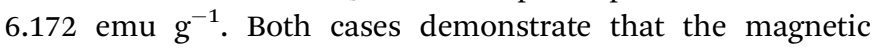
properties of MNP blended NFs are not proportional to the mass ratio of MNPs. Polymers do not simply act as a loading matrix but interact with MNPs and mutually influence the overall magnetic properties.

Additionally, there are other iron oxides that can be used to produce magnetic nanomaterials. For example Zhu et al. ${ }^{91}$ produced core-shell Fe-FeO nanoparticles with an average diameter of $20 \mathrm{~nm}$. The $M_{\mathrm{s}}$ of the Fe@FeO NPs was $108.1 \mathrm{emu}^{-1}$ whilst that of the nanocomposite fibres was $30.6 \mathrm{emu}^{-1}$; with a nanoparticle loading of $30 \mathrm{wt} \%$. Before electrospinning, the radii of the core and shell was calculated to be 13.2 and $6.8 \mathrm{~nm}$, respectively. However, after electrospinning the radii became 12.7 (core) and $7.3 \mathrm{~nm}$ (shell). The shell thickness increase was attributed to an increase in particle oxidation at the extremely high voltages used during the electrospinning process.

Finally, Murillo-OrtÍz et al. ${ }^{76}$ embedded strontium hexaferrite nanoparticles (SrM-NPs) in PVA NFs. The ratio of $M_{\mathrm{r}} / M_{\mathrm{S}}$ increased by 81 when $30 \mathrm{wt} \%$ SrM-NPs were added to the PVA solution.
As observed in Fig. 5(g), these nanoparticles have uniform size and have a localised distribution of NPs inside the surface of the NFs. Additionally, they do not show the presence of agglomerates. Fig. 5(h) then shows that the nanoparticles are ordered on the surface of the fibre and aligned with respect to the NFs' growth. This is a consequence of the nanoparticles' interaction with the highly intense electric field aligned with the electrodes in a point-plate configuration.

2.2.3 $\mathrm{MFe}_{2} \mathrm{O}_{4}(\mathbf{M}=$ metal). In typical spinel and inverse spinel structures of magnetite, Fe(II) and Fe(III) ions are distributed in either octahedral or tetrahedral voids. $\mathrm{MFe}_{2} \mathrm{O}_{4}$ can be prepared by doping $\mathrm{Mn}^{2+}, \mathrm{Fe}^{2+}, \mathrm{Co}^{2+}$ and $\mathrm{Ni}^{2+}$ metal ions into the crystal voids of the iron oxide nanoparticles (IONPs). ${ }^{92}$ This has resulted in nanoscale spinel ferrites $\mathrm{MFe}_{2} \mathrm{O}_{4}(\mathrm{M}=\mathrm{Co}$, $\mathrm{Mn}$, or Ni) with 1D structures (e.g. fibres) being studied more actively in recent years. ${ }^{93}$

Chen et al. ${ }^{94}$ synthesised and modified $\mathrm{CoFe}_{2} \mathrm{O}_{4}$ nanoparticles to improve dispersion. The diameter of the $\mathrm{CoFe}_{2} \mathrm{O}_{4}$ particles produced was $5 \mathrm{~nm}$ and the $M_{\mathrm{s}}$ achieved was $50 \mathrm{emu} \mathrm{g}^{-1}$. The diameter achieved is smaller than that of the bulk materials, due to the size of the $\mathrm{CoFe}_{2} \mathrm{O}_{4}$ crystallites and fewer defects being present in the structure. Finally, the $\mathrm{CoFe}_{2} \mathrm{O}_{4}$ NPs were mixed with polyacrylonitrile (PAN) and the composite exhibited an $M_{\mathrm{S}}$ of $45 \mathrm{emu}^{-1}$. The decrease in $M_{\mathrm{s}}$ is attributed to the non-magnetic material coating (PAN) and its influence on the uniformity and magnitude of magnetisation by extinguishing the surface magnetic moment. Alternatively, Wang et al. ${ }^{95}$ fabricated Janus NFs using $\mathrm{CoFe}_{2} \mathrm{O}_{4}$ to achieve magnetism-luminescence bifunctionality. When the mass ratio of $\mathrm{CoFe}_{2} \mathrm{O}_{4}$ : PAN was $1: 3$ the $M_{\mathrm{s}}$ and $H_{\mathrm{c}}$ achieved were 5.09 memu $\mathrm{g}^{-1}$ and $20 \mathrm{kOe}$, respectively. Additionally, Bi et al. ${ }^{75}$ electrospun $\left[\mathrm{Fe}\left(\mathrm{NO}_{3}\right)_{3}+\right.$ $\left.\mathrm{Co}\left(\mathrm{NO}_{3}\right)_{2}\right] / \mathrm{PVP}$ precursor solution before annealing in air at $700{ }^{\circ} \mathrm{C}$ for 4 hours to prepare $\mathrm{CoFe}_{2} \mathrm{O}_{4}$ NFs. YAG:5\% $\mathrm{Eu}^{3+}$ calcinated NFs were also prepared via the same method. Janus NFs were then fabricated from both the $\mathrm{CoFe}_{2} \mathrm{O}_{4} \mathrm{NFs} / \mathrm{PVP}$ and YAG:5\% $\mathrm{Eu}^{3+}$ NFs/PVP solutions, as shown in Fig. 5(f). The $M_{\mathrm{S}}$ of the $\mathrm{CoFe}_{2} \mathrm{O}_{4} \mathrm{NFs}$ was $41.34 \mathrm{emu}^{-1}$ whilst the $M_{\mathrm{s}}$ of the Janus NFs ranged from 3.12-20.32 emu $\mathrm{g}^{-1}$. The observed enhanced performance is attributed to the isolation of YAG:5\% $\mathrm{Eu}^{3+}$ luminescent NFs from the $\mathrm{CoFe}_{2} \mathrm{O}_{4}$ magnetic NFs. Gonçalves et al. ${ }^{96}$ prepared composite fibres of $\mathrm{CoFe}_{2} \mathrm{O}_{4}$ and poly(vinylidene fluoride) (PVDF). The composites demonstrated an increase in magnetisation with increasing $\mathrm{CoFe}_{2} \mathrm{O}_{4}$ content. They also found that the piezoelectric coefficient of the NF composites increased with increasing applied magnetic field. This is a result of the strain-mediated coupling between the magnetostrictive $\mathrm{CoFe}_{2} \mathrm{O}_{4}$ nanoparticles and the piezoelectric PVDF matrix. However, when compared with bulk polymers the piezoelectric coefficients were lower. It is speculated that this reduction is due to clamping by the surrounding material; which may significantly reduce the local deformation of the NFs.

Ghanbari et al. ${ }^{97}$ synthesised $\mathrm{CaFe}_{2} \mathrm{O}_{4}$ nanoparticles that exhibit ferrimagnetism before producing cellulose acetate (CA)- $\mathrm{Ag}-\mathrm{CaFe}_{2} \mathrm{O}_{4}$ nanocomposites by electrospinning. The $M_{\mathrm{s}}$, of the nanoparticle compared to the NF, decreased from 6.1 to $0.31 \mathrm{emu}^{-1}$ whereas the $H_{\mathrm{c}}$ increased from 40 to $78 \mathrm{Oe}$, respectively. The authors stated 
that the magnetic moments of the $\mathrm{CaFe}_{2} \mathrm{O}_{4}$ nanoparticles are pinned by the polymer chains so that a higher magnetic field is required to align the single domain nanoparticles in the field direction. Additionally, Khan et al. ${ }^{77}$ prepared $\mathrm{Ni}_{0.6} \mathrm{Zn}_{0.4} \mathrm{Fe}_{2} \mathrm{O}_{4}$ nanoparticles (see the transmission electron microscopy (TEM) image in Fig. 5(i)) with $M_{\mathrm{s}}$ of $26.81 \mathrm{emu}^{-1}$. The NPs were then incorporated into composite NFs [with carbon nanotubes and recycled polystyrene (PS)] at 7.5, 15, and $30 \mathrm{wt} \%$ to produce fabrics with $M_{\mathrm{S}}$ values of 2,4 , and 8 emu $\mathrm{g}^{-1}$, respectively.

2.2.4 Other magnetic materials. Other active magnetic materials that have also been incorporated into NPs include Ni, Co, and some dopants (such as Sr). Chen et al. ${ }^{98}$ reported the $M_{\mathrm{s}}$ of pure Ni nanoparticles as $14.3 \mathrm{emu}^{-1}$, which was considerably lower than bulk nickel (58.57 emu $\left.\mathrm{g}^{-1}\right)$. The decrease is attributed to the oxidation of the nickel nanoparticles as a consequence of their large surface area. In another study, Gupta et al. ${ }^{99}$ measured the $M_{\mathrm{s}}$ of pure MnZnFe-Ni as 25.47 emu $\mathrm{g}^{-1}$ before forming a blend with Estane ${ }^{\circledR} 5750$; a polyester-based segmented polyurethane (PU). The $M_{\mathrm{S}}$ of the blend increased from $1.71 \mathrm{emu} \mathrm{g}^{-1}$ to 6.33 emu $\mathrm{g}^{-1}$, with increasing MnZnFe-Ni content, and the composite NFs formed demonstrated superparamagnetic behaviour. Murillo-Ortíz et al. ${ }^{17}$ synthesised $\mathrm{SrFe}_{12} \mathrm{O}_{19}$ with diameters ranging from $37 \mathrm{~nm}$ to $179 \mathrm{~nm}$. The $M_{\mathrm{r}} / M_{\mathrm{s}}$ and $H_{\mathrm{c}}$ of the $\mathrm{SrFe}_{12} \mathrm{O}_{19}$ were 0.63 and $6.22 \mathrm{kOe}$, respectively. The remanent squareness increased by $15 \%$ and the coercivity by $1.2 \%$ when $\mathrm{SrFe}_{12} \mathrm{O}_{19}$ nanoparticles were added to the PVA NFs by electrospinning. Additionally, the thermal stability and arsenic adsorption ability of the NFs was improved upon $\mathrm{SrFe}_{12} \mathrm{O}_{19}$ addition.

Erfan et al. ${ }^{78}$ prepared ferrimagnetic glass ceramics, with a diameter of $10 \mathrm{~nm}$, through the use of high-energy ball milling. The $M_{\mathrm{s}}$ of the magnetic glass ceramic nanoparticles (MGNPs) was $53 \mathrm{emu} \mathrm{g}^{-1}$ and the $H_{\mathrm{c}}$ equal to $88 \mathrm{Oe}$. The $M_{\mathrm{s}}$ of the composite fibre reached a maximum of $4.16 \mathrm{emu}^{-1}$ when the mass ratio of MGNPs was 7\%. Low MGNPs concentration (1 wt\%) NFs (Fig. 5(j)) appear clear and smooth, however, the roughness and nanoparticle aggregation on the surface of the NF increased at higher MGNP content (Fig. 5(k) (3 wt\%) and 5 (l) $(5 \mathrm{wt} \%))$.

Min et $a .^{100}$ fabricated PVA/ferritin superparamagnetic fibres. The interaction between the host PVA hydrogel and the protein shell on the ferritin bio-nanoparticles was controlled by thermal methods to vary the size and concentration of the ferritin clusters. The average size and concentration of the ferritin clusters increased in the PVA NFs when the mixing temperature was raised from 30 to $80{ }^{\circ} \mathrm{C}$. The close proximity of the ferritin cores within the clusters resulted in magnetic ordering and increased magnetisation in some cases.

Additionally, many research groups are now developing novel magnetic nanomaterials. One example is FePt which has demonstrated good chemical stability and high magnetocrystalline anisotropy. ${ }^{101}$ Another example shows micron size graphene sheets decorated with cobalt NPs to endow magnetism. ${ }^{102}$ There has also been an increasing focus on producing composite fibres with a range of polymeric materials. However, the mechanism regarding the interaction between the magnetic nanoparticles and polymer materials remains unclear.

\section{Electrospun fibrous templates}

This section discusses the various approaches used to create magnetic nanofibrous materials by electrospinning template constructs and the post-spinning treatment used: (i) deposition of magnetic NPs; (ii) carbonisation; and (iii) calcination. Fig. 1(b and c) highlights the different routes that have been used in this area of research. Table 2 serves as a comprehensive summary of this section, listing the various systems that have been explored, the magnetic reagent(s), polymer(s), electrospinning and processing approach, the final morphology obtained, major magnetic property and applications (where relevant) in each case.

\subsection{Product morphology and corresponding processing}

The template method is a cost-effective and scalable route used to produce both pure inorganic magnetic NFs and organicinorganic hybrid magnetic NFs. Electrospun fibrous templating is also a convenient method for inorganic magnetic nanofibre (MNF) fabrication and the MNFs produced sometimes exhibit an increase in $M_{\mathrm{s}}{ }^{103}$ However, the change in $M_{\mathrm{S}}$ depends on a range of complex factors and is not always enhanced. The appearance of a magnetically inert layer in the fibrous structure, ${ }^{104}$ the formation of ferromagnetic phase ${ }^{105}$ and smaller grain size are all factors that may contribute to a decrease in $M_{\mathrm{s}}$ in 1D nanostructures prepared by the electrospun fibrous template method. ${ }^{106}$ The templating procedure of the MNFs (Fig. 1(b and c)) generally encompasses two steps: electrospinning to create a fibrous template followed by post-treatment of the template. A typical template-assisted electrospinning precursor solution is made up of three parts: (i) a magnetic component; (ii) polymer(s); and (iii) a solvent system. The magnetic component is typically in the form of magnetic nanoparticles (MNPs) ${ }^{107}$ or metal salts. Polymers are added to the system to meet the viscosity demand of electrospinning (i.e. to provide entanglements). The most widely used polymers include PANI, ${ }^{108}$ poly(ethylene oxide) (PEO), ${ }^{109}$ polyurethane, ${ }^{107}$ PVA $^{110}{ }^{110 N},{ }^{111,112}$ and PVP. ${ }^{48,113-116}$ The purpose of the solvent is to dissolve the polymer(s), disperse or dissolve the magnetic component used and improve the charge-carrying capacity of solution. Typical solvents used are DMF, dichloromethane (DCM), methyl ethyl ketone (MEK), deionised water, ethanol ${ }^{116}$ or a combination thereof. ${ }^{107}$ The viscosity, concentration, surface tension and dielectric properties of the spinning solution exert a great influence on the electrospinnability of the solution and the diameter, morphology, crystallinity and tensile strength of the NFs. Such influences have been referred to in previous studies. ${ }^{117,118}$ Finally, Fig. 1(c) highlights an alternative route where NFs without any magnetic components are used as templates before MNPs are deposited upon them.

In the sol-gel process, literature reports have demonstrated the use of metal nitrate ${ }^{114,116,119}$ and acetate ${ }^{114}$ precursors with polymer(s) in the production of electrospun NFs with uniform distributions, even at very high loadings. ${ }^{120}$ Although the mechanisms for such processes were not explicitly discussed, the conditions in which the precursor solutions were prepared are reported. ${ }^{48,121,122}$ 
Following initial deposition, the obtained fibres are often dried and pre-sintered to evaporate any solvents. ${ }^{94,114-116,119,121,123}$ This is followed by calcination, at a given heating rate, in order to (partially or completely) remove the polymers to form pure inorganic fibres. Concomitantly, the metal ions are converted to their neutral elemental state ${ }^{48}$ and the atoms aggregate to form nanoparticles. ${ }^{124}$ The calcination conditions are adapted to meet the varying demands of a given system. For example, air is an idealised atmosphere if metal oxide $\mathrm{NFs}^{125}$ are targeted, whereas hydrogen $\left(\mathrm{H}_{2}\right){ }^{126-128}$ often in combination with an inert gas such as argon $(\mathrm{Ar}),{ }^{129-132}$ and ammonia gas $\left(\mathrm{NH}_{3}\right)$ are adopted as a reduction (often referred to as de-oxidation in the literature) source. In some cases, the calcination atmosphere is selected to generate oxygen vacancies or eliminate impure phases. ${ }^{133}$ For example, $\alpha-\mathrm{Fe}_{2} \mathrm{O}_{3}$ NFs obtained in a study by Guo et al. ${ }^{134}$ were heated in an $\mathrm{NH}_{3}$ atmosphere and the crystallites were transformed into $\mathrm{Fe}_{3} \mathrm{O}_{4}$ crystallites. Additionally, when the temperature was raised, $\mathrm{Fe}_{2} \mathrm{~N}$ NFs were obtained. The electrospinning parameters, environmental conditions, physical and electrical properties of the spinning solution, and calcinating conditions (temperature, rate, profile and duration) all enable the crystal structure, morphology and ultimate properties of the final product to be manipulated. ${ }^{135}$ For example, the preparation of mullite-nickel nanocomposite $\mathrm{NFs}^{132}$ was performed through two heating stages. The first was used to convert $\mathrm{Ni}^{2+}$ to Ni NPs in a reducing atmosphere between $550-750{ }^{\circ} \mathrm{C}$ before the mullite phase was formed at $1000{ }^{\circ} \mathrm{C}$. However, if the first stage was not allowed to proceed for sufficient time (to permit $\mathrm{Ni}^{2+}$ to be fully reduced to Ni NPs), an undesirable spinel phase mixed with a mullite phase was formed during the second heating stage. In a similar procedure, a $\mathrm{Fe} / \mathrm{Ni}$ alloy was prepared from the reduction of $\mathrm{NiFe}_{2} \mathrm{O}_{4}\left(300-600{ }^{\circ} \mathrm{C}\right)$ to produce $\mathrm{Fe}-\mathrm{Ni}$ alloy nanoribbons. ${ }^{126,136}$ The morphology of the Fe-Ni alloy precursor (body-centred cubic or face-centred cubic) was influenced by the heating temperature used during the reduction stage.

Often the calcinated products are formed as powders and do not maintain their structure. ${ }^{41}$ Efforts have been made to resolve this problem by shifting towards the production of fibre mats that offer the added benefit of being flexible, easy to produce, recyclable and cost-effective. In one example, flexible fibre mats have been utilised in the development of magnetic devices; offering a new design method for electromagnetic shielding systems. ${ }^{121}$ Additionally, the ease of recycling the mats and the enhanced structural stability, when compared to powders, is highly desirable in applications such as waste water treatment. ${ }^{118}$ The key factors that influence the flexibility of these fibrous mats are the uniform distribution of NPs throughout the NFs, ${ }^{110}$ the porous structure of the mats ${ }^{110}$ and the interfacial energy between NPs and NFs. ${ }^{110}$ Consequently, attempts have been made to improve the interfacial interactions between the MNPs and the matrix. ${ }^{94}$ For example, zein (a maize protein) was used as an adhesive between $\mathrm{NiFe}_{2} \mathrm{O}_{4}$ NPs and $\mathrm{SiO}_{2}$ NFs to render the resultant fibre mats with extraordinary flexibility. ${ }^{110}$ In addition, Wang et al. reported that oxygen plasma treatment was an effective way to keep the membrane integrated during the stage where the organic component is removed. ${ }^{41}$ Finally, flexible calcinated $\gamma-\mathrm{Fe}_{2} \mathrm{O}_{3} / \mathrm{C}$ NF mats have

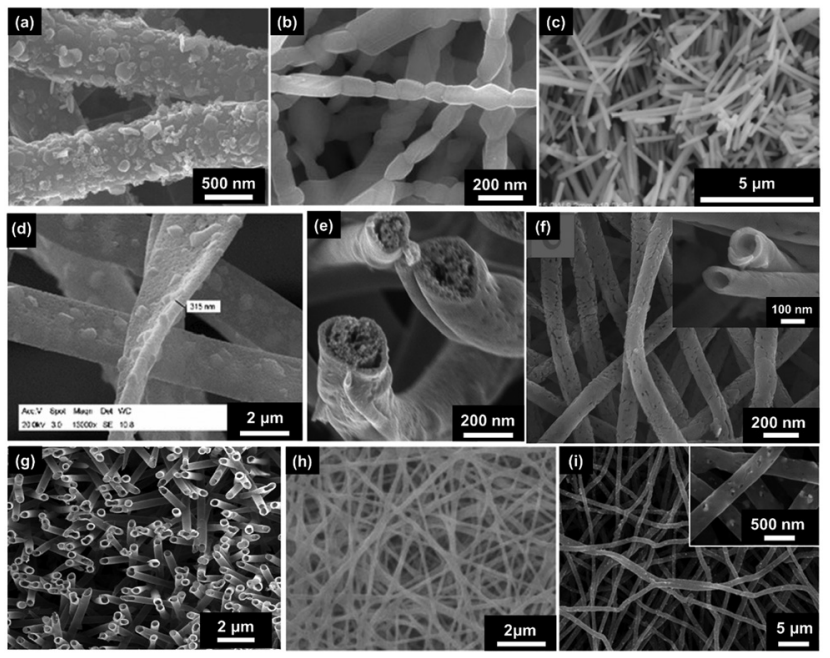

Fig. 6 Example SEM images of: (a) fibres with particle deposition; ${ }^{107}$

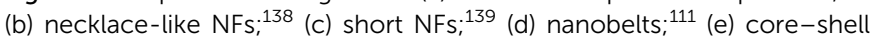
NFs, ${ }^{140}$ reproduced from ref. 140 with permission from The Royal Society of Chemistry; (f) hollow NFs; ${ }^{134}$ reproduced from ref. 134 with permission from The Royal Society of Chemistry; (g) nanotubes; ${ }^{141}$ reprinted with permission from ref. 141. Copyright (2021) American Chemical Society; (h) $3 \mathrm{D}$ crosslinking NFs; ${ }^{109}$ and (i) regular NFs (calcinated). ${ }^{142}$ Specific details: (a) $\mathrm{Fe}_{3} \mathrm{O}_{4}$ (aPU NFs, $\mathrm{Fe}_{3} \mathrm{O}_{4} \mathrm{NPs}$ at $1 \mathrm{mg} \mathrm{ml}^{-1}$; (b) $\mathrm{SrFe}_{12} \mathrm{O}_{19}$ NFs calcinated at $1000{ }^{\circ} \mathrm{C}$; (c) $\mathrm{BiFeO}_{3} \mathrm{NFs}$ calcinated at $550{ }^{\circ} \mathrm{C}$; (d) $\mathrm{Fe}_{3} \mathrm{O}_{4} / \mathrm{C}$ NFs calcinated at $800{ }^{\circ} \mathrm{C}$; (e) $\mathrm{CoFe}_{2} \mathrm{O}_{4}-\mathrm{Pb}\left(\mathrm{Zr}_{0.52} \mathrm{Ti}_{0.48}\right) \mathrm{O}_{3} \mathrm{NFs}$ calcinated at $750{ }^{\circ} \mathrm{C}$; (f) $\mathrm{Fe}_{2} \mathrm{~N}$ NFs calcinated at $400{ }^{\circ} \mathrm{C}$; (g) $\mathrm{SnO}_{2}$ NFs calcinated at $500{ }^{\circ} \mathrm{C}$; (h) $\mathrm{Fe}_{3} \mathrm{O}_{4}-$ alginate (SA)/PVA crosslinked NFs; and (i) $\mathrm{NiFe}_{2} \mathrm{O}_{4} /$ multi-walled carbon nanotube (MWCNT) carbon-based NFs (CNFs) calcinated at $850{ }^{\circ} \mathrm{C}$.

also been prepared by combining electrospinning, hydrothermal synthesis and calcination. ${ }^{121,137}$

NFs with different morphologies can also be fabricated by changing the shape of the liquid supply nozzle or by adjusting the calcination parameters used to remove the polymer construct. In the first stage, when polymers are present, fibres decorated with inorganic particles are obtained. Once the polymers have been removed, necklace like NFs, short NFs, nanobelts, core shell NFs, hollow NFs and regular NFs can be obtained. Fig. 6 shows the various types of MNFs that can be targeted by electrospinning, as discussed in the following sections.

3.1.1 Decorated fibres. Fig. 1(c) shows how fibres decorated with particles can be created and Fig. 6(a) shows an example of such surface topology. Polymers are electrospun to form fibres and then MNPs are coated onto the fibres either by in situ synthesis ${ }^{109,143}$ or post-spinning deposition. ${ }^{107,108,112}$ Both approaches face the issue of aggregation, however, there have been few research efforts focused on resolving this problem. ${ }^{107,110,143}$ In one notable example, in situ synthesis was studied, focussing on the influence of drying mode on the morphology of iron oxides upon polyimide (PI) NFs. ${ }^{143}$ This study concluded that drying under vacuum was more effective than drying in air to allow for uniform particle distribution. When using the deposition method, specific techniques are used to provide uniform distribution of the MNPs. These techniques include use of a surfactant, ${ }^{110}$ polyol immersion $^{107}$ and layer-by-layer assembly. ${ }^{144}$ In some cases, where the polymer completely remains, cross-linking agents 
can be used to form 3D cross-linked networks ${ }^{109}$ to improve water resistance and mechanical integrity. ${ }^{145}$

3.1.2 Necklace-like nanofibres. In single nozzle electrospinning, where amorphous polymer templates are removed by calcination, NFs will inevitably transform from smooth morphologies to rough surfaces before necklace-like structures are eventually formed (Fig. 6(b)). This happens when the calcination temperature reaches a relatively high value. For example, Xiang et al. ${ }^{122}$ found that the calcinated $\mathrm{Co}_{0.5} \mathrm{Ni}_{0.5} \mathrm{Fe}_{2} \mathrm{O}_{4}$ NFs formed the necklace-like morphology when the temperature was greater than $800{ }^{\circ} \mathrm{C}$. The transmission electron microscopy (TEM) images collected in this study revealed that the rapid growth of nanocrystals, aggregation of small NPs and resultant formation of larger NPs at high temperatures gave rise to their unique morphology.

3.1.3 Short nanofibres. The length of electrospun NFs can reach several tens to even hundreds of microns, ${ }^{146,147}$ where 'short' NFs are defined as those that are less than ten microns in length (Fig. 6(c)). Short/broken fibres are typically generated under two circumstances: (1) when the NPs experience uneven thermal stress and they aggregate; and (2) by the inhomogeneous distribution of sacrificial templates. ${ }^{139,148}$ In both cases, the local area will fracture readily. For example, Sakar et al. ${ }^{139}$ fabricated $\mathrm{BiFeO}_{3}$ NFs at varied spinning voltages $(8,10,15$ and $20 \mathrm{kV}$ ) and found that $10 \mathrm{kV}$ or less was not sufficient to homogenously distribute the polymer. The calcinated products then have the tendency to be broken at the area where the polymer is scarce.

3.1.4 Nanobelts and nanoribbons. Necklace-like NFs (Fig. 6(b)), nanobelts (Fig. 6(d)) or nanoribbons can be fabricated with minor adjustment to the composition of the spinning solution and electrospinning experimental conditions. ${ }^{111}$ One possible formation mechanism suggests that if the solvent evaporates rapidly during jet flow, a columnar transition state structure is formed with a thin elastic polymer skin. This structure buckles gradually and finally becomes belt-like. ${ }^{119,149}$ Additionally, in this process, specific polymers (such as PMMA) are found to be beneficial towards the formation of the flat shape belt NF morphology. ${ }^{111}$ Additionally, the effects of calcination have been investigated and show no significant changes to the morphology of the nanobelt following removal of the polymer.

3.1.5 Core-shell nanofibres. An example of the core-shell structure is illustrated in Fig. 6(e). These structures are typically generated by coaxial electrospinning or, alternatively, by using a single nozzle, followed by calcination and finally coating. There have been a number of reports where magnetic coreshell NFs are produced. In one example, Bayat et al. coated polydimethylsiloxane (PDMS) on $\mathrm{Fe}_{3} \mathrm{O}_{4} / \mathrm{C}$ NFs, which were produced via electrospinning followed by pyrolysis at $900{ }^{\circ} \mathrm{C}$, for future use as electromagnetic interference (EMI) shields. ${ }^{150}$ In a second method, $\alpha-\mathrm{Fe}_{2} \mathrm{O}_{3}$ NFs were soaked in a tetraethyl orthosilicate (TEOS) precursor solution whereby a catalysed hydrolysis and condensation polymerisation reaction resulted in a uniform silica $\left(\mathrm{SiO}_{2}\right)$ coating along the fibres. ${ }^{151} \mathrm{Li}$ et al. ${ }^{3}$ and Zou et al. ${ }^{152}$ coated $\mathrm{SrFe}_{12} \mathrm{O}_{19}$ and $\mathrm{CuFe}_{2} \mathrm{O}_{4}$ NFs with $\mathrm{TiO}_{2}$ and $\mathrm{CeO}_{2}$, respectively, via a soaking and calcination procedure. In addition to these multi-step procedures, as aforementioned, core-shell NFs can be fabricated through a straightforward onestep method by coaxial electrospinning. In this case, two different spinning solutions are loaded into inner and outer syringes. Each jet flow is then formed with a different velocity and collected before being annealed to obtain magnetic-magnetic, ${ }^{153-155}$ magneticluminescent ${ }^{156}$ or magnetic-electric ${ }^{48,140,157}$ bifunctional coreshell nanofibrous materials.

3.1.6 Hollow nanofibres. Similar to the construction of core-shell MNFs, hollow fibres (Fig. 6(f)) can be prepared with single ${ }^{158-160}$ or coaxial nozzles, ${ }^{15,161}$ both followed by calcination. During the single spinning procedure, both Cheng et al. ${ }^{160}$ and Chen et al. ${ }^{98}$ identify the key factor critical in hollow or solid morphology determination. Cheng et al. shows that the gas diffusion rate, from the interspaces between the nanoparticles, is slower than the PVP decomposition. As the polymer decomposition continues, the observed increase in internal pressure forces the nanoparticles to the exterior and hollow fibres form. ${ }^{160}$ However, the study of Chen et al. highlighted that metallic shell formation is the key factor in hollow morphology determination. ${ }^{103,158}$ When the NFs are heated in air, metal oxide clusters begin to form on the surface of the fibre until they create a shell. After which, at even higher temperatures, the polymer component degrades to form volatile decomposition products leaving behind the hollow NF structure. This illustrates that hollow structures are difficult to produce in cases where the metal oxide forming temperature is higher than the decomposition temperature of the polymer matrix. Further studies by Zhao et $a l .{ }^{159}$ have determined that a concentration gradient (which causes varied consumption rates of $\mathrm{Cu}^{2+}$ and $\mathrm{Fe}^{3+}$ ) and difference in gas pressure between the inside and outside of the fibre are also two important factors to consider when preparing hollow $\mathrm{CuFe}_{2} \mathrm{O}_{4}$ NFs. On the other hand, Fu et al. determined that phase separation caused by a concentration gradient is the most critical factor in the preparation of hollow MNFs. ${ }^{135}$ Notably, the organic nanofibrous template can be removed afterwards to create hollow MNFs. ${ }^{162}$

Nanotubes (Fig. 6(g)) are similar in structure to hollow fibres and the differences between them are subtle and sometimes difficult to identify. ${ }^{163}$ In some cases, the term 'nanotube' is used to describe shorter, defect-free hollow fibres, but there is no clear definition and the term tends to be used interchangeably with hollow NFs across the literature. Accurate heating methods are required for nanotube construction via single nozzle electrospinning and Jiang et al. has reported the successful synthesis of nanotubes several microns in length. ${ }^{164}$ Additionally, Li et al. obtained $\mathrm{NaYF}_{4}: \mathrm{Yb} / \mathrm{Er} / \mathrm{Gd}$-decorated $\mathrm{SiO}_{2}$ nanotubes via single nozzle electrospinning followed by calcination using a spinning solution comprised of $\mathrm{NaYF}_{4}: \mathrm{Yb} / \mathrm{Er} / \mathrm{Gd}$ nanocrystals, TEOS and PVP. The as-spun NFs were annealed between $200-600{ }^{\circ} \mathrm{C}$ at a heating rate of $2{ }^{\circ} \mathrm{C} \mathrm{min}^{-1}$. In this example, PVP is forced to migrate to the surface once leaving the nozzle resulting in a PVP-silica shell with the magnetic component and TEOS within the core. Upon removal of the organic material, nanotubes were produced. $^{165}$

In the coaxial spinning procedure, the pure organic part (such as mineral oil, polymers or components that incorporate magnetic ingredients ${ }^{166}$ ) can be adopted as the core solution. ${ }^{167}$ 
However, the flow rate of the inner solution should be controlled to prevent leakage. ${ }^{166}$

In addition to the aforementioned traditional single-walled hollow structures, there are novel structures that have been obtained, such as hollow-core-double-shell NFs. Kim et al. ${ }^{158}$ produced $\mathrm{CoFe}_{2} \mathrm{O}_{4}$ core-PANI double shell structures. Initially hollow $\mathrm{CoFe}_{2} \mathrm{O}_{4}$ NFs were obtained by calcinating the precursor fibres between $80-550{ }^{\circ} \mathrm{C}$ at a heating rate of $5{ }^{\circ} \mathrm{C} \mathrm{min}^{-1}$ for 2 hours. The inner and outer surfaces were then coated with PANI via in situ oxidative polymerisation.

3.1.7 Three dimensional networks. Post-treatment can be adopted to enhance the properties of NF mats. If the polymer scaffold is retained in the final product, a cross-linking agent is frequently used to form 3D cross-linked networks ${ }^{109}$ (Fig. 6(h)) to improve water resistance and enhance mechanical stability. ${ }^{145}$ For example, Gao et al. adopted $N, N^{\prime}$-trimethylene-bis[2-(vinylsulfonyl)acetamide] as a chemical cross-linking agent for PVA. Whilst a slight weight loss $(<0.4 \%)$ was observed after immersing the mat in hot water for two hours the cross-linked PVA NF mats demonstrated enhanced water resistance. ${ }^{168}$ Chemically crosslinking the polymer chains prevents dissolution of the macromolecules and changes the mechanical properties of the constructs, due to the creation of a chemically bound mesh that no longer relies on physical entanglements for structural integrity.

3.1.8 Regular nanofibres. If the NFs are calcinated solid fibres that cannot be categorised into any of the aforementioned morphologies, they are defined as regular NFs (Fig. 6(i)). Regular NFs are then subdivided into two categories, depending on whether they have rough or smooth surface morphology. Generally, aggregated crystals consisting of NFs appear after the removal of organic components and result in the surface morphology of the NFs being rough. However, there are two exceptions to this rule. The first case is when carbon-containing backbone polymers are carbonised instead of being completely removed. In this case, MNPs are embedded in the continuous carbon phase. ${ }^{94}$ The second case is when the calcination atmosphere is controlled. For example, Barakat et al. ${ }^{169}$ revealed that smooth morphologies of nickel NFs were retained even after heat treatment in argon. However, previous studies where hydrogen has been adopted to reduce the nickel precursor NFs do not produce a smooth morphology. To obtain NFs with a uniform size distribution, the surface tension, viscosity and electronic conductivity can be adjusted through the addition of a low molecular weight agent, if optimum conditions cannot be otherwise identified. ${ }^{168}$

\subsection{Processing parameters and magnetic properties}

The most common processing parameter for electrospinning NF templates is calcination. Calcinated NFs still possess superior magnetic performance than their zero-dimensional (0D, i.e. nanoparticles) or bulk counterparts. The most apparent property enhancement is in the coercivity $\left(H_{\mathrm{c}}\right)$ due to the anisotropic nature of NFs, as compared to NPs. ${ }^{127}$ The magnitude of the coercivity is related to the anisotropy of the material, which includes magnetocrystalline anisotropy, shape anisotropy and stress anisotropy. However, the NF structure possesses large shape anisotropy as a

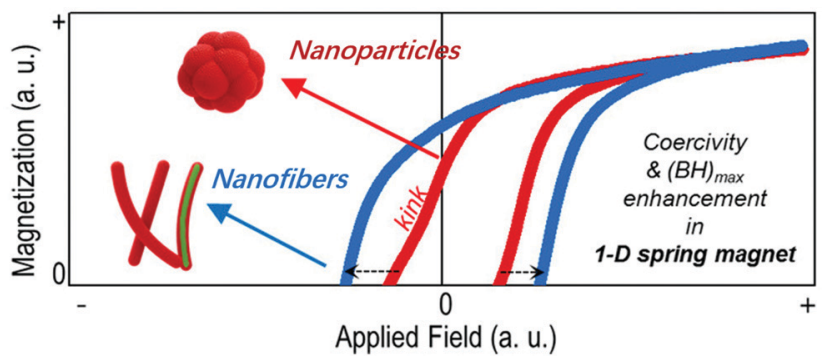

Fig. 7 Scheme of expected magnetic performance in a uniform, onedimensional, hard-soft magnetic core-shell nanocomposite and its counterpart. ${ }^{154}$ Adapted with permission from ref. 154. Copyright (2021) American Chemical Society.

result of the strict restriction of magnetic moment along the fibre axis. ${ }^{170}$ For example, $\mathrm{LaFeO}_{3}$ exhibits antiferromagnetism in the bulk, yet is ferromagnetic when in processed as a one-dimensional (1D) nanostructure with an increased coercivity value of 28000 Oe. ${ }^{171}$ In addition, 1D hard-soft exchange-coupling nanomaterials offer a unique platform for enhancing the maximum magnetic energy product $[(B H) \max ]$ due to the reduced selfaggregation when compared to their 0D counterparts. ${ }^{124,154}$ In another case, Lee et al. ${ }^{154}$ fabricated core-shell $\mathrm{Sm}_{2} \mathrm{Co}_{17} / \mathrm{FeCo}$ NFs by electrospinning, calcination, calciothermic reduction and electroless plating. Relative to its OD counterpart, the well-dispersed 1D/core-shell nanostructure demonstrates an enhancement in $(B H) \max (46 \%$ increase) as a result of the dense homogeneous soft magnetic coating as shown in Fig. 7. However, it should be noted that the magnetic properties are not always improved by simply introducing anisotropy (going from nanoparticles (0D) to NFs (1D) nanomaterials). This was highlighted in a study where the $M_{\mathrm{S}}$ value of $\mathrm{CoFe}_{2} \mathrm{O}_{4}$ NFs was lower than that of $\mathrm{CoFe}_{2} \mathrm{O}_{4} \mathrm{NPs}$ and even the bulk counterparts. ${ }^{172}$

3.2.1 Morphology. As aforementioned, morphology is another factor that influences the magnetic properties of the final NFs. Manipulating the electrospinning voltage can cause the morphology of the MNFs to go through a series of changes. However, this has only been demonstrated in a limited number of studies. In one example, at lower voltages $(\sim 8 \mathrm{kV})$ the NFs aggregate and by gradually increasing the voltage pass through the following formations: rods $(\sim 10 \mathrm{kV})$, fibres $(\sim 15 \mathrm{kV})$ and finally, belts $(\sim 20 \mathrm{kV})$. The $M_{\mathrm{s}}$ values are then shown to decrease in the sequence of belts $>$ rods $>$ fibres $>$ aggregated fibres. ${ }^{139}$ In another notable example, Zhao et al. highlighted that $\mathrm{SnO}_{2}$ nanotubes exhibit stronger room-temperature ferromagnetism than the corresponding NFs. This observation is attributed to a larger number of surface defects that result from the Sn interstitial and $\mathrm{O}$ vacancies having lower formation energies than the Sn vacancy and the surface area-to-volume atom quantities for the nanotubes being greater. ${ }^{173}$ Additionally, the average particle size for the nanotubes $(30 \mathrm{~nm})$ was larger than that of the NFs $(20 \mathrm{~nm})$. Similarly, the average outer diameter of the nanotubes (110 nm, with a $10 \mathrm{~nm}$ wall thickness) was also larger than that of the NFs $(100 \mathrm{~nm})$.

3.2.2 Calcination. The magnetic properties of NFs are strongly dependent on calcination. Diamagnetic as-spun NFs 
have been shown to exhibit ferromagnetic behaviour after calcination. The calcination parameters such as rate, temperature and calcination atmosphere exert influence on the final properties of the NFs. ${ }^{174}$ When the organic components are completely removed, the calcinated products are typically composed of nanocrystallites of various size. Overall, the magnetic behaviour of the nanocrystallites assembly is determined by the shape and size of the crystalline NPs and the interactions between them. ${ }^{114,120,159,175}$

3.2.2.1 Calcination temperature. The relationship between calcination temperature and $M_{\mathrm{s}}$ is often system dependent. Generally, for a given system, lower thermal treatment temperatures result in smaller particles being formed (down to a critical minimum size) and the smaller particles exhibit smaller $M_{\text {s }}$ values. ${ }^{106,114,119,122,132,133,170,172,176-188}$ Larger particles have less magnetic contribution from the surface (whilst the contribution from the interior concomitantly increases) and thus the $M_{\mathrm{s}}$ value increases. ${ }^{114}$ However, the smaller $M_{\mathrm{s}}$ values observed at low calcination temperatures are not always only due to the decrease in size of the particles. For example, in Liu's study, the $\mathrm{CoFe}_{2} \mathrm{O}_{4} \mathrm{NFs}$ were calcinated at 700, 750, 800, $850{ }^{\circ} \mathrm{C}$, respectively. In addition to the increase in particle size, the XPS results suggested that as the calcination temperature increases, the migration of cobalt ions to the tetrahedral sites as well as iron ions to the octahedral sites increases, thus also contributing to the larger $M_{\mathrm{S}}$ observed. ${ }^{189}$ However, there are examples that do deviate from this trend. For example, the $M_{\mathrm{s}}$ values of $\mathrm{CuCo}_{2} \mathrm{O}_{4}$ fibres have been found to decrease with increasing calcination temperature. ${ }^{190}$ In this case, the decrease is attributed to surface distortions brought about by interactions between oxygen atoms and transition metal ions. $\mathrm{Ti}_{0.9} \mathrm{~V}_{0.1} \mathrm{O}_{2}$ NFs were also shown to exhibit a decrease in $M_{\mathrm{s}}$ with increasing heat treatment temperature, which was assigned to the increase of nearestneighbour $\mathrm{V}$ ions with direct antiferromagnetic coupling. ${ }^{191}$

In the study of Liu et al., the $M_{\mathrm{s}}$ value of $\alpha-\mathrm{Fe}_{2} \mathrm{O}_{3} / \mathrm{TiO}_{2} \mathrm{NFs}$ decreased with increasing calcination temperature. The authors ascribed this to an increased density of $\alpha-\mathrm{Fe}_{2} \mathrm{O}_{3} \cdot{ }^{177}$ The decrease in $M_{\mathrm{S}}$ with arising calcination temperature was also found in other studies. ${ }^{192}$ In more recent work, Ponhan et al. ${ }^{193}$ determined that the $M_{\mathrm{s}}$ dependency on calcination temperature of $\mathrm{ZnFe}_{2} \mathrm{O}_{4}$ NFs exhibits through both of the observed trends. Initially, $M_{\mathrm{s}}$ increases with calcination temperature before then decreasing, with crystallite size increasing typically from 19 to $26 \mathrm{~nm}$.

Similarly, the $H_{\mathrm{c}}$ transition with calcination temperature is also system dependent. In most cases, $H_{\mathrm{c}}$ increases with calcination temperature; including that observed for $\mathrm{MgFe}_{2} \mathrm{O}_{4}$ nanotubes, ${ }^{135} \mathrm{CoFe}_{2} \mathrm{O}_{4} \mathrm{NFs},{ }^{194} \mathrm{NiFe}_{2} \mathrm{O}_{4} \mathrm{NFs},{ }^{183} \mathrm{MnFe}_{2} \mathrm{O}_{4}$ $\mathrm{NFs},{ }^{186} \mathrm{Ni} /$ mullite $\mathrm{NFs}^{132}$ and $\mathrm{Co}_{0.5} \mathrm{Ni}_{0.5} \mathrm{Fe}_{2} \mathrm{O}_{4}$ NFs. ${ }^{122}$ However, there are also reports where the $H_{\mathrm{c}}$ transition does not follow this trend. For example, the $H_{c}$ value of $\mathrm{MnFe}_{2} \mathrm{O}_{4} / \mathrm{C}$ NFs decreases with increasing calcination temperature ${ }^{185}$ and is attributed to the $\mathrm{MnFe}_{2} \mathrm{O}_{4} / \mathrm{C}$ NFs exhibiting ferromagnetic properties due to the distribution of cations over tetrahedral and octahedral sites. In the study by Lu et al., ${ }^{106}$ the $H_{\mathrm{c}}$ value of $\mathrm{CoFe}_{2} \mathrm{O}_{4} \mathrm{NFs}$ demonstrated an initial increase followed by a decrease with increasing annealing temperature. The same phenomenon was reported in both $\mathrm{SrTiO}_{3} / \mathrm{SrFe}_{12} \mathrm{O}_{19} \mathrm{NFs}^{181}$ and yttrium iron garnet NFs, ${ }^{170}$ attributed to the motion of domains experienced at different particle sizes. Furthermore, the same trend was found in hollow $\mathrm{CuFe}_{2} \mathrm{O}_{4}$ NFs. ${ }^{159}$ In this case, higher calcination temperatures gave rise to larger MNPs and thus a higher field force was required to alter the magnetic moment direction; in turn resulting in higher $H_{\mathrm{c}}$. However, when the particle size exceeded the critical size for a single-multi domain transition, $H_{\mathrm{c}}$ declined. Findings from the study of $\mathrm{CoFe}_{2} \mathrm{O}_{4}$ hollow fibres further support this claim as $H_{\mathrm{c}}$ increases with annealing temperature. ${ }^{160}$ The $H_{\mathrm{c}}$ value of the $\mathrm{CoFe}_{2} \mathrm{O}_{4}$ nanobelts ${ }^{119}$ achieved a maximum value of 1802 Oe before decreasing with further increases in calcination temperature as a result of the particle size being below the critical domain size. In addition, the absence of domain walls and unique rectangular cross-sectional shape contributed to the high magneto-crystalline properties observed.

The final important magnetic property to be discussed in relation to calcination temperature is remanent magnetisation, $M_{\mathrm{r}}$. In one example, $\mathrm{CoFe}_{2} \mathrm{O}_{4}$ NFs, fabricated by single spinning and calcination, and were shown to exhibit a uniform increase in $M_{\mathrm{r}}$ with increasing calcination temperature. This is commonly attributed to an increase in the particle size. ${ }^{194}$ The same phenomenon was found for $\mathrm{MnFe}_{2} \mathrm{O}_{4} \mathrm{NFs},{ }^{186} \mathrm{SrTiO}_{3} / \mathrm{SrFe}_{12} \mathrm{O}_{19}$ NFs, ${ }^{181} \mathrm{MgFe}_{2} \mathrm{O}_{4}$ nanotubes, ${ }^{135}$ hollow $\mathrm{CuFe}_{2} \mathrm{O}_{4} \mathrm{NFs}^{159}$ and hollow $\mathrm{CoFe}_{2} \mathrm{O}_{4}$ NFs. ${ }^{160}$ In one contradictory case, the $M_{\mathrm{r}}$ value of $\mathrm{CuCo}_{2} \mathrm{O}_{4}$ fibres ${ }^{190}$ was found to decrease with increasing calcination temperature, which was suggested to be due to weakening of the superexchange interaction between the $\mathrm{Cu}^{3+}$ and $\mathrm{Co}^{2+}$ cations.

In some fabrication methodologies, the heat treatment encompasses two stages; calcination and reduction. The magnetic properties are known to be dependent on the reduction temperature. For example, the reduction temperature of $\mathrm{Fe} / \mathrm{Ni}$ alloy nanobelts ${ }^{126}$ show an increase followed by decreasing trend in $M_{\mathrm{s}}$, whereas the $H_{\mathrm{c}}$ initially decreases before remaining almost constant with increasing temperature. In this example, the $\mathrm{Fe} / \mathrm{Ni}$ alloy nanobelts were reduced from $\mathrm{NiFe}_{2} \mathrm{O}_{4}$ and the initial relative low temperatures used resulted in the observed partial reduction of $M_{\mathrm{s}}$.

The relationship between calcination temperature and $M_{\mathrm{s}}, H_{\mathrm{c}}$ and $M_{\mathrm{r}}$ has been identified as significantly system dependent. Factors such as density, surface distortions, cation distribution, particle size and cation interaction have all been shown to contribute to the final magnetic properties of the NFs produced.

3.2.2.2 Calcination atmosphere. The calcination atmosphere used can have a significant effect on the magnetic properties of NFs. For example, $\mathrm{SrFe}_{12} \mathrm{O}_{19} / \mathrm{CoFe}_{2} \mathrm{O}_{4}$ obtained from as-spun NFs calcinated in air showed a $H_{c}$ value of 3190 Oe. On the other hand, $\mathrm{SrFe}_{12} \mathrm{O}_{19} / \mathrm{FeCo}$ obtained from as-spun NFs calcinated in air and then reduced in hydrogen showed a significantly lower $H_{\text {c }}$ value of 1249 Oe. This change is attributed to the close contact of the soft and hard phases which in turn results in strong exchange coupling. In addition, $\mathrm{Fe}_{2} \mathrm{O}_{3}$ hollow NFs obtained from as-spun NFs calcinated in air were superparamagnetic and achieved an $M_{\mathrm{S}}$ value of $4.34 \mathrm{emu}^{-1}$, whilst 
$\mathrm{Fe}_{3} \mathrm{O}_{4}$ and $\mathrm{Fe}_{2} \mathrm{~N}$ hollow NFs obtained from as-spun NFs calcinated in air and then reduced in gaseous ammonia achieved $M_{\mathrm{S}}$ values of $82.99 \mathrm{emu} \mathrm{g}^{-1}$ and 2.07 emu $\mathrm{g}^{-1}$, respectively. Finally, the $\mathrm{Fe}_{3} \mathrm{O}_{4}$ hollow NFs exhibited ferromagnetism whilst the $\mathrm{Fe}_{2} \mathrm{~N}$ hollow NFs demonstrated superparamagnetism. ${ }^{134,153}$ The morphology of the fibre can also be altered depending on the calcination atmosphere used and, as previously discussed, is directly related to the magnetic properties of the final fibre. In one example $\alpha-\mathrm{Fe}_{2} \mathrm{O}_{3}$ nanotubes and $\mathrm{Fe}_{3} \mathrm{O}_{4}$ NFs were produced when the calcination atmospheres were air and argon, respectively. Nanotubes were formed due to the lack of oxygen present as gas diffusion from the decomposed organic component (PEO) drives the nanoparticles from the inside to the outside of the fibres. ${ }^{195}$

3.2.3 Magnetic component loading. The most influential factor on the overall magnetic performance of NFs are the components used to make them, rather than how they are made. This is particularly evident in cases that involve the combination of magnetic inorganic constituents and non-magnetic polymers. Typically, $M_{\mathrm{s}}$ has a linear correlation with the quantity of magnetic components, ${ }^{107,156,196-199}$ whilst the addition of nonmagnetic components generally impairs the $M_{\mathrm{S}}$ value. ${ }^{200-202}$ Therefore, the $M_{\mathrm{S}}$ values of NFs where polymers are retained are lower than those observed for fibres that consist of pure MNPs. ${ }^{94,107}$ Another common example, reflecting this logical observation, is $M_{\mathrm{s}}$ enhancement after carbonisation. Again, due to the loss of the non-magnetic compounds during the procedure. With ascending carbonisation temperature, $M_{\mathrm{s}}$ will increase when the size and coarsening of MNPs within the NFs increases and if a new phase with larger $M_{\mathrm{S}}$ comes into force. ${ }^{198}$ However, one report claims that the $M_{\mathrm{s}}$ value in their system was independent of shape and size of the MNPs and is only affected by the total quantity of magnetic atoms. ${ }^{198}$

Moreover, carbonisation often induces the transformation from superparamagnetism to ferromagnetism in electrospun NFs. ${ }^{194}$ This is due to the formation of a new phase, such as the carbide crystal, which destroys the single crystal domain of the original NFs. ${ }^{172}$ It has also been claimed that enhancement of particle size leads to higher magnetocrystalline anisotropy. ${ }^{197,198}$

3.2.4 Types of polymer. The different types of sacrificial polymer result in varied magnetic properties in the final NF. For example, NiO NFs obtained from poly(2-ethyl-2-oxazoline) $\left(\mathrm{PEtO}_{x}\right) /$ nickel(II) acetate tetrahydrate precursor were shown to exhibit antiferromagnetism, whereas NiO NFs obtained from styrene-acrylonitrile random copolymer (SAN)/nickel(II) acetate tetrahydrate precursor exhibited ferromagnetism at RT. ${ }^{203}$ The authors suggested that the change in magnetism occurs because of the distinct degradation mechanism of the different polymers. The degradation of SAN begins with elimination of the nitrile group followed by random scission of the backbone. In contrast, $\mathrm{PEtO}_{x}$ begins with random chain scission followed by elimination of the side chains. Additionally, the activation energy for grain growth and corresponding grain sizes were also different. Both factors lead to non-stoichiometry of the NiO NFs.

3.2.5 Polymer concentration. Polymer concentration notably influences the electrospinning process, which determines the morphology and magnetic properties of the fibres produced.
Typically, increasing the concentration of the polymer produces fibres with increased diameter, uniformity and tensile strength. ${ }^{204}$ The variation in morphology, particularly NF diameter and uniformity, is also often attributed to the solution properties (polymer and solvent) on the electrospinning process; most significantly the viscosity of the electrospinning solution. The viscosity, alongside the surface tension, ultimately determine the ability of a given solution to be electrospun. Therefore, it is unsurprising to see examples in the literature that describe increased solution viscosity due to higher concentrations of polymer resulting in NFs with increased diameter. ${ }^{205}$ In one investigation, the effect of PVP concentration on the morphology and magnetic properties of $\mathrm{SrFe}_{12} \mathrm{O}_{19}$ nanobelts was investigated. ${ }^{116}$ It was found that increasing the PVP concentration from 8.5-12.3 wt\% led to the increase in the width of the nanobelts produced. Additionally, the diameter of NPs were reduced and the NPs' overall size was largely below the single domain size. As a direct result of this, $H_{\mathrm{c}}$ achieved a maximum value of 7310 Oe (the highest known value in the literature to the best of our knowledge) of all the pure 1D $\mathrm{SrFe}_{12} \mathrm{O}_{19}$ structures. This value is also close to the theoretical limit. ${ }^{116}$

3.2.6 Dopants. Doping has been shown to affect the crystal size of magnetic materials, which influences the magnetic properties of the final MNFs. The extent of this effect depends on the properties and loading of the dopant. ${ }^{206-212}$ Typical dopants that have been explored to enhance the magnetic properties and direct the morphology of MNFs include graphene oxide (GO), ${ }^{213} \mathrm{Co}^{214} \mathrm{Ni}^{215} \mathrm{Cu}^{210}$ and $\mathrm{Zn}^{216}$ For example, GO-doped $\mathrm{Ni}_{0.8} \mathrm{Gd}_{0.2} \mathrm{Fe}_{2} \mathrm{O}_{4}$ NFs showed a transformation from fibre to ribbon morphology and a decrease in $M_{\mathrm{s}}$ with increasing GO content. Additionally, Ni-doped Fe NFs were shown to exhibit lower $M_{\mathrm{S}}$ and $H_{\mathrm{c}}$ values compared to pure Fe NFs. ${ }^{128}$ Ni-doped $\mathrm{CoFe}_{2} \mathrm{O}_{4}$ NFs were also found to show a decreasing trend in $M_{\mathrm{s}}$ and $H_{\mathrm{c}}$ with increasing $\mathrm{Ni}^{2+}$ concentration, which was due to the lower magnetic moment and magnetocrystalline anisotropy of $\mathrm{Ni}^{2+}$ compared to $\mathrm{Co}^{2+}$ ions. ${ }^{215}$ It is important to note that the change in magnetic properties with dopant concentration is not always uniform $^{209}$ and can contradict known theories (such as Brown's theory ${ }^{217}$ ) where $M_{\mathrm{s}}$ and $H_{\mathrm{c}}$ are inversely related. For example, the $M_{\mathrm{S}}$ value of $\mathrm{Zn}$-doped $\mathrm{CuFe}_{2} \mathrm{O}_{4}$ NFs initially increases before decreasing with increasing $\mathrm{Zn}^{2+}$ concentration due to increased exchange interaction between ions within the lattice. ${ }^{216}$ Co-Doped ZnO NFs were fabricated by electrospinning a PVA/Co-doped ZnO suspension followed by sintering in air. ${ }^{218}$ Doping ZnO NFs with 1.8-7.2 wt\% Co was shown to change the material properties from ferromagnetism to ferrimagnetism, as shown by the temperaturedependent magnetisation curves and Curie-Weiss fits in Fig. 8. The origin of ferrimagnetism in $\mathrm{Zn}_{1-x} \mathrm{Co}_{x} \mathrm{O}$ NFs is attributed to the substitution of Co for $\mathrm{Zn}$ and the corresponding change of characteristics in the electronic state.

Doping has also been known to lead to the production of NFs with unique properties. For example, hole-doped manganites, with the general formula $\mathrm{R}_{1-x} \mathrm{~A}_{x} \mathrm{MnO}_{3}$ (where $\mathrm{R}$ refers to a trivalent rare earth element and $\mathrm{A}$ is a divalent alkaline earth element) were found to exhibit colossal magneto resistance (CMR). $\mathrm{La}_{0.33} \mathrm{Pr}_{0.34} \mathrm{Ca}_{0.33} \mathrm{MnO}_{3}$ NFs (prepared at a calcination temperature of $600{ }^{\circ} \mathrm{C}$ ) exhibited 


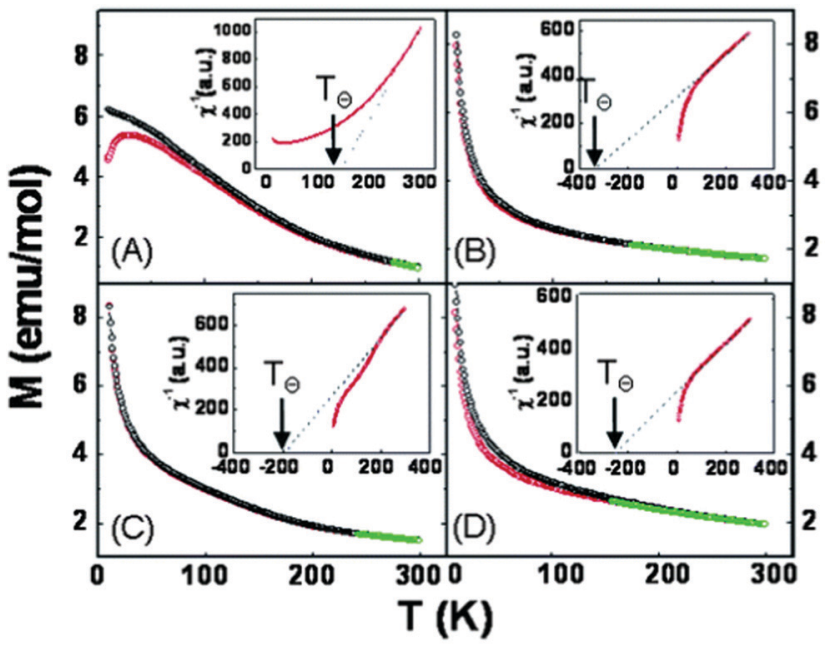

(E)

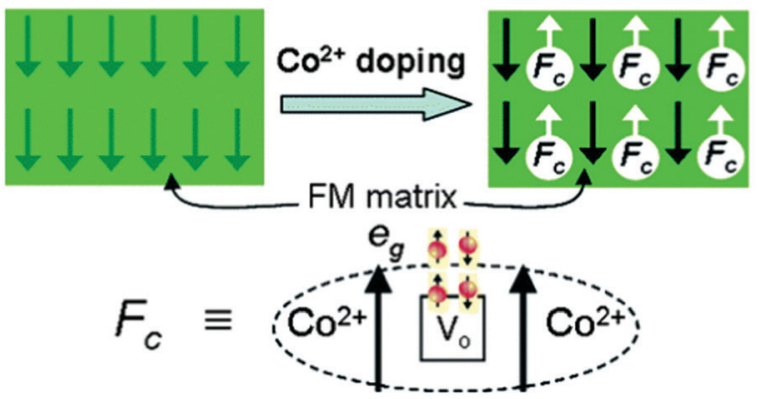

Fig. 8 The effect of doping $\mathrm{ZnO}$ NFs with $\mathrm{Co}^{2+}$ on magnetic properties, illustrated through: $(A)-(D)$ temperature-dependent magnetisation $(M-T)$ curves of $\mathrm{Zn}_{1-x} \mathrm{Co}_{x} \mathrm{O}$ ( $x=0$, pure $\mathrm{ZnO}$ nanowires) NFs with 1.8, 4.4 and $7.2 \% \mathrm{Co}$, respectively. This visually shows the transition from ferromagnetism to ferrimagnetism. (E) $\mathrm{Co}^{2+}$ doping-induced ferromagnetism to ferrimagnetism crossover. ${ }^{218}$ Reproduced from ref. 218 with permission from The Royal Society of Chemistry.

CMR over a wide temperature range and the magneto resistance reached a maximum value of $95 \%$ at the metal-insulator transition temperature of $70 \mathrm{~K}$ under 7 Tesla. ${ }^{219}$ In another case, doping $\alpha-\mathrm{Fe}_{2} \mathrm{O}_{3}$ nanotubes with $\mathrm{V}_{2} \mathrm{O}_{5}$ was found to increase $M_{\mathrm{s}}$, and decrease $H_{\mathrm{c}}$, which was attributed to the aforementioned Brown's theory; where $H_{\mathrm{c}}$ and $M_{\mathrm{s}}$ are inversely proportional to one another. ${ }^{217}$ In other work, after Co doping, $\mathrm{SrTiO}_{3}$ was endowed with room temperature ferromagnetism due to Co addition and oxygen vacancies, ${ }^{130,173}$ which has also been demonstrated in the study of $\mathrm{SnO}_{2}$ nanotubes. ${ }^{220}$ However, Mohanapriya et al. suggests that ferromagnetism in Mn-doped $\mathrm{SnO}_{2} \mathrm{NFs}$ is induced only by precipitated impurity phases instead of pure $\mathrm{SnO}_{2}$ or dopant. ${ }^{21}$ Nevertheless, Mn doping was found to impair the ferromagnetism of $\mathrm{BaTiO}_{3}$ and resulted in dia- and paramagnetic behaviour of the $\mathrm{BaTi}_{0.9} \mathrm{Mn}_{0.1} \mathrm{O}_{3}$ NFs that were produced. ${ }^{222}$ Fe-Doped NiO NFs were prepared as a diluted magnetic semiconductor (DMS) and, notably, doping was shown not to affect the fibre diameter or surface morphology. ${ }^{223}$ Finally, the addition of GO dopant to $\mathrm{CoFe}_{2} \mathrm{O}_{4}$ NFs demonstrated enhanced crystallinity, which boosted $M_{\mathrm{s}}$ values at low loadings, but was then shown to exhibit a slight decrease in $M_{\mathrm{s}}$ with higher GO loadings. ${ }^{224}$
3.2.7 Alloys. Alloy systems with nanoscale dimensions often demonstrate outstanding magnetic properties. There have been a number of reports where alloys have been processed into NFs to create magnetic materials. For example, Zhang et al. ${ }^{128}$ reported $\mathrm{Fe}-\mathrm{Ni}$ NFs for the first time and demonstrated that the use of an $\mathrm{Fe}-\mathrm{Ni}$ alloy resulted in superior ferromagnetic properties. Additionally, it was suggested by Jiang et al. ${ }^{126}$ that an Fe-Ni alloy also produces NFs with high saturation magnetisation, permeability, Curie temperature $\left(T_{\mathrm{c}}\right)$, low coercivity and low energy loss. FeCo is another promising soft magnetic nanomaterial which exhibits low magneto-striction, high saturation magnetisation, high resistivity, small coercive forces, high Curie temperature and high magnetic anisotropy energies. ${ }^{225}$ Finally, a range of novel $\mathrm{Sm}_{2} \mathrm{Co}_{17} \mathrm{NFs}$ were fabricated by Lee et al. reporting a decrease in $M_{\mathrm{S}}$ and concomitant $H_{\mathrm{c}}$ increase with arising Sm content within the alloy. ${ }^{206}$

\section{Applications}

In this section, the application of magnetic materials, and how this relates to their final properties, are explored. This aptly highlights the versatility of electrospun magnetic materials whilst concomitantly highlighting the need for future work into their production and design.

\subsection{Electromagnetic shielding/absorption}

With the extensive utilisation of electronic devices for civil and military purposes there is a strong desire to reduce electromagnetic (EM) pollution due to its associated negative impact on human health, national defence security and electronic safety. ${ }^{121,226-231}$ EM wave shielding, or absorption materials, are designed to address this challenge. Fig. 9 shows a schematic diagram that illustrates the working mechanism of so-called microwave absorption materials (MAMs). When incident waves reach the surface of the material, they are either reflected off the sample or transmitted into a porous channel; where multiple reflections occur and the energy is dissipated. The difference between MAMs and electromagnetic-induced (EMI) shielding materials is that MAMs require EM waves to be transmitted into

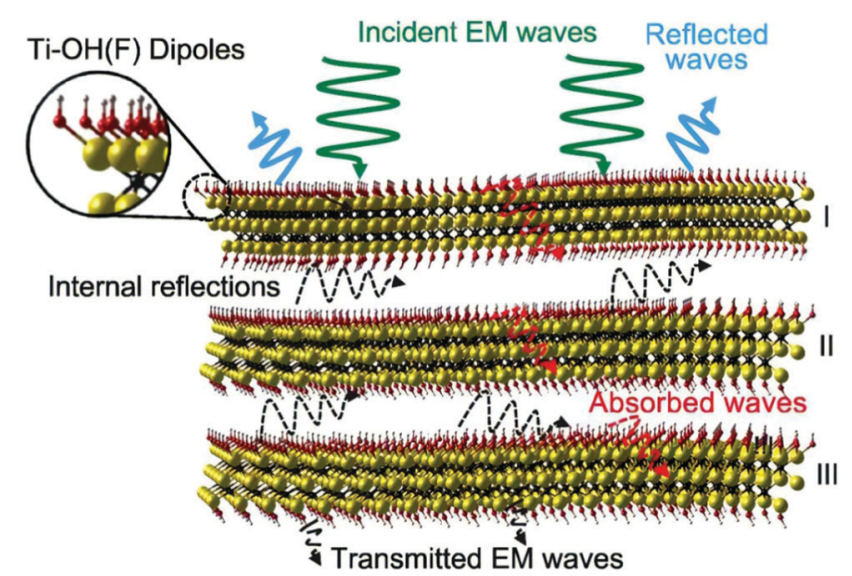

Fig. 9 Electromagnetic wave attenuation through a shielding material. ${ }^{233}$ 
the materials to be dissipated rather than simply reflected at the surface. ${ }^{150,196}$ MAMs achieve EM attenuation through a combination of magnetic loss, electric loss and geometry (morphology). ${ }^{26,228}$ Magnetic loss originates from the eddy current effect, natural ferromagnetic resonance and exchange resonance. For ferromagnetic materials, the magnetic loss ability is related to initial permeability $\left(\mu_{\mathrm{i}}\right)$, as shown in eqn (1), where a and b represent constants relating to the material being used, and $\lambda, k, \xi, M_{\mathrm{s}}$ and $H_{\mathrm{c}}$ are the wavelength, magnetisation constant, elastic strain parameter of a crystal, saturation magnetisation and coercivity, respectively. Eqn (1) shows that high $M_{\mathrm{s}}$ and low $H_{\mathrm{c}}$ values are required to increase $\mu_{\mathrm{i}}$, to deliver better magnetic loss ability. ${ }^{226,232}$

$$
\mu_{\mathrm{i}}=\frac{M_{\mathrm{s}}^{2}}{a k H_{\mathrm{c}} M_{\mathrm{s}}+b \lambda \xi}
$$

For electromagnetic wave absorption (EWA) properties, complex permittivity $\varepsilon_{\mathrm{r}}=\varepsilon^{\prime}-j \varepsilon^{\prime \prime}$ and complex permeability $\mu_{\mathrm{r}}=\mu^{\prime}-j \mu^{\prime \prime}$ are two critical factors in microwave absorption property determination. The real part $\left(\varepsilon^{\prime}\right.$ or $\mu^{\prime}$ ) corresponds to the energy storage whilst the imaginary part $\left(\varepsilon^{\prime \prime}\right.$ or $\left.\mu^{\prime \prime}\right)$ corresponds to the energy dissipation. Dielectric loss and magnetic loss are expressed by $\tan \left(\frac{\varepsilon^{\prime}}{\varepsilon^{\prime \prime}}\right)$ and $\tan \left(\frac{\mu^{\prime}}{\mu^{\prime \prime}}\right)$, respectively. ${ }^{196,226,228}$

Reflection loss (RL) is calculated from eqn (2)-(4): ${ }^{196,226,228}$

$$
\begin{gathered}
\mathrm{RL}(\mathrm{dB})=20 \log \left|\frac{Z_{\text {in }}-Z_{0}}{Z_{\text {in }}+Z_{0}}\right| \\
Z_{0}=\sqrt{\mu_{0} / \varepsilon_{0}} \\
Z_{\text {in }}=\sqrt{\frac{\mu_{\mathrm{r}}}{\varepsilon_{\mathrm{r}}}} \tanh \left[j \frac{2 \pi}{c} \sqrt{\mu_{\mathrm{r}} \varepsilon_{\mathrm{r}} f t}\right]
\end{gathered}
$$

where, $Z_{\text {in }}$ and $Z_{0}$ are the input impedance of the absorber and impedance of free space, $\varepsilon_{0}$ and $\mu_{0}$ are vacuum permittivity and permeability, and $\varepsilon_{\mathrm{r}}, \mu_{\mathrm{r}}, f, c$ and $t$ are the relative complex permittivity, permeability, frequency of the electromagnetic wave, velocity of electromagnetic waves in free space and thickness of the absorber, respectively. ${ }^{226}$ Accordingly, thickness plays an important role in the magnitude of RL. ${ }^{226,227} \mathrm{RL}$ decreases and the absorption peaks shift to lower frequencies with increasing absorber thickness. Dielectric and magnetic losses also influence RL and are used in combination to improve the microwave absorption performance. ${ }^{228}$ Additionally, crosslinking the structure can cause a geometric effect that contributes to RL, as demonstrated with $\mathrm{Fe} / \mathrm{C}$ cross-linked network structures. ${ }^{228}$

Carbon fibres can be equipped with magnetic properties through the addition of MNPs to create EM absorbing materials. The ultimate EM wave absorption capability is a direct result of both the dielectric and magnetic properties, with higher $M_{\mathrm{s}}$ and lower $H_{\mathrm{c}}$ values also contributing to the magnetic wave absorption properties. ${ }^{26,228}$ Notably, $\mathrm{NiFe}_{2} \mathrm{O}_{4} /$ multi-walled carbon nanotubes (MWCNTs)/carbon nanofibrous membranes, with thicknesses of 2-5 $\mathrm{mm}$, have been created as MAMs that achieve high permeability and reflection losses $>20 \mathrm{~dB}(5.36-18 \mathrm{GHz}) .{ }^{142}$

\subsection{Separation: pollutant treatment and catalysis}

Functional pollutant absorbers and photocatalysts are used extensively in wastewater treatment. However, the challenge on how to avoid secondary pollution of any residual absorber or catalysts remains a significant problem. One method used to address this issue is the incorporation of electrospun NFs with unique magnetic properties. After degradation, these materials are easily recycled by use of a permanent magnet. ${ }^{45,158,166,177,199,200,202,234-247}$ For example, Liang et al. ${ }^{248}$ prepared multifunctional switchable chemosensors for $\mathrm{Hg}^{2+}$ with fluorescent probe 1-benzoyl-3-[2-(2allyl-1,3-dioxo-2,3-dihydro-1H-benzo[de]isoquinolin-6-ylamino)ethyl]-thiourea (BNPTU), PNIPAM copolymer moiety for thermo-responsiveness and on-off photoluminescence and $\mathrm{Fe}_{3} \mathrm{O}_{4}$ NPs for easy removal. Chang et al. deposited bismuth oxyiodide nanoflakes on $\alpha-\mathrm{Fe}_{2} \mathrm{O}_{3}$ NFs via the SILAR (successive ion layer absorption and reaction) method. ${ }^{237}$ The final product reached a maximum specific surface area of $35.27 \mathrm{~m}^{2} \mathrm{~g}^{-1}$, rhodamine B degradation efficiency of $98 \%$ after 2 hours of visible light irradiation and an $M_{\mathrm{s}}$ value of $0.9 \mathrm{emu}^{-1}$, demonstrating its potential for use as practical separable photocatalysts. As these MNPs render the fibres ferromagnetic, or superparamagnetic, they can be attracted to external magnetic fields. ${ }^{239,249-251}$ In addition to this, it has been shown that under stronger magnetic fields the catalysts can be demulsified and therefore recycled back for reuse. ${ }^{252}$

\subsection{Tissue engineering scaffolds, cell culture and differentiation}

Electrospun NFs have been extensively explored as scaffolds for regenerative medicine. Recently, superparamagnetic fibrous scaffolds have been discovered to have a positive effect regarding cell differentiation (Fig. 10). Furthermore, after implanting the scaffold into the human body, the magnetic property enables the device to be manipulated remotely. The most common approach in this area is to combine MNPs, such as $\gamma-\mathrm{Fe}_{2} \mathrm{O}_{3},{ }^{253-255}$ $\mathrm{Fe}_{3} \mathrm{O}_{4}{ }^{8,85,256-259} \mathrm{CoFe}_{2} \mathrm{O}_{4}$ and bioglass, ${ }^{260}$ with bio-compatible polymers [such as PVA, ${ }^{253-255,260}$ polycaprolactone (PCL), poly(Llactide), poly(lactic-co-glycolic acid) (PLGA), poly(succinimide) and poly(aspartic acid $\left.{ }^{8,85,256-259}\right]$ to create flexible composite fibrous mats. These mats have been shown to exhibit enhanced mechanical properties compared to pristine non-magnetic NF mats. NFs with a dense, uniform, surface coverage of MNPs are targeted, however, their production remains a challenge. ${ }^{144,242}$

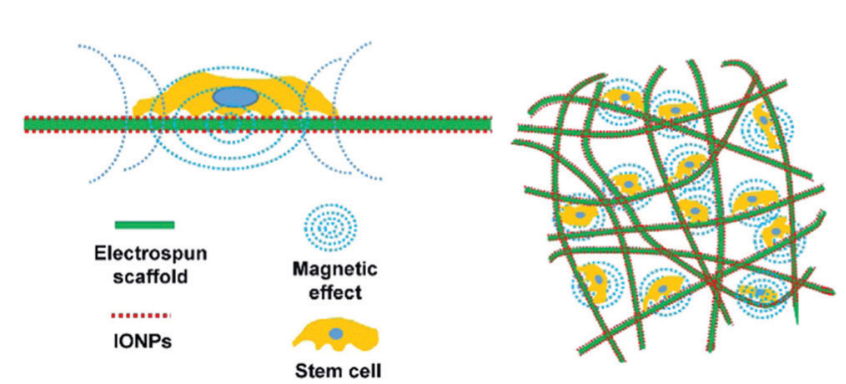

Fig. 10 Schematic showing the mechanism and effect of the IONPassembled electrospun scaffold on the cells. ${ }^{144}$ Adapted with permission from ref. 144. Copyright (2021) American Chemical Society. 
There have been attempts to employ electrospun fibrous templates to create tissue engineering scaffolds, where such methods appear to facilitate better distribution of MNPs on the surface of the NFs. For example, the layer-by-layer assembly technique was used to afford virtually continuous, compact and uniform $\alpha-\mathrm{Fe}_{2} \mathrm{O}_{3}$ nanoparticle immobilisation on PLGA/PCL electrospun scaffold surfaces. ${ }^{144}$ In this example, the superparamagnetic scaffold was found to significantly enhance the differentiation of adipose-derived stem cells for the treatment of osteogenesis. Moreover, the capping layer brings about auxiliary benefits such as hydrophilicity, elasticity of the interface and the affinity for stem cells. In other work, composite $\mathrm{Fe}_{3} \mathrm{O}_{4}$ /silk fibroin NFs were compared to silk fibroin fibrous templates with coated $\mathrm{Fe}_{3} \mathrm{O}_{4}$ NPs to show the effect of the fabrication method on the final properties of the fabrics. The composite material (electrospun from a single solution) was more effective as a cell scaffold whilst the fibrous mat coated with MNPs was more suitable as a magnetic-sensitive interface. ${ }^{8}$

\subsection{Hyperthermia treatment}

The treatment of cancer cells includes chemotherapy, radiation therapy and surgery. Whilst these treatments have been used for decades it has been suggested that methods typically used to treat hypothermia could be an effective and ideal approach. This is based on the incorporation of superparamagnetic NFs which can either give out a fatal amount of heat to kill the cancer cells or the raised temperature of targeted tissues can enhance the effects of other therapy (such as drug release as shown in Fig. 11) used to destroy the cancer. ${ }^{107,109,145,261,262}$ Superparamagnetic fibres produce a thermal effect in response

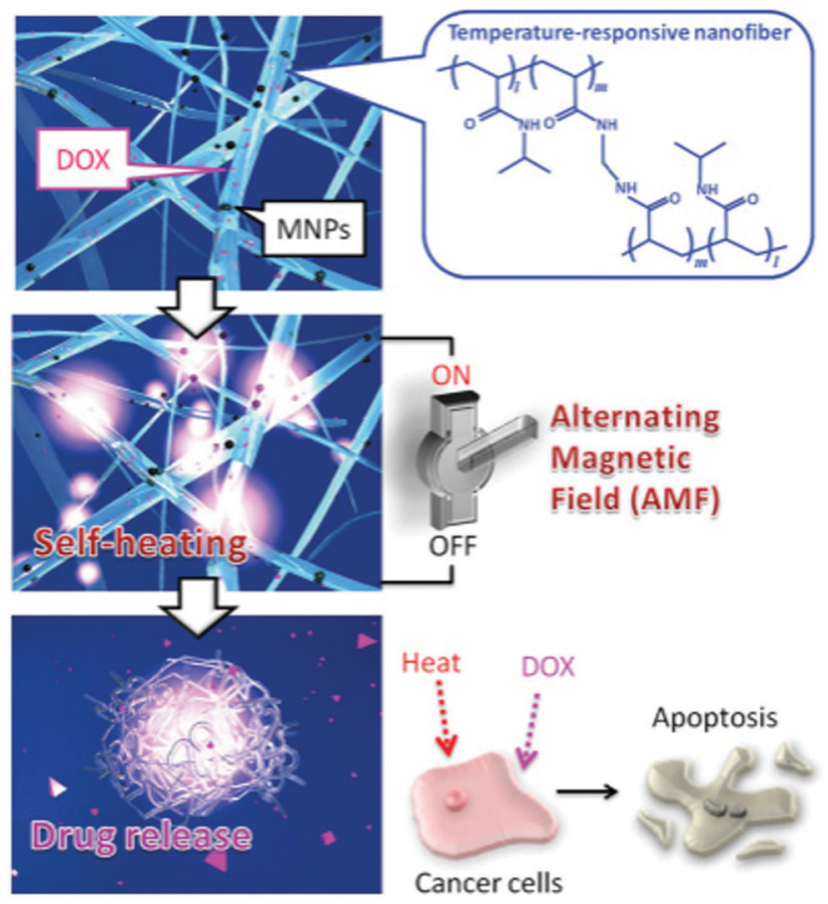

Fig. 11 Design concept for a smart hyperthermia NF system that uses MNPs dispersed in temperature-responsive polymers. ${ }^{1}$ to an applied alternating magnetic field. The significant advantage of superparamagnetic NFs is their demagnetisation in the absence of an external field. Non-toxic, biodegradable polymeric matrices $^{109}$ serve as carriers to provide mechanical support alongside other performance-enhancing properties, such as inhibiting the overgrowth of malignant tissues. ${ }^{107}$ The further merit of NFs in biomedical applications lies with their large surface area-to-volume ratios that lead to faster degradation of the scaffold after they have served their purpose. A large ratio of superparamagnetic NPs relative to polymer is required to provide an adequate number of accessible sites and immobilise the NPs on the NFs. ${ }^{145}$ There are reports where the number of MNPs on fibres have been quantified. Chen et al. used $\mathrm{Fe}^{2+}$ to chelate with alginates before fabricating a crosslinked $\mathrm{Fe}_{3} \mathrm{O}_{4}-\mathrm{SA} / \mathrm{PVA}$ mat by chemical co-precipitation. Immobilising the NPs on the fibre was then shown to eliminate cytotoxicity effects towards human lung fibroblast cells. ${ }^{107,109}$

\subsection{Drug delivery}

Recent developments in nanotechnology have led to polymeric matrices (e.g. NFs) being exploited as controllable drug release media. ${ }^{263}$ Encapsulating bioactive agents in a polymer matrix is an effective method for preventing drug degradation in potentially hostile environments (e.g. high or low $\mathrm{pH}$ ). Electrospun ultrathin fibres exhibit ideal characteristics such as high porosity, large surface area and diverse controllable morphologies to facilitate the development of electrospun fibrous drug delivery systems. ${ }^{88,264}$

For example, a core-shell fibrous drug delivery system was produced by coaxial electrospinning using Eudragit S100 as the shell and a core composed of PEO loaded with Gd(DTPA) (gadolinium diethylenetriamine pentaacetate hydrate, magnetic resonance contrast agent) and indomethacin (model therapeutic agent). ${ }^{265}$ Eudragit is insoluble in acidic environments and when used as oral medication protects the core ingredient as it passes through the stomach. The core materials are only released when the fibres reach the intestinal fluids, enabling this core-shell fibre delivery system to achieve targeted drug delivery to the colon. In another example, PVA/ferritin NF hydrogels with controllable magnetic properties were fabricated by partially unfolding the ferritin protein shell at varied mixing temperatures. ${ }^{100}$ The negative image contrast generated by ferritin in the PVA matrix under MRI provided a method for in vivo imaging of the tissueengineered scaffolds.

Meanwhile, magnetic reagents loaded into electrospun fibres have been shown to demonstrate synergistic effects. Sasikala et $a{ }^{266}$ designed and synthesised an implantable magnetic nanofibrous device for hyperthermia treatment comprised of iron oxide nanoparticles and tumour-triggered controlled drug release (bortezomib). The fibres exhibited a synergistic anticancer effect by applying the hyperthermia treatment and drug delivery simultaneously. In other work, a similar design was employed by embedding MNPs (as heat generators) and DOX (doxorubicin, anticancer drug) inside a temperature responsive copolymer of poly( $N$-isopropylacrylamide)-co-( $N$-hydroxymethylacrylamide) [P(NIPAM-co-HMAAm) $].{ }^{1}$ When placed in an alternating magnetic field, the crosslinked P(NIPAM-co-HMAAm) NF mesh showed 
reversible changes in swelling, which created an 'on-off' response allowing DOX to be released.

Beyond their use in externally triggered controlled release, the addition of MNPs can have a varied effect on drug release rate, depending on how the MNPs impact on the system within which they are placed. Demir et al. ${ }^{267}$ found that RhodB (hydrophilic dye) loaded in PCL NFs was released faster when MNPs were present due to the magnetic interaction between the nanoparticles and drug. Similarly, Haroosh et al. ${ }^{268}$ also found that the addition of MNPs increased drug release rate. In this case, the inclusion of the MNPs increased the conductivity of the electrospinning solution and also decreased its viscosity, which led to the production of thinner fibres. The larger specific surface area of the thinner fibres resulted in the increased drug release rate observed. Conversely, Wang et al. ${ }^{18}$ found that the release rate of indomethacin and aspirin (model drugs) was not affected by the incorporation of $\mathrm{Fe}_{3} \mathrm{O}_{4}$ NPs within the cellulose matrix; even when the MNPs occupied nearly $50 \%$ of the fibre mass.

In short, MNPs can be incorporated into NFs for controlled, triggered drug delivery, or to enhance the properties of the nanofibrous drug delivery system. In the latter case, caution must be made when designing and fabricating the device, as the incorporation of the magnetic nanoparticles can have variable effects on the drug delivery performance of the system.

\subsection{Nanogenerators}

The development of wearable electronic devices has created a demand for flexible, lightweight, self-powering and energy scavenging technologies. ${ }^{269,270}$ In 2001, Glynne-Jones et al. ${ }^{271}$ introduced the piezoelectric vibration-powered microgenerator before various materials, such as organic materials, metals, textiles and papers were developed for use in nanogenerators. ${ }^{234,272-276}$

Fabricating PVDF fibrous nanogenerators by electrospinning has been widely researched and is considered a good method to enhance energy generation performance. ${ }^{277-281} \mathrm{Im}$ et $a .^{282}$ fabricated $\mathrm{Fe}_{3} \mathrm{O}_{4} / \mathrm{PVDF}$ composite NFs for use in a triboelectric nanogenerator device. Incorporating PVDF resulted in an increase in the surface area and preferential formation of the PVDF polar $\beta$-phase, which, in turn, enhanced the triboelectric performance of the device. Additionally, increasing the $\mathrm{Fe}_{3} \mathrm{O}_{4}$ content increased the output voltage initially from 124 to $138 \mathrm{~V}$ and enhanced the EMI shielding performance when added in small quantities. However, a decrease in the output voltage (94 V) was then observed due to aggregation when the $\alpha-\mathrm{Fe}_{2} \mathrm{O}_{3}$ loading was too high $(28.3 \mathrm{wt} \%)$. Similarly, the tensile strength of the NF initially increased before decreasing, this time due to the dispersion strengthening mechanism. In another example, $\mathrm{Wu}$ et al. ${ }^{283}$ reported a method to synthesise a lead zirconate titanate textile (using PVP as a scaffold) in which the nanowires were parallel to one another. This nanogenerator generated a $6 \mathrm{~V}$ output voltage, $45 \mathrm{nA}$ output current and qualified to power common liquid crystal displays and UV sensors. Additionally, the nanowires were soft and flexible, ideal for use in wearable nanogenerators.

In summary, organic materials have been investigated as potentially useful counterparts in magnetic NFs for use as nanogenerators. As demonstrated, incorporating polymers, such as
PVDF, into the NFs has resulted in enhancement to the triboelectric performance of such devices. Further advances have also been made to produce soft and flexible materials to be used in wearable nanogenerator devices.

\subsection{Data storage and transfer}

It is well known that modern data storage media function by storing information as binary data (marked as 0 and 1). Magnetic materials are widely used for data storage as they can be magnetised into two opposing directions, which can respectively represent the binary codes, 0 and 1 . Both simulations and experiments have shown that nanocylinders or beads that are several hundred nanometres in diameter can form a vortex state under small or vanishing external magnetic fields. ${ }^{284}$ The magnetisation of these nanostructures rotates in a closed loop and is often referred to as a vortex-core. In a fibre, the magnetisation state of the beads controls the signal to transfer from one side of the beads to another. The vortex-core can be switched between the two orientations using short magnetic field pulses, ${ }^{285-287}$ which can be used to write binary data.

Electrospinning is considered a useful tool to create combinations of nanofibrous mats with embedded beads. The beaded fibres can be fabricated when the polymer solid content in the spinning solution is reduced. Döpke et al. ${ }^{50}$ electrospun $\mathrm{PAN} / \mathrm{Fe}_{3} \mathrm{O}_{4} / \alpha-\mathrm{Fe}_{2} \mathrm{O}_{3} /$ NiO beaded fibres from $14 \mathrm{wt} \%$ polymer solution and computer simulated signal transfer in the beaded fibres. Without an applied static magnetic field the signal transferred through the beads in the shape of a snake-like gyrotropic precess from one side to another. Upon applying a static magnetic field, the magnetisation of the bead fully oriented along the direction perpendicular to the fibre and the signal was blocked. This 'on'/'off' state could not only be used for data storage, but also as logic elements (such as AND or NAND) for neuromorphic computing. Blachowicz et al. ${ }^{288}$ further simulated the magnetisation reversal mechanisms under different local spatial distributions and mutual influences of neighbouring magnetic fibres. They found a tendency towards larger coercive fields as the NFs were distributed at a larger random angle range. Fibre mats consisting of two types of NFs (with and without branches) were also simulated. In this case the magnetisation reversal was found to start at smaller negative magnetic fields and end at larger negative fields compared to that of the single nanofibre.

In general, using electrospun magnetic fibres for data storage and neuromorphic computing is still in its infancy but demonstrates promising results. Of the work currently completed there has been a focus on simulating magnetic properties with respect to complex intra- and inter-fibre electrospun MNFs. Blachowicz et al. ${ }^{288}$ studied the influence of numbers and dimensions of contact points of electrospun NFs, and proposed a scheme to verify the mechanism. However, this application requires further investigation to enable widespread implementation.

\section{Summary and future prospects}

Current production methods used to make electrospun MNFs can be divided into two categories. The first introduces magnetic 
components into the electrospinning precursor solutions to fabricate continuous MNFs. The second method uses electrospun MNFs as templates in order to process them into various morphologies and structures. Despite the fact that the magnetic properties of MNPs have been widely studied, the overall magnetic properties of resultant MNFs cannot be predicted since the interactions between polymers and MNPs are not wellunderstood and are therefore rarely discussed. Many types of MNPs have been added to polymeric materials. In some cases, the MNPs and polymers were simply blended and there were no interactions between them, resulting in a linear trend of $M_{\mathrm{s}}$ with MNP content. However, for many composite systems a non-linear trend is observed. $M_{\mathrm{S}}$ values were often increased, and yet some were attenuated, compared to the simple blended systems. However, to the best of our knowledge, there is no evidence provided to establish the relevant interactions between MNPs and polymer materials and the mechanism behind the non-linear relationship remains unclear. Theoretical modelling is required to predict the relationship between structure and magnetic performance for pure inorganic MNFs. Given that this field is very much in its infancy, novel composite and inorganic magnetic systems have been typically investigated to showcase their unique magnetic performance and are not employed in a given application.

Where specific applications are described there are often challenges that remain to be addressed. Loading magnetic resonance imaging contrast agents via electrospinning was a common method to boost the MRI signal of fibre-based materials for in vivo applications. However, passively imaging the materials is not enough for real medical treatment. Smart or environmentally responsive magnetic fibres are needed not only for location and shape information of the fibres under MRI, but also for linking physiological indices, microenvironment parameters $(\mathrm{pH}$, temperature), degrees of degradation or concentration of bio-factors with MRI signal intensity to provide greater internal body information.

Nanofibres with deposited particles have been found to be useful in wastewater treatment due to their high surface area (as compared with MNFs that have MNPs embedded in the matrix), leading to more catalytically active sites. However, MNPs that have been deposited onto NFs (post-electrospinning) are often detached from the fibrous matrix after several absorption-desorption test cycles, which hampers their viability for long-term use. Therefore, further investigation is needed to identify how MNPs could be adhered to the NFs (to survive hundreds of cyclic tests) would be meaningful work. Sensing technologies for heavy metal ions and toxic gases that can cause ill effect to humans have been summarized elsewhere. ${ }^{251}$ Integrating existing pollutant removal technologies with advanced nanofibrous systems, alongside in-depth studies on these toxicants would significantly extend their applications.

In summary, advances in electrospinning have allowed a wide range of magnetic nanofibrous materials to be created over the past two decades. These advanced materials have shown huge potential and are set to play a role in smart technologies of the future. To unlock their true potential, significant work is needed to understand the key interactions between the various components in the system to overcome the current drawbacks that have been encountered.

The processing methods of electrospun magnetic composite NFs and pure inorganic NFs from templates, their properties and related applications have been summarised and discussed throughout this review. Alongside this, key areas for future research have been highlighted with the aim of stimulating advances in the development of electrospun magnetic nanomaterials for a wide range of applications.

\section{Glossary}

AR

BA-a

(BH)max

$\mathrm{BM}$

BNPTU

CA

CMC

CMR

CNFs

CS

CTMB

DCM

DMA

DMF

DMS

DNA-CTMA

\section{EMI}

EMS

EWA

$\alpha-\mathrm{Fe}_{2} \mathrm{O}_{3}$

$\gamma-\mathrm{Fe}_{2} \mathrm{O}_{3}$

FESEM

Gd(DTPA)

GO

$H_{\mathrm{c}}$

HPMCP

$H_{\mathrm{s}}$

IONPS

MADO

MAMS

MEK

MGNPs

MMA

$\operatorname{MNF}(\mathrm{s})$

$\mathrm{MNP}(\mathrm{s})$

$M_{\mathrm{r}}$

$M_{\mathrm{s}}$

MWCNTs

NFs
Acid red 27

Bisphenol-A, paraformaldehyde and aniline monomer hybrid

Maximum magnetic energy product Biological microscopy 1-Benzoyl-3-[2-(2-allyl-1,3-dioxo-2,3-dihydro$1 H$-benzo[de]isoquinolin-6-ylamino)ethyl]thiourea

Cellulose acetate

Carboxymethyl-cellulose

Colossal magneto resistance

Carbon-based nanofibers

Chitosan

Cellulose tris-(4-methylbenzoate)

Dichloromethane

$N, N$-Dimethylacrylamide

Dimethylformamide

Diluted magnetic semiconductor

Deoxyribonucleic acid-cetyltrimethylammonium chloride

Electromagnetic interference

Electromagnetic interference shielding

Electromagnetic wave absorption

Hematite

Maghemite

Field emission scanning electron microscopy

Gd(III) (diethylenetriamine pentaacetate hydrate)

Graphene oxide

Coercivity

Dehydroxypropyl methyl cellulose phthalate

Saturation field

Iron oxide nanoparticles

P(MMA-co-DMA)

Microwave absorption materials

Methyl ethyl ketone

Magnetic glass ceramic nanoparticles

Methyl methacrylate

Magnetic nanofibre(s)

Magnetic nanoparticle(s)

Remanent magnetisation

Saturation magnetisation

Multi-walled carbon nanotubes

Nanofibers 


\begin{tabular}{|c|c|}
\hline NPs & Nanoparticles \\
\hline $\mathrm{P}(\mathrm{AN}-c o-\mathrm{AA})$ & Poly(acrylonitrile-co-acrylic acid) \\
\hline P123 & Pluronic \\
\hline PA6 & Polyamide-6 \\
\hline PAA & Polyamic acid \\
\hline PAAm & Polyacrylamide \\
\hline PAN & Polyacrylonitrile \\
\hline PANI & Polyaniline \\
\hline PBT & Poly(butylene terephthalate) \\
\hline PBZ & Polybenzoxazine \\
\hline PCL & Polycaprolactone \\
\hline PDA & Polydopamine \\
\hline PDLLA & Poly(D,L-lactide) \\
\hline PDMS & Polydimethylsiloxane \\
\hline PEI & Polyethyleneimine \\
\hline PEK-C & Phenolphthalein polyetherketone \\
\hline PEO & Poly(ethylene oxide) \\
\hline PET & Poly(ethylene terephthalate) \\
\hline PEtO $_{x}$ & Poly(2-ethyl-2-oxazoline) \\
\hline $\mathrm{PF}-\mathrm{Na}$ & Polyfluorene-Na \\
\hline PHB & Poly(3-hydroxybutyrate) \\
\hline PHEMA & Poly(2-hydroxyethyl methacrylate) \\
\hline PHVB & $\begin{array}{l}\text { Poly(3-hydroxybutyrate-co-3- } \\
\text { hydroxyvalerate) }\end{array}$ \\
\hline PI & Polyimide \\
\hline PLGA & Poly(lactic-co-glycolic acid) \\
\hline PMMA & Poly(methyl methacrylate) \\
\hline PNIPAM & Poly( $N$-isopropylacrylamide $)$ \\
\hline P(NIPAM-co-HMAAm) & $\begin{array}{l}\text { Poly(N-isopropylacrylamide })-c o-(N- \\
\text { hydroxymethylacrylamide })\end{array}$ \\
\hline POSS & Polyhedral oligomeric silsesquioxane \\
\hline PS & Polystyrene \\
\hline PS- $b$-PI & Poly(styrene-block-isoprene) \\
\hline PU & Polyurethane \\
\hline PVA & Poly(vinyl alcohol) \\
\hline PVAc & Poly(vinyl acetate) \\
\hline PVDF & Poly(vinylidene fluoride) \\
\hline PVDF-TrFE & Poly(vinylidene fluoride-trifluoroethylene) \\
\hline PVP & Polyvinylpyrrolidone \\
\hline RL & Reflection loss \\
\hline RT & Room temperature \\
\hline SAN & Styrene-acrylonitrile random copolymer \\
\hline SEM & Scanning electron microscopy \\
\hline SILAR & $\begin{array}{l}\text { Successive ion layer absorption and } \\
\text { reaction technique }\end{array}$ \\
\hline$T_{\mathrm{B}}$ & Blocking temperature \\
\hline$T_{\mathrm{c}}$ & Curie (transition) temperature \\
\hline TEM & Transmission electron microscopy \\
\hline TEOS & Tetraethyl orthosilicate \\
\hline THF & Tetrahydrofuran \\
\hline TPEE & Thermoplastic ester elastomer \\
\hline
\end{tabular}

\section{Conflicts of interest}

The authors declare no competing financial interest.

\section{Acknowledgements}

The authors thank the financial support from the National Key R\&D Program of China (No. 2017YFC11050003), National Natural Science Foundation of China (No. 51890871 and 21807046), Science and Technology Program of Guangzhou (201907010032), Guangdong Project (2016ZT06C322), National Natural Science Foundation of Guangdong (No. 2018A030310628, 2020A151501744), and the Fundamental Research Funds for the Central Universities (2020ZYGXZR064). HJH thanks W. Joe Homer for support.

\section{References}

1 Y.-J. Kim, M. Ebara and T. Aoyagi, Adv. Funct. Mater., 2013, 23, 5753-5761.

2 O. A. Inozemtseva, Y. E. Salkovskiy, A. N. Severyukhina, I. V. Vidyasheva, N. V. Petrova, H. A. Metwally, I. Y. Stetciura and D. A. Gorin, Russ. Chem. Rev., 2015, 84, 251-274.

3 C.-J. Li, J.-N. Wang, X.-Y. Li and L.-L. Zhang, J. Mater. Sci., 2011, 46, 2058-2063.

4 F. Ahmadi, Y. Sozer, M. J. Donahue and I. Tsukerman, IET Electr. Power Appl., 2020, 14, 282-290.

5 D. Li and Y. Xia, Adv. Mater., 2004, 16, 1151-1170.

6 B. Sun, Y. Z. Long, H. D. Zhang, M. M. Li, J. L. Duvail, X. Y. Jiang and H. L. Yin, Prog. Polym. Sci., 2014, 39, 862-890.

7 Y.-Z. Long, M. Yu, B. Sun, C.-Z. Gu and Z. Fan, Chem. Soc. Rev., 2012, 41, 4560-4580.

8 O. Lalegul-Ulker, M. T. Vurat, A. E. Elcin and Y. M. Elcin, J. Appl. Polym. Sci., 2019, 136, 48040.

9 L. Wang, P. D. Topham, O. O. Mykhaylyk, H. Yu, A. J. Ryan, J. P. A. Fairclough and W. Bras, Macromol. Rapid Commun., 2015, 36, 1437-1443.

10 K. Suneet, S. Sridhar, P. Agiwal, M. S. Sridhar, K. Sanyal and S. Jain, Int. J. Hyperthermia, 2019, 36, 545-553.

11 Y. Song, L. Xu and J. Sui, Therm. Sci., 2019, 23, 2365-2372.

12 F. Mohammadkhani, M. Montazer and M. Latifi, J. Text. Inst., 2019, 110, 989-999.

13 L. Mei, H. Chen, Y. Shao, J. Wang and Y. Liu, High Perform. Polym., 2019, 31, 230-237.

14 X. Zhou, Q. Ma, W. Yu, T. Wang, X. Dong, J. Wang and G. Liu, J. Mater. Sci., 2015, 50, 7884-7895.

15 S. Niu, L. Zhang, N. Wang, J. Zhu, W. Zhang, Z. Cheng and X. Zhu, React. Funct. Polym., 2013, 73, 1447-1454.

16 M. Yang, S. Sheng, Q. Ma, N. Lv, W. Yu, J. Wang, X. Dong and G. Liu, Mater. Res.-Ibero-Am. J. Mater., 2016, 19, 308-313.

17 R. Murillo-Ortiz, M. Mirabal-Garcia, J. J. Cruz-Rivera, D. Valdez-Perez, J. R. Martinez, F. Perez-Moreno and A. Lobo-Guerrero, Mater. Chem. Phys., 2019, 234, 151-157.

18 L. Wang, M. Wang, P. D. Topham and Y. Huang, RSC Adv., 2012, 2, 2433-2438.

19 S. Wang, Q. Liu, Y. Zhang, S. Wang, Y. Li, Q. Yang and Y. Song, Appl. Surf. Sci., 2013, 279, 150-158.

20 S. Wang, Z. Sun, E. Yan, J. Yuan, Y. Gao, Y. Bai, Y. Chen, C. Wang, Y. Zheng and T. Jing, Mater. Sci. Eng., B, 2014, 190, 126-132. 
21 X. Song, G. Cheng, B. Cheng and J. Xing, J. Mater. Res., 2016, 31, 2662-2671.

22 E. Yan, M. Cao, J. Jiang, J. Gao, C. Jiang, X. Ba, X. Yang and D. Zhang, Solid State Sci., 2017, 72, 94-102.

23 A. Marmur, Langmuir, 2003, 19, 8343-8348.

24 L. Wang, P. D. Topham, O. O. Mykhaylyk, J. R. Howse, W. Bras, R. A. L. Jones and A. J. Ryan, Adv. Mater., 2007, 19, 3544-3548.

25 J. Lin, F. Tian, Y. Shang, F. Wang, B. Ding and J. Yu, Nanoscale, 2012, 4, 5316-5320.

26 W. Yu, Q. Ma, X. Li, X. Dong, J. Wang and G. Liu, Mater. Lett., 2014, 120, 126-129.

27 L. Wang, X. Dong, G. Gai, L. Zhao, S. Xu and X. Xiao, J. Nanopart. Res., 2015, 17, 91.

28 Q. Ma, J. Wang, X. Dong, W. Yu and G. Liu, Adv. Funct. Mater., 2015, 25, 2436-2443.

29 P. Jing, J. Du, J. Wang, W. Lan, L. Pan, J. Li, J. Wei, D. Cao, X. Zhang, C. Zhao and Q. Liu, Nanoscale, 2015, 7, 14738-14746.

30 J. Tian, Q. Ma, X. Dong, W. Yu, M. Yang, Y. Yang, J. Wang and G. Liu, RSC Adv., 2016, 6, 36180-36191.

31 R. Patwa, N. Soundararajan, N. Mulchandani, S. M. Bhasney, M. Shah, S. Kumar, A. Kumar and V. Katiyar, Biopolymers, 2018, 109, e23231.

32 H. Hu, W. Jiang, F. Lan, X. Zeng, S. Ma, Y. Wu and Z. Gu, RSC Adv., 2013, 3, 879-886.

33 L. Fan, Q. Ma, J. Tian, D. Li, X. Xi, X. Dong, W. Yu, J. Wang and G. Liu, J. Mater. Sci., 2018, 53, 2290-2302.

34 Z. Jiang, L. D. Tijing, A. Amarjargal, C. H. Park, K.-J. An, H. K. Shon and C. S. Kim, Composites, Part B, 2015, 77, 311-318.

35 L. Yang, Q. Ma, X. Xi, D. Li, J. Liu, X. Dong, W. Yu, J. Wang and G. Liu, Chem. Eng. J., 2019, 361, 713-724.

36 Z. Wang, Q. Ma, X. Dong, D. Li, X. Xi, W. Yu, J. Wang and G. Liu, Phys. Chem. Chem. Phys., 2017, 19, 118-126.

37 C.-H. Park, S.-J. Kang, L. D. Tijing, H. R. Pant and C. S. Kim, Ceram. Int., 2013, 39, 9785-9790.

$38 \mathrm{~J} . \mathrm{Li}, \mathrm{X}$. Chen, D. Xu and K. Pan, Ecotoxicol. Environ. Saf., 2019, 170, 716-721.

39 D. Ponnamma, O. Aljarod, H. Parangusan and M. A. A. AlMaadeed, Results Phys., 2019, 13, 102130.

40 B. J. Tefft, S. Uthamaraj, J. J. Harburn, O. Hlinomaz, A. Lerman, D. Dragomir-Daescu and G. S. Sandhu, J. Magn. Magn. Mater., 2017, 427, 100-104.

41 H. Wang, H. Tang, J. He and Q. Wang, Mater. Res. Bull., 2009, 44, 1676-1680.

42 N. Sharma, G. H. Jaffari, S. I. Shah and D. J. Pochan, Nanotechnology, 2010, 21, 085707.

43 Y. K. Sung, B. W. Ahn and T. J. Kang, J. Magn. Magn. Mater., 2012, 324, 916-922.

44 H. Wang, Y. Li, L. Sun, Y. Li, W. Wang, S. Wang, S. Xu and Q. Yang, J. Colloid Interface Sci., 2010, 350, 396-401.

45 S. Bharathkumar, M. Sakar, R. K. Vinod and S. Balakumar, Phys. Chem. Chem. Phys., 2015, 17, 17745-17754.

46 K. Jain, S. Pathak and R. P. Pant, RSC Adv., 2016, 6, 70943-70946.
47 G. Wang, Q. Ma, J. Tian, L. Fan, D. Li, X. Dong, W. Yu, J. Wang and G. Liu, RSC Adv., 2019, 9, 206-214.

48 G. Sreenivasulu, J. Zhang, R. Zhang, M. Popov, V. Petrov and G. Srinivasan, Materials, 2018, 11, 18.

49 S.-B. Lee, S.-J. Hong, J.-W. Yi, S.-K. Lee, Y.-H. Choa and J.-B. Kim, Met. Mater. Int., 2012, 18, 165-170.

50 C. Doepke, T. Grothe, P. Steblinski, M. Kloecker, L. Sabantina, D. Kosmalska, T. Blachowicz and A. Ehrmann, Nanomaterials, 2019, 9, 92.

51 H. J. Wang, B. Liu, W. L. Huang, Z. Lin, J. Luo, Y. Li, L. Zhuang, W. Wang and L. L. Jiang, J. Magn. Magn. Mater., 2018, 452, 1-4.

52 K. P. Matabola and R. M. Moutloali, J. Mater. Sci., 2013, 48, 5475-5482.

53 V. Beachley and X. Wen, Mater. Sci. Eng., C, 2009, 29, 663-668.

54 R. Ghelich, M. K. Rad and A. A. Youzbashi, J. Eng. Fibers Fabr., 2015, 10, 12-19.

55 S. Sheng, Q. Ma, X. Dong, N. Lv, J. Wang, W. Yu and G. Liu, J. Mater. Sci.: Mater. Electron., 2014, 25, 2279-2286.

56 L. Fan, Q. Ma, J. Tian, D. Li, X. Xi, X. Dong, W. Yu, J. Wang and G. Liu, RSC Adv., 2017, 7, 48702-48711.

57 C. Huang, S. J. Soenen, J. Rejman, J. Trekker, C. Liu, L. Lagae, W. Ceelen, C. Wilhelm, J. Demeester and S. C. De Smedt, Adv. Funct. Mater., 2012, 22, 2479-2486.

58 Y. Zhong, V. Leung, L. Y. Wan, S. Dutz, F. K. Ko and U. O. Haefeli, J. Magn. Magn. Mater., 2015, 380, 330-334.

59 T. I. Shalaby, M. F. El-Kady, A. E. H. M. Zaki and S. M. ElKholy, Water Sci. Technol.: Water Supply, 2017, 17, 176-187.

60 L. Li, F. Wang, Y. Lv, J. Liu, H. Bian, W. Wang, Y. Li and Z. Shao, ACS Omega, 2018, 3, 4220-4230.

61 S. Harsojo, A. F. Waluyo, H. Sosiati and K. Triyana, Adv. Mater. Res., 2015, 1123, 237-240.

62 T. Gong, W. Li, H. Chen, L. Wang, S. Shao and S. Zhou, Acta Biomater., 2012, 8, 1248-1259.

63 H. Shao, W. Yu, Q. Ma, X. Wang, X. Dong, Z. Liu, J. Wang, G. Liu and L. Chang, RSC Adv., 2017, 7, 32850-32860.

64 H. Shao, Q. Ma, X. Dong, W. Yu, M. Yang, Y. Yang, J. Wang and G. Liu, Sci. Rep., 2015, 5, 14052.

65 J. Tian, Q. Ma, W. Yu, X. Dong, Y. Yang, B. Zhao, J. Wang and G. Liu, New J. Chem., 2017, 41, 13983-13992.

66 H. Shao, Q. Ma, W. Yu, X. Wang, X. Dong, Z. Liu, J. Wang, G. Liu and L. Chang, J. Mater. Sci.: Mater. Electron., 2017, 28, 16762-16775.

67 J. Li, Q. Ma, X. Dong, D. Li, X. Xi, W. Yu, J. Wang and G. Liu, $R S C A d v$. , 2016, 6, 96084-96092.

68 L. Han, Q. Ma and X. Dong, RSC Adv., 2015, 5, 95674-95681. 69 X. Zhou, Q. Ma, X. Dong, J. Wang, W. Yu and G. Liu, RSC Adv., 2015, 5, 35948-35957.

70 X. Xi, Q. Ma, X. Dong, D. Li, W. Yu, J. Wang and G. Liu, J. Mater. Sci.: Mater. Electron., 2018, 29, 7119-7129.

71 B. W. Ahn and T. J. Kang, J. Appl. Polym. Sci., 2012, 125, 1567-1575.

72 F. Liu, Q.-Q. Ni and Y. Murakami, Text. Res. J., 2013, 83, 510-518.

73 I. Savva, D. Constantinou, O. Marinica, E. Vasile, L. Vekas and T. Krasia-Christoforou, J. Magn. Magn. Mater., 2014, 352, 30-35. 
74 Q. Ma, J. Wang, X. Dong, W. Yu and G. Liu, ChemPlusChem, 2014, 79, 290-297.

75 F. Bi, X. Dong, J. Wang and G. Liu, RSC Adv., 2015, 5, 12571-12577.

76 R. Murillo-Ortiz, M. Mirabal-Garcia, J. M. Martinez-Huerta, J. G. Cabal Velarde, I. E. Castaneda-Robles and A. LoboGuerrero, J. Appl. Phys., 2018, 123, 105108.

77 W. S. Khan, R. Asmatulu, S. Davuluri and V. K. Dandin, J. Mater. Sci. Technol., 2014, 30, 854-859.

78 N. A. Erfan, N. Barakat and B. J. Muller-Borer, Colloids Surf., A, 2019, 576, 63-72.

79 J. Y. Han, W. B. Im, D. Kim, S. H. Cheong, G. Y. Lee and D. Y. Jeon, J. Mater. Chem., 2012, 22, 5374-5381.

80 W. Ahmad, L. J. Zhang and Y. S. Zhou, CrystEngComm, 2014, 16, 3521-3531.

81 K. Diest, J. A. Dionne, M. Spain and H. A. Atwater, Nano Lett., 2009, 9, 2579-2583.

82 S. Y. Kim, K. Woo, K. Lim, K. Lee and H. S. Jang, Nanoscale, 2013, 5, 9255-9263.

83 G. Gai, L. Wang, X. Dong, C. Zheng, W. Yu, J. Wang and X. Xiao, J. Nanopart. Res., 2013, 15, 1539.

84 G. Gai, L. Wang, X. Dong and S. Xu, J. Mater. Sci., 2013, 48, 5140-5147.

85 K. Lai, W. Jiang, J. Z. Tang, Y. Wu, B. He, G. Wang and Z. Gu, RSC Adv., 2012, 2, 13007-13017.

86 Q. Ma, W. Yu, X. Dong, J. Wang and G. Liu, Nanoscale, 2014, 6, 2945-2952.

87 N. Lv, Q. Ma, X. Dong, J. Wang, W. Yu and G. Liu, ChemPlusChem, 2014, 79, 690-697.

88 D. Zhang, X.-Z. Jin, T. Huang, N. Zhang, X.-D. Qi, J.-H. Yang, Z.-W. Zhou and Y. Wang, ACS Appl. Mater. Interfaces, 2019, 11, 5073-5083.

89 J. Meng, Y. Zhang, X. Qi, H. Kong, C. Wang, Z. Xu, S. Xie, N. Gu and H. Xu, Nanoscale, 2010, 2, 2565-2569.

90 H. M. Khanlou, B. C. Ang, S. Talebian, M. M. Barzani, M. Silakhori and H. Fauzi, Measurement, 2015, 70, 179-187.

91 J. Zhu, S. Wei, X. Chen, A. B. Karki, D. Rutman, D. P. Young and Z. Guo, J. Phys. Chem. C, 2010, 114, 8844-8850.

92 Z. Zhou, L. Yang, J. Gao and X. Chen, Adv. Mater., 2019, 31, 1804567.

93 Z. X. Jiang, Y. Zhao and P. Yang, Mater. Chem. Phys., 2018, 214, 1-7.

94 I. H. Chen, C.-C. Wang and C.-Y. Chen, Carbon, 2010, 48, 604-611.

95 Q. Wang, Y. Geng, J. Li, M. Yin, Y. Hu, Y. Liu and K. Pan, Nanotechnology, 2018, 29, 135702.

96 R. Goncalves, P. Martins, X. Moya, M. Ghidini, V. Sencadas, G. Botelho, N. D. Mathur and S. Lanceros-Mendez, Nanoscale, 2015, 7, 8058-8061.

97 D. Ghanbari, M. Salavati-Niasari, F. Beshkar and O. Amiri, J. Mater. Sci.: Mater. Electron., 2015, 26, 8358-8366.

98 X. Chen, S. Wei, C. Gunesoglu, J. Zhu, C. S. Southworth, L. Sun, A. B. Karki, D. P. Young and Z. Guo, Macromol. Chem. Phys., 2010, 211, 1775-1783.

99 P. Gupta, R. Asmatulu, R. Claus and G. Wilkes, J. Appl. Polym. Sci., 2006, 100, 4935-4942.
100 M. K. Shin, S. I. Kim, S. J. Kim, S. Y. Park, Y. H. Hyun, Y. Lee, K. E. Lee, S.-S. Han, D.-P. Jang, Y.-B. Kim, Z.-H. Cho, I. So and G. M. Spinks, Langmuir, 2008, 24, 12107-12111.

101 T. Song, Y. Z. Zhang, T. J. Zhou, C. T. Lim, S. Ramakrishna and B. Liu, Chem. Phys. Lett., 2005, 415, 317-322.

102 S. Hatamie, F. Mohamadyar-Toupkanlou, S. Mirzaei, M. M. Ahadian, S. Hosseinzadeh, M. Soleimani, W.-J. Sheu, Z. H. Wei, T.-F. Hsieh, W.-C. Chang and C.-L. Wang, Spin, 2019, 9, 1940011.

103 X. Chen, K. M. Unruh, C. Ni, B. Ali, Z. Sun, Q. Lu, J. Deitzel and J. Q. Xiao, J. Phys. Chem. C, 2011, 115, 373-378.

104 Y. Wang, C. Dong, Y. Chuai and Y. Wang, J. Wuhan Univ. Technol., Mater. Sci. Ed., 2015, 30, 1-5.

105 Z. Zhang, Z. Li, J. Zhang, H. Bian, T. Wang, J. Gao and J. Li, Ceram. Int., 2019, 45, 457-461.

106 R. E. Lu, K. G. Chang, B. Fu, Y. J. Shen, M. W. Xu, S. Yang, X. P. Song, M. Liu and Y. D. Yang, J. Mater. Chem. C, 2014, 2, 8578-8584.

107 A. Amarjargal, L. D. Tijing, C.-H. Park, I.-T. Im and C. S. Kim, Eur. Polym. J., 2013, 49, 3796-3805.

108 Q.-Z. Yu, Mater. Sci. Eng., B, 2010, 167, 26-30.

109 Y.-H. Chen, C.-H. Cheng, W.-J. Chang, Y.-C. Lin, F.-H. Lin and J.-C. Lin, Mater. Sci. Eng., C, 2016, 62, 338-349.

110 F. Hong, C. Yan, Y. Si, J. He, J. Yu and B. Ding, ACS Appl. Mater. Interfaces, 2015, 7, 20200-20207.

111 C. Han, Q. Ma, X. Dong, W. Yu, J. Wang and G. Liu, J. Mater. Sci.: Mater. Electron., 2015, 26, 2457-2465.

112 R. Zhao, X. Li, Y. Li, Y. Li, B. Sun, N. Zhang, S. Chao and C. Wang, J. Colloid Interface Sci., 2017, 505, 1018-1030.

113 L. Wu, W. Sui, C. Dong, C. Zhang and C. Jiang, Appl. Surf. Sci., 2016, 384, 368-375.

114 Z. Wang, X. Liu, M. Lv, P. Chai, Y. Liu, X. Zhou and J. Meng, J. Phys. Chem. C, 2008, 112, 15171-15175.

115 Z. Wang, X. Liu, M. Lv, P. Chai, Y. Liu and J. Meng, J. Phys. Chem. B, 2008, 112, 11292-11297.

116 P. Jing, J. Du, J. Wang, J. Wei, L. Pan, J. Li and Q. Liu, Sci. Rep., 2015, 5, 131.

117 C. J. Luo, E. Stride and M. Edirisinghe, Macromolecules, 2012, 45, 4669-4680.

118 J. Xue, T. Wu, Y. Dai and Y. Xia, Chem. Rev., 2019, 119, 5298-5415.

119 P. Jing, J. Du, C. Jin, J. Wang, L. Pan, J. Li and Q. Liu, J. Mater. Sci., 2016, 51, 885-892.

120 N. S. Hansen, D. Cho and Y. L. Joo, Small, 2012, 8, 1510-1514. 121 I. Abdalla, J. Shen, J. Yu, Z. Li and B. Ding, Sci. Rep., 2018, 8, 12402.

122 J. Xiang, Y. Chu, X. Zhang and X. Shen, Appl. Surf. Sci., 2012, 263, 320-325.

123 X. L. Zhang, W. W. Pan, J. Dong, Q. F. Liu and J. B. Wang, J. Mater. Sci., 2015, 50, 7218-7226.

124 J. Xiang, X. Zhang, J. Li, Y. Chu and X. Shen, Chem. Phys. Lett., 2013, 576, 39-43.

125 D. Li, Q. Ma, Y. Song, X. Xi, X. Dong, W. Yu, J. Wang and G. Liu, Phys. Chem. Chem. Phys., 2016, 18, 27536-27544.

126 P. P. Jing, M. T. Liu, Y. P. Pu, Y. F. Cui, Z. Wang, J. B. Wang and Q. F. Liu, Sci. Rep., 2016, 6, 37701. 
127 Y. Ji, X. B. Zhang, Y. J. Zhu, B. Li, Y. Wang, J. C. Zhang and Y. Feng, Mater. Res. Bull., 2013, 48, 2426-2429.

128 X. Y. Zhang, Y. Liu, J. Li and X. J. Yang, Mater. Res. Innovations, 2013, 17, 436-439.

129 W. Zhang, H. P. Li and W. Pan, in High-Performance Ceramics Vii, Pts 1 and 2, ed. W. Pan and J. H. Gong, 2012, vol. 512-515, pp. 1438-1441.

130 W. Zhang, H. P. Li and W. Pan, J. Mater. Sci., 2012, 47, 8216-8222.

131 W. Pan, R. Han, X. Chi, Q. Liu and J. Wang, J. Alloys Compd., 2013, 577, 192-194.

132 Z. Chen, Y. Gu, P. Aprelev, K. Kornev, I. Luzinov, J. Chen and F. Peng, J. Am. Ceram. Soc., 2016, 99, 1504-1511.

133 S. H. Xie, J. Y. Li, R. Proksch, Y. M. Liu, Y. C. Zhou, Y. Y. Liu, Y. Ou, L. N. Lan and Y. Qiao, Appl. Phys. Lett., 2008, 93, 222904.

134 J. Guo, Y. Yang, W. Yu, X. Dong, J. Wang, G. Liu and T. Wang, RSC Adv., 2016, 6, 111447.

135 J. C. Fu, J. L. Zhang, C. H. Zhao, Y. Peng, X. D. Li, Y. M. He, Z. X. Zhang, X. J. Pan, N. J. Mellors and E. Q. Xie, J. Alloys Compd., 2013, 577, 97-102.

136 J. Xiang, X. Shen, F. Song, M. Liu, G. Zhou and Y. Chu, Mater. Res. Bull., 2011, 46, 258-261.

137 C. Gao, Z. Pui, C. Zhang and Q. Gao, Mater. Res. Express, 2019, 6, 025049.

138 X. Q. Shen, M. Q. Liu, F. Z. Song and X. F. Meng, J. Sol-Gel Sci. Technol., 2010, 53, 448-453.

139 M. Sakar, S. Balakumar, P. Saravanan and S. N. Jaisankar, Mater. Des., 2016, 94, 487-495.

140 S. Xie, F. Ma, Y. Liu and J. Li, Nanoscale, 2011, 3, 3152-3158.

141 X. Qu, N. Kobayashi and T. Komatsu, ACS Nano, 2010, 4, 1732-1738.

142 I. Abdalla, J. Yu, Z. Li and B. Ding, Composites, Part B, 2018, 155, 397-404.

143 P. Li, F. Lv, L. Liu, L. Ding and Y. Zhang, J. Magn. Magn. Mater., 2016, 414, 105-110.

144 H. Chen, J. Sun, Z. Wang, Y. Zhou, Z. Lou, B. Chen, P. Wang, Z. Guo, H. Tang, J. Ma, Y. Xia, N. Gu and F. Zhang, ACS Appl. Mater. Interfaces, 2018, 10, 44279-44289.

145 T.-C. Lin, F.-H. Lin and J.-C. Lin, Acta Biomater., 2012, 8, 2704-2711.

146 P. Wang, L. Cheng, Y. Zhang and L. Zhang, J. Alloys Compd., 2017, 716, 306-320.

147 M. Hussain, S. S. Batool, Z. Imran, M. Ahmad, K. Rasool, M. A. Rafiq and M. M. Hasan, Sens. Actuators, B, 2014, 192, 429-438.

148 Q. Yu, H. Chen, P. Chen, Q. Wang, C. Lu and C. Jia, J. Mater. Sci.: Mater. Electron., 2017, 28, 2769-2774.

149 S. Koombhongse, W. Liu and D. H. Reneker, J. Polym. Sci., Part B: Polym. Phys., 2001, 39, 2598-2606.

150 M. Bayat, H. Yang, F. K. Ko, D. Michelson and A. Mei, Polymer, 2014, 55, 936-943.

151 H. Ziyadi, A. Heydari and S. M. Rezayat, Ceram. Int., 2014, 40, 5913-5919.

152 L. Zou, Q. Wang, X. Shen, Z. Wang, M. Jing and Z. Luo, Appl. Surf. Sci., 2015, 332, 674-681.
153 J. Dong, Y. Zhang, X. Zhang, Q. Liu and J. Wang, Mater. Lett., 2014, 120, 9-12.

154 J. Lee, J. Kim, D. Kim, G. Lee, Y.-B. Oh, T.-Y. Hwang, J.-H. Lim, H.-B. Cho, J. Kim and Y.-H. Choa, ACS Appl. Mater. Interfaces, 2019, 11, 26222-26227.

155 L. N. Pan, F. M. Gu, D. R. Cao, P. P. Jing, J. N. Li, J. B. Wang and Q. F. Liu, Appl. Phys. A: Mater. Sci. Process., 2016, 122, 583.

156 F. Bi, X. Dong, J. Wang and G. Liu, J. Mater. Sci.: Mater. Electron., 2014, 25, 4259-4267.

157 G. Sreenivasulu, M. Popov, R. Zhang, K. Sharma, C. Janes, A. Mukundan and G. Srinivasan, Appl. Phys. Lett., 2014, 104, 052910.

158 K. N. Kim, H. R. Jung and W. J. Lee, J. Photochem. Photobiol., A, 2016, 321, 257-265.

159 J. X. Zhao, Y. L. Cheng, X. B. Yan, D. F. Sun, F. L. Zhu and Q. J. Xue, CrystEngComm, 2012, 14, 5879-5885.

160 Y. Cheng, B. Zou, J. Yang, C. Wang, Y. Liu, X. Fan, L. Zhu, Y. Wang, H. Ma and X. Cao, CrystEngComm, 2011, 13, 2268-2272.

161 C. Han, Q. Ma, Y. Yang, M. Yang, W. Yu, X. Dong, J. Wang and G. Liu, J. Mater. Sci.: Mater. Electron., 2015, 26, 8054-8064.

162 Q. Gao, J. Luo, X. Wang, C. Gao and M. Ge, Nanoscale Res. Lett., 2015, 10, 176.

163 C. Eid, D. Luneau, V. Salles, R. Asmar, Y. Monteil, A. Khoury and A. Brioude, J. Phys. Chem. C, 2011, 115, 17643-17646.

164 P. Jing, J. Li, L. Pan, J. Wang, X. Sun and Q. Liu, J. Hazard. Mater., 2015, 284, 163-170.

165 X. Li, Z. Hou, P. A. Ma, X. Zhang, C. Li, Z. Cheng, Y. Dai, J. Lian and J. Lin, RSC Adv., 2013, 3, 8517-8526.

166 Y. Zhou, W. Song, L. Zhang and S. Tao, J. Mater. Chem. A, 2018, 6, 12298-12307.

167 Z. Wang, L. Zhao, P. Wang, L. Guo and J. Yu, J. Alloys Compd., 2016, 687, 541-547.

168 Q. Gao, J. Takizawa and M. Kimura, Polymer, 2013, 54, 120-126.

169 N. A. M. Barakat, B. Kim and H. Y. Kim, J. Phys. Chem. C, 2009, 113, 531-536.

170 L. Pan, X. Zhang, J. Wang and Q. Liu, Ceram. Int., 2017, 43, 1236-1241.

171 W.-Y. Lee, H. J. Yun and J.-W. Yoon, J. Alloys Compd., 2014, 583, 320-324.

172 B. Mordina, R. K. Tiwari, D. K. Setua and A. Sharma, RSC Adv., 2015, 5, 19091-19105.

173 J.-G. Zhao, W.-Y. Zhang, E.-Q. Xie, X.-Y. An, J.-C. Fu, Z.-J. Liu, Z.-L. Liu, Y.-J. Zhang, Y.-F. Chen and C.-Y. Zhang, NANO, 2014, 9, 1450026.

174 U. Kurtan, D. Dursun, H. Aydin, M. S. Toprak, A. Baykal and A. Bozkurt, Ceram. Int., 2016, 42, 18189-18195.

175 J. Bhagwan, S. Rani, V. Sivasankaran, K. L. Yadav and Y. Sharma, Appl. Surf. Sci., 2017, 426, 913-923.

176 Y. Lu, X. C. Yang, J. L. Zhu, F. Z. Song and X. Q. Shen, Adv. Mater. Res., 2012, 399-401, 736-740.

177 H. Liu, Z.-G. Zhang, X.-X. Wang, G.-D. Nie, J. Zhang, S.-X. Zhang, N. Cao, S.-Y. Yan and Y.-Z. Long, J. Phys. Chem. Solids, 2018, 121, 236-246. 
178 X. Q. Shen, J. C. Zheng, X. F. Meng and Q. R. Liang, J. Wuhan Univ. Technol., Mater. Sci. Ed., 2011, 26, 384-387.

179 R. Yensano, S. Pinitsoontorn, V. Amornkitbamrung and S. Maensiri, J. Supercond. Novel Magn., 2014, 27, 1553-1560. 180 Y. Zhang, W. W. Pan, J. Dong, Z. K. Wang, Q. F. Liu and J. B. Wang, J. Phys. D: Appl. Phys., 2013, 46, 105001.

181 Q. R. Liang, X. Q. Shen, F. Z. Song and M. Q. Liu, J. Mater. Sci. Technol., 2011, 27, 996-1000.

182 W. Ponhan and S. Maensiri, Solid State Sci., 2009, 11, 479-484.

183 O. Saensuk, S. Phokha, A. Bootchanont, S. Maensiri and E. Swatsitang, Ceram. Int., 2015, 41, 8133-8141.

184 S. Maensiri, M. Sangmanee and A. Wiengmoon, Nanoscale Res. Lett., 2009, 4, 221-228.

185 P. Kidkhunthod, S. Nilmoung, S. Mahakot, S. Rodporn, S. Phumying and S. Maensiri, J. Magn. Magn. Mater., 2016, 401, 436-442.

186 Y.-W. Ju, J.-H. Park, H.-R. Jung, S.-J. Cho and W.-J. Lee, Compos. Sci. Technol., 2008, 68, 1704-1709.

187 C. Luo, X. Wang, J. Wang and K. Pan, Compos. Sci. Technol., 2016, 133, 97-103.

188 Y. Zhu, J. C. Zhang, J. Zhai and L. Jiang, Thin Solid Films, 2006, 510, 271-274.

189 N. N. Liu, P. C. Du, P. Zhou, R. G. Tanguturi, Y. J. Qi, T. J. Zhang and C. Q. Zhuang, Appl. Surf. Sci., 2020, 532, 147440.

190 R. Nakhowong and R. Chueachot, J. Alloys Compd., 2017, 715, 390-396.

191 W. Ponhan and S. Maensiri, presented in part at the 3rd IEEE International Nanoelectronics Conference, City University Hong Kong, Hong Kong, 2010.

192 A. K. Das, M. Kar and A. Srinivasan, Phys. B, 2014, 448, 112-114.

193 W. Ponhan, E. Swatsitang and S. Maensiri, Mater. Sci. Technol., 2010, 26, 1298-1303.

194 Y. W. Ju, J. H. Park, H. R. Jung, S. J. Cho and W. J. Lee, Mater. Sci. Eng., B, 2008, 147, 7-12.

195 J. Li, Y. Wu, M. Yang, Y. Yuan, W. Yin, Q. Peng, Y. Li and X. He, J. Am. Ceram. Soc., 2017, 100, 5460-5470.

196 T. Zhang, D. Huang, Y. Yang, F. Kang and J. Gu, Mater. Sci. Eng., B, 2013, 178, 1-9.

197 Y. Yang, Z. Guo, H. Zhang, D. Huang, J. Gu, Z. Huang, F. Kang, T. A. Hatton and G. C. Rutledge, J. Appl. Polym. Sci., 2013, 127, 4288-4295.

198 M. Bayat, H. Yang and F. Ko, Polymer, 2011, 52, 1645-1653.

199 C. Lu, Z. Bao, C. Qin, L. Dai and A. Zhu, RSC Adv., 2016, 6, 110155.

200 C.-J. Li, J.-N. Wang, B. Wang, J. R. Gong and Z. Lin, Mater. Res. Bull., 2012, 47, 333-337.

201 P. Jing, L. Pan, J. Du, J. Wang and Q. Liu, Phys. Chem. Chem. Phys., 2015, 17, 12841-12848.

202 B. Y. Ren, W. Shen, L. Li, S. Z. Wu and W. Wang, Appl. Surf. Sci., 2018, 447, 711-723.

203 G. George and S. Anandhan, Mater. Sci. Semicond. Process., 2015, 32, 40-48.

204 B. Tarus, N. Fadel, A. Al-Oufy and M. El-Messiry, Alexandria Eng. J., 2016, 55, 2975-2984.
205 V. Pillay, C. Dott, Y. E. Choonara, C. Tyagi, L. Tomar, P. Kumar, L. C. du Toit and V. M. K. Ndesendo, J. Nanomater., 2013, 2013, 789289.

206 J. Lee, T.-Y. Hwang, M. K. Kang, H.-B. Cho, J. Kim, N. V. Myung and Y.-H. Choa, Front. Chem., 2018, 6, 18.

207 Q. Yang, Q. Xu, M. Sobhan, Q. Ke, F. Anariba, K. P. Ong and P. Wu, Phys. Status Solidi RRL, 2014, 8, 653-657.

208 C.-J. Li, B. Wang and J.-N. Wang, J. Magn. Magn. Mater., 2012, 324, 1305-1311.

209 M. Liu, X. Shen, F. Song, J. Xiang and X. Meng, J. Solid State Chem., 2011, 184, 871-876.

210 O. Saensuk, S. Maensiri, A. Bootchanont and E. Swatsitang, Microelectron. Eng., 2014, 126, 158-164.

211 J. Xiang, X. Shen, F. Song and M. Liu, J. Solid State Chem., 2010, 183, 1239-1244.

212 C.-J. Li, B.-N. Huang and J.-N. Wang, J. Mater. Sci., 2013, 48, 1702-1710.

213 M. Mansour, M. Bechelany, R. Habchi and C. Eid, Phys. Lett. A, 2017, 381, 658-662.

214 M. S. Cortes, A. Martinez-Luevanos, L. A. Garcia-Cerda, O. S. Rodriguez-Fernandez, A. F. Fuentes, J. Romero-Garcia and S. M. Montemayor, J. Alloys Compd., 2015, 653, 290-297.

215 J. Xiang, Y. Q. Chu, X. Q. Shen, G. Z. Zhou and Y. T. Guo, J. Colloid Interface Sci., 2012, 376, 57-61.

216 W. Pan, F. Gu, K. Qi, Q. Liu and J. Wang, Mater. Chem. Phys., 2012, 134, 1097-1101.

217 G. D. Nie, X. F. Lu, J. Y. Lei, Z. Q. Jiang and C. Wang, J. Mater. Chem. A, 2014, 2, 15495-15501.

218 J. M. Li, X. L. Zeng, G. Q. Wu and Z. A. Xu, CrystEngComm, 2012, 14, 525-532.

219 J. X. Sui, X. X. Wang, C. Song, Q. Liu, F. Yuan and Y. Z. Long, J. Magn. Magn. Mater., 2018, 467, 74-81.

220 S. Sonsupap, P. Kidkhunthod, N. Chanlek, S. Pinitsoontorn and S. Maensiri, Appl. Surf. Sci., 2016, 380, 16-22.

221 P. Mohanapriya, C. I. Sathish, R. Pradeepkumar, H. Segawa, K. Yamaura, K. Watanabe, T. S. Natarajan and N. V. Jaya, J. Nanosci. Nanotechnol., 2013, 13, 5391-5400.

222 M. C. Maldonado-Orozco, M. T. Ochoa-Lara, J. E. SosaMarquez, R. P. Talamantes-Soto, A. Hurtado-Macias, R. Lopez Anton, J. A. Gonzalez, J. T. Holguin-Momaca, S. F. OliveMendez and F. Espinosa-Magana, J. Am. Ceram. Soc., 2019, 102, 2800-2809.

223 S. Liu, J. Jia, J. Wang, S. Liu, X. Wang, H. Song and X. Hu, J. Magn. Magn. Mater., 2012, 324, 2070-2074.

224 C. Eid, E. Assaf, R. Habchi, P. Miele and M. Bechelany, RSC Adv., 2015, 5, 97849-97854.

225 N. A. M. Barakat, M. F. Abadir, K. T. Nam, A. M. Hamza, S. S. Al-Deyab, W.-I. Baek and H. Y. Kim, J. Mater. Chem., 2011, 21, 10957-10964.

226 F. Wang, Y. Sun, D. Li, B. Zhong, Z. Wu, S. Zuo, D. Yan, R. Zhuo, J. Feng and P. Yan, Carbon, 2018, 134, 264-273.

227 J. Zhang, P. Wang, Y. Chen, G. Wang, D. Wang, L. Qiao, T. Wang and F. Li, J. Electron. Mater., 2018, 47, 4703-4709.

228 Y. Jiang, X. Fu, Z. Zhang, W. Du, P. Xie, C. Cheng and R. Fan, J. Alloys Compd., 2019, 804, 305-313. 
229 I. Abdalla, A. Salim, M. Zhu, J. Yu, Z. Li and B. Ding, ACS Appl. Mater. Interfaces, 2018, 10, 44561-44569.

230 A. Chaudhary, S. Kumari, R. Kumar, S. Teotia, B. P. Singh, A. P. Singh, S. K. Dhawan and S. R. Dhakate, ACS Appl. Mater. Interfaces, 2016, 8, 10600-10608.

231 F. M. Oliveira and R. Gusmão, ACS Appl. Electron. Mater., 2020, 2, 3048-3071.

232 T. Wang, H. Wang, X. Chi, R. Li and J. Wang, Carbon, 2014, 74, 312-318.

233 F. Shahzad, M. Alhabeb, C. B. Hatter, B. Anasori, S. Man Hong, C. M. Koo and Y. Gogotsi, Science, 2016, 353, 1137-1140.

234 M. An, J. Cui and L. Wang, J. Phys. Chem. C, 2014, 118, 3062-3068.

235 W. Song, Z. Z. Yang, F. Q. Ma, M. Q. Chi, B. Zhao and X. F. Lu, RSC Adv., 2017, 7, 40334-40341.

236 H. Zhao, L. Zhang, X. Gu, S. Li, B. Li, H. Wang, J. Yang and J. Liu, RSC Adv., 2015, 5, 10951-10959.

237 M.-J. Chang, H. Wang, H.-L. Li, J. Liu and H.-L. Du, J. Mater. Sci., 2018, 53, 3682-3691.

238 A. M. El-Rafei, A. S. El-Kalliny and T. A. Gad-Allah, J. Magn. Magn. Mater., 2017, 428, 92-98.

239 W. Wang, N. Li, Y. Chi, Y. Li, W. Yan, X. Li and C. Shao, Ceram. Int., 2013, 39, 3511-3518.

240 Y.-N. Feng, H.-C. Wang, Y.-D. Luo, Y. Shen and Y.-H. Lin, J. Appl. Phys., 2013, 113, 146101.

241 R. Yang, H. Sun, J. Li and Y. A. Li, Ceram. Int., 2018, 44, 14032-14035.

242 V. Pongsorrarith, C. Srisitthiratkul, K. Laohhasurayotin and N. Intasanta, Mater. Lett., 2012, 67, 1-4.

243 K. Y. A. Lin, M. T. Yang, J. T. Lin and Y. C. Du, Chemosphere, 2018, 208, 502-511.

244 Z. Zhang, Y. Jiang, M. Chi, Z. Yang, G. Nie, X. Lu and C. Wang, Appl. Surf. Sci., 2016, 363, 578-585.

245 E. Ghasemi, H. Ziyadi, A. M. Afshar and M. Sillanpaa, Chem. Eng. J., 2015, 264, 146-151.

246 D. Chen, Y. Li, M. Bao, Y. Hou, J. Jin, Z. Yin and Z. Wang, ACS Sustainable Chem. Eng., 2019, 7, 13786-13795.

247 J. J. Du and C. Y. Jing, J. Phys. Chem. C, 2011, 115, 17829-17835.

248 F.-C. Liang, Y.-L. Luo, C.-C. Kuo, B.-Y. Chen, C.-J. Cho, F.-J. Lin, Y.-Y. Yu and R. Borsali, Polymers, 2017, 9, 136.

249 S. Zhan, D. Zhu, G. Ren, Z. Shen, M. Qiu, S. Yang, H. Yu and Y. Li, ACS Appl. Mater. Interfaces, 2014, 6, 16841-16850.

250 S. Al-Meer, Z. K. Ghouri, K. Elsaid, A. Easa, M. T. Al-Qahtani and M. S. Akhtar, J. Alloys Compd., 2017, 723, 477-483.

251 M. Venkatesan, L. Veeramuthu, F.-C. Liang, W.-C. Chen, C.-J. Cho, C.-W. Chen, J.-Y. Chen, Y. Yan, S.-H. Chang and C.-C. Kuo, Chem. Eng. J., 2020, 397, 125431.

252 P. Zhou, F. Liang, Y. Liu, R. Deng, H. Yang, Q. Wang, X. Qu and Z. Yang, Sci. China Mater., 2015, 58, 961-968.

253 N. H. A. Ngadiman, A. Idris, M. Irfan, D. Kurniawan, N. M. Yusof and R. Nasiri, J. Mech. Behav. Biomed. Mater., 2015, 49, 90-104.

254 J. Meng, B. Xiao, Y. Zhang, J. Liu, H. Xue, J. Lei, H. Kong, Y. Huang, Z. Jin, N. Gu and H. Xu, Sci. Rep., 2013, 3, 2655.

255 N. H. A. Ngadiman, N. Mohd Yusof, A. Idris, D. Kurniawan and E. Fallahiarezoudar, J. Bioact. Compat. Polym., 2017, 32, 411-428.
256 R. K. Singh, K. D. Patel, J. H. Lee, E.-J. Lee, J.-H. Kim, T.-H. Kim and H.-W. Kim, PLoS One, 2014, 9, e91584.

257 Q. Cai, Y. Shi, D. Shan, W. Jia, S. Duan, X. Deng and X. Yang, Mater. Sci. Eng., C, 2015, 55, 166-173.

258 J. T. Kannarkat, J. Battogtokh, J. Philip, O. C. Wilson and P. M. Mehl, J. Appl. Phys., 2010, 107, 09 B307.

259 A. Jedlovszky-Hajdu, K. Molnar, P. M. Nagy, K. Sinko and M. Zrinyi, Colloids Surf., A, 2016, 503, 79-87.

260 N. Shankhwar, M. Kumar, B. B. Mandal and A. Srinivasan, Mater. Sci. Eng., C, 2016, 69, 1167-1174.

261 J. Jose, R. Kumar, S. Harilal, G. E. Mathew, D. G. T. Parambi, A. Prabhu, M. S. Uddin, L. Aleya, H. Kim and B. Mathew, Environ. Sci. Pollut. Res., 2020, 27, 19214-19225.

262 H. P. Kok, P. Wust, P. R. Stauffer, F. Bardati, G. C. van Rhoon and J. Crezee, Radiat. Oncol., 2015, 10, 196.

263 X. Feng, J. Li, X. Zhang, T. Liu, J. Ding and X. Chen, J. Controlled Release, 2019, 302, 19-41.

264 S. Thakkar and M. Misra, Eur. J. Pharm. Sci., 2017, 107, 148-167.

265 M. Jin, D.-G. Yu, C. F. G. C. Geraldes, G. R. Williams and S. W. A. Bligh, Mol. Pharmaceutics, 2016, 13, 2457-2465.

266 A. R. K. Sasikala, A. R. Unnithan, Y.-H. Yun, C. H. Park and C. S. Kim, Acta Biomater., 2016, 31, 122-133.

267 H. Zhang, J. Xia, X. Pang, M. Zhao, B. Wang, L. Yang, H. Wan, J. Wu and S. Fu, Mater. Sci. Eng., C, 2017, 73, 537-543.

268 H. J. Haroosh, Y. Dong and G. D. Ingram, J. Polym. Sci., Part B: Polym. Phys., 2013, 51, 1607-1617.

269 M. R. Hasan, S. H. Baek, K. S. Seong, J. H. Kim and I. K. Park, ACS Appl. Mater. Interfaces, 2015, 7, 5768-5774.

270 F.-R. Fan, Z.-Q. Tian and Z. Lin Wang, Nano Energy, 2012, 1, 328-334.

271 P. Glynne-Jones, S. Beeby and N. White, IEE Proc.-A: Sci., Meas. Technol., 2001, 148, 68-72.

272 X. Chen, Y. Wu, A. Yu, L. Xu, L. Zheng, Y. Liu, H. Li and Z. Lin Wang, Nano Energy, 2017, 38, 91-100.

273 K. Dong, J. Deng, Y. Zi, Y.-C. Wang, C. Xu, H. Zou, W. Ding, Y. Dai, B. Gu, B. Sun and Z. L. Wang, Adv. Mater., 2017, 29, 1702648.

274 G. Zhu, C. Pan, W. Guo, C.-Y. Chen, Y. Zhou, R. Yu and Z. L. Wang, Nano Lett., 2012, 12, 4960-4965.

275 Z. L. Wang, ACS Nano, 2013, 7, 9533-9557.

276 W. Zeng, L. Shu, Q. Li, S. Chen, F. Wang and X.-M. Tao, Adv. Mater., 2014, 26, 5310-5336.

277 Y. Mao, P. Zhao, G. McConohy, H. Yang, Y. Tong and X. Wang, Adv. Energy Mater., 2014, 4, 1301624.

278 Z. Pi, J. Zhang, C. Wen, Z.-B. Zhang and D. Wu, Nano Energy, 2014, 7, 33-41.

279 S. Cheon, H. Kang, H. Kim, Y. Son, J. Y. Lee, H.-J. Shin, S.-W. Kim and J. Cho, Adv. Funct. Mater., 2017, 28, 1703778.

280 R. A. Whiter, V. Narayan and S. Kar-Narayan, Adv. Energy Mater., 2014, 4, 1400519.

281 D. Ponnamma, O. Aljarod, H. Parangusan and M. A. AlMaadeed, Mater. Chem. Phys., 2020, 239, 122257.

282 J.-S. Im and I.-K. Park, ACS Appl. Mater. Interfaces, 2018, 10, 25660-25665. 
283 W. Wu, S. Bai, M. Yuan, Y. Qin, Z. L. Wang and T. Jing, ACS Nano, 2012, 6, 6231-6235.

284 A. Ehrmann and T. Blachowicz, J. Magn. Magn. Mater., 2019, 475, 727.

285 N. Kikuchi, S. Okamoto, O. Kitakami, Y. Shimada, S. G. Kim, Y. Otani and K. Fukamichi, J. Appl. Phys., 2001, 90, 6548-6549.

286 B. Van Waeyenberge, A. Puzic, H. Stoll, K. W. Chou, T. Tyliszczak, R. Hertel, M. Faehnle, H. Brueckl, K. Rott, G. Reiss, I. Neudecker, D. Weiss, C. H. Back and G. Schuetz, Nature, 2006, 444, 461-464.

287 M. Weigand, B. Van Waeyenberge, A. Vansteenkiste, M. Curcic, V. Sackmann, H. Stoll, T. Tyliszczak, K. Kaznatcheev, D. Bertwistle, G. Woltersdorf, C. H. Back and G. Schuetz, Phys. Rev. Lett., 2009, 102, 077201.

288 T. Blachowicz, C. Dopke and A. Ehrmann, Nanomaterials, 2020, 10, 738.

289 H.-R. Kim, B.-S. Kim and I.-S. Kim, Mater. Chem. Phys., 2012, 135, 1024-1029.

290 E. Fallahiarezoudar, M. Ahmadipourroudposht, N. M. Yusof and A. Idris, Int. J. Polym. Mater. Polym. Biomater., 2015, 64, 15-24.

291 A. F. Lubambo, L. Ono, V. Drago, N. Mattoso, J. Varalda, M. R. Sierakowski, C. N. Sakakibara, R. A. Freitas and C. K. Saul, Carbohydr. Polym., 2015, 134, 775-783.

292 L. Hou, W. M. R. N. Udansawa, A. Pochiraju, W. Dong, Y. Zheng, R. J. Linhardt and T. J. Simmons, ACS Biomater. Sci. Eng., 2016, 2, 1905-1913.

293 L. Li, F. Wang, Y. Lv, J. Liu, D. Zhang and Z. Shao, Appl. Clay Sci., 2018, 161, 225-234.

294 T.-C. Lin, F.-H. Lin and J.-C. Lin, J. Biomater. Sci., Polym. Ed., 2013, 24, 1152-1163.

295 J. G. Duran-Guerrero, M. A. Martinez-Rodriguez, M. A. Garza-Navarro, V. A. Gonzalez-Gonzalez, A. Torres-Castro and J. R. De La Rosa, Carbohydr. Polym., 2018, 200, 289-296.

296 Y. Wei, X. Zhang, Y. Song, B. Han, X. Hu, X. Wang, Y. Lin and X. Deng, Biomed. Mater., 2011, 6, 055008.

297 T. Huang, P. Song, L. Jiang, Y. Peng, S. Feng and J. Wang, Electrophoresis, 2016, 37, 2050-2053.

298 D. Navarathne, Y. Ner, M. Jain, J. G. Grote and G. A. Sotzing, Mater. Lett., 2011, 65, 219-221.

299 A. GhavamiNejad, A. R. K. Sasikala, A. R. Unnithan, R. G. Thomas, Y. Y. Jeong, M. Vatankhah-Varnoosfaderani, F. J. Stadler, C. H. Park and C. S. Kim, Adv. Funct. Mater., 2015, 25, 2867-2875.

300 J. Guo, X. Ye, W. Liu, Q. Wu, H. Shen and K. Shu, Mater. Lett., 2009, 63, 1326-1328.

301 M. S. A. Darwish, A. Bakry, L. M. Al-Harbi, M. M. Khowdiary, A. A. El-Henawy and J. Yoon, J. Dispersion Sci. Technol., 2020, 41, 1711-1719.

302 M. S. A. Darwish, A. Bakry, O. Kolek, L. Martinova and I. Stibor, Polym. Compos., 2019, 40, 296-303.

303 R. Mincheva, O. Stoilova, H. Penchev, T. Ruskov, I. Spirov, N. Manolova and I. Rashkov, Eur. Polym. J., 2008, 44, 615-627.
304 D. Zhang, A. B. Karki, D. Rutman, D. R. Young, A. Wang, D. Cocke, T. H. Ho and Z. Guo, Polymer, 2009, 50, 4189-4198.

305 B. Wang, Y. Sun and H. Wang, J. Appl. Polym. Sci., 2010, 115, 1781-1786.

306 A. Sindelo and T. Nyokong, Heliyon, 2019, 5, e02352.

307 Z. Wang, Q. Ma, X. Dong, D. Li, X. Xi, W. Yu, J. Wang and G. Liu, ACS Appl. Mater. Interfaces, 2016, 8, 26226-26234.

308 S. Cavaliere, V. Salles, A. Brioude, Y. Lalatonne, L. Motte, P. Monod, D. Cornu and P. Miele, J. Nanopart. Res., 2010, 12, 2735-2740.

309 D. Li, Y. Gu, X. Xu, Y. Feng, Y. Ma, S. Li and C. Yao, Microchim. Acta, 2019, 186, 542.

310 X.-Y. Ye, Z.-M. Liu, Z.-G. Wang, X.-J. Huang and Z.-K. Xu, Mater. Lett., 2009, 63, 1810-1813.

311 N. Sabzroo, T. R. Bastami, M. Karimi, T. Heidari, S. Agarwal and V. K. Gupta, J. Ind. Eng. Chem., 2018, 60, 237-249.

312 H. Bagheri, M. N. Mobara, A. Roostaie and M. Y. Baktash, J. Sep. Sci., 2017, 40, 3857-3865.

313 H. Bagheri, P. Khanipour and S. Asgari, Anal. Chim. Acta, 2016, 934, 88-97.

314 P. Tiwari, S. Agarwal, S. Srivastava and S. Jain, J. Biomed. Mater. Res., Part B, 2018, 106, 40-51.

315 W. Xue, Y. Hu, F. Wang, X. Yang and L. Wang, Colloids Surf., A, 2019, 564, 115-121.

316 D. Demir, D. Gures, T. Tecim, R. Genc and N. Bolgen, Appl. Nanosci., 2018, 8, 1461-1469.

317 B. Wang, H. Zheng, M.-W. Chang, Z. Ahmad and J.-S. Li, Colloids Surf., B, 2016, 145, 757-767.

318 S. Wu, B. Wang, Z. Ahmad, J. Huang, M.-W. Chang and J.-S. Li, Mater. Lett., 2017, 204, 73-76.

319 M. Hadjian, D. Semnani and J. Varshosaz, Polym. Adv. Technol., 2019, 30, 2729-2741.

320 Q. Yu, M. Ma, P. Chen, Q. Wang, C. Lu, Y. Gao, R. Wang and H. Chen, Polym. Eng. Sci., 2017, 57, 1186-1192.

321 A. Wang, H. Singh, T. A. Hatton and G. C. Rutledge, Polymer, 2004, 45, 5505-5514.

322 I. Savva, O. Marinica, C. A. Papatryfonos, L. Vekas and T. Krasia-Christoforou, RSC Adv., 2015, 5, 16484-16496.

323 L. Burke, C. J. Mortimer, D. J. Curtis, A. R. Lewis, R. Williams, K. Hawkins, T. G. G. Maffeis and C. J. Wright, Mater. Sci. Eng., C, 2017, 70, 512-519.

324 D. Guo, Z. Sun, L. Xu, Y. Gao, M. Dai, S. Wang, Q. Chang, C. Wang and D. Ma, Mater. Lett., 2015, 159, 159-162.

325 E. Korina, O. Stoilova, N. Manolova and I. Rashkov, J. Mater. Sci., 2014, 49, 2144-2153.

326 M.-H. Ho, S.-Y. Li, C.-Y. Ciou and T.-M. Wu, J. Appl. Polym. Sci., 2014, 131, 41070.

327 S. T. Tan, J. H. Wendorff, C. Pietzonka, Z. H. Jia and G. Q. Wang, ChemPhysChem, 2005, 6, 1461-1465.

328 M. Kumar, D. Unruh, R. Sindelar and F. Renz, Nano Hybrids, 2017, 14, 39-47.

329 D. Shan, Y. Shi, S. Duan, Y. Wei, Q. Cai and X. Yang, Mater. Sci. Eng., C, 2013, 33, 3498-3505.

330 X. Xi, W. Yu, Q. Ma, D. Li, X. Dong, J. Wang and G. Liu, RSC Adv., 2018, 8, 31608-31617. 
331 H. Shao, Q. Ma, X. Dong, W. Yu, M. Yang, Y. Yang, J. Wang and G. Liu, Phys. Chem. Chem. Phys., 2015, 17, 21845-21855.

332 J. Tian, Q. Ma, W. Yu, D. Li, X. Dong, G. Liu and J. Wang, RSC Adv., 2019, 9, 10679-10692.

333 Y. Xie, Q. Ma, H. Qi, Y. Song, J. Tian, M. A. Musa, W. Yu, X. Dong, D. Li and G. Liu, RSC Adv., 2019, 9, 30890-30904.

334 Y. Xie, Q. Ma, H. Qi, Y. Song, J. Tian, W. Yu, X. Dong, D. Li, G. Liu and J. Wang, Nanotechnology, 2019, 30, 435602.

335 X. Xi, W. Yu, D. Li, Q. Ma, X. Dong, J. Wang and G. Liu, New J. Chem., 2018, 42, 18708-18716.

336 Q. Ma, J. Wang, X. Dong, W. Yu and G. Liu, Chem. Eng. J., 2015, 260, 222-230.

337 J. Tian, Q. Ma, W. Yu, D. Li, X. Dong, G. Liu and J. Wang, Mater. Des., 2019, 170, 107701.

338 D. Yin, Q. Ma, X. Dong, N. Lv, J. Wang, W. Yu and G. Liu, ChemPlusChem, 2015, 80, 568-575.

339 S.-R. Huang, K.-F. Lin, T.-M. Don, W.-Y. Chiu and M.-F. Lin, J. Polym. Sci., Part A: Polym. Chem., 2015, 53, 2152-2162.

340 A. Feizbakiish and S. Ehteshami, J. AOAC Int., 2017, 100, 198-205.

341 B. Song, J. Zhu and H. Fan, Mar. Pollut. Bull., 2017, 120, 159-164.

342 S. Wang, C. Wang, B. Zhang, Z. Sun, Z. Li, X. Jiang and X. Bai, Mater. Lett., 2010, 64, 9-11.

343 X. Huang, R. Wang, T. Jiao, G. Zou, F. Zhan, J. Yin, L. Zhang, J. Zhou and Q. Peng, ACS Omega, 2019, 4, 1897-1906.

344 E. Korina, O. Stoilova, N. Manolova and I. Rashkov, J. Environ. Chem. Eng., 2018, 6, 2075-2084.

345 O. Chiscan, I. Dumitru, P. Postolache, V. Tura and A. Stancu, Mater. Lett., 2012, 68, 251-254.

346 T. Zheng, Z. Yue, G. G. Wallace, Y. Du, P. Martins, S. LancerosMendez and M. J. Higgins, Nanotechnology, 2017, 28, 065707.

347 V. Kalra, J. Lee, J. H. Lee, S. G. Lee, M. Marquez, U. Wiesner and Y. L. Joo, Small, 2008, 4, 2067-2073.

348 Y. Liu, Q. Ma, X. Dong, W. Yu, J. Wang and G. Liu, Phys. Chem. Chem. Phys., 2015, 17, 22977-22984.

349 Y. Liu, Q. Ma, M. Yang, X. Dong, Y. Yang, J. Wang, W. Yu and G. Liu, Chem. Eng. J., 2016, 284, 831-840.

350 B. Wang, P.-p. Zhang, G. R. Williams, C. Branford-White, J. Quan, H.-l. Nie and L.-m. Zhu, J. Mater. Sci., 2013, 48, 3991-3998.

351 X. Xi, Q. Ma, X. Dong, J. Wang, W. Yu and G. Liu, IEEE Trans. Nanotechnol., 2015, 14, 243-249.

352 D. Yin, Q. Ma, X. Dong, N. Lv, J. Wang, W. Yu and G. Liu, J. Mater. Sci.: Mater. Electron., 2015, 26, 2658-2667.

353 X. Xi, Q. Ma, X. Dong, D. Li, W. Yu, J. Wang and G. Liu, J. Mater. Sci.: Mater. Electron., 2018, 29, 10284-10300.

354 H. Chen, Q. Ma, J. Tian, X. Li, D. Li, X. Dong, W. Yu, J. Wang and G. Liu, New J. Chem., 2019, 43, 7984-7996.

355 K. Nasouri and A. M. Shoushtari, J. Thermoplast. Compos. Mater., 2018, 31, 431-446.

356 C.-R. Lin, T.-C. Tsai, M. Chung and S.-Z. Lu, J. Appl. Phys., 2009, 105, 07B509.

357 S. Sheng, Q. Ma, X. Dong, N. Lv, J. Wang, W. Yu and G. Liu, J. Mater. Sci.: Mater. Electron., 2014, 25, 1309-1316.
358 J. Choi, J. Kim, H. Yang, F. K. Ko and K. H. Kim, J. Magn., 2015, 20, 215-220.

359 M. Chen, H. Qu, J. Zhu, Z. Luo, A. Khasanov, A. S. Kucknoor, N. Haldolaarachchige, D. R. Young, S. Wei and Z. Guo, Polymer, 2012, 53, 4501-4511.

360 J. Dankova, M. Buzgo, J. Vejpravova, S. Kubickova, V. Sovkova, L. Vyslouzilova, A. Mantlikova, A. Necas and E. Amler, Int. J. Nanomed., 2015, 10, 7307-7317.

361 L. Li, G. Yang, J. Li, S. Ding and S. Zhou, Mater. Sci. Eng., C, 2014, 34, 252-261.

362 N. Hernandez, V. A. Gonzalez-Gonzalez, I. B. Dzul-Bautista, N. Ornelas-Soto, J. M. Barandiaran and J. Gutierrez, Eur. Polym. J., 2018, 109, 336-340.

363 T. Song, Y. Z. Zhang and T. J. Zhou, J. Magn. Magn. Mater., 2006, 303, E286-E289.

364 Z. Thompson, S. Rahman, S. Yarmolenko, J. Sankar, D. Kumar and N. Bhattarai, Materials, 2017, 10, 937.

365 M. Asadi, S. Shahabuddin, A. Mollahosseini, J. Kaur and R. Saidur, J. Inorg. Organomet. Polym. Mater., 2019, 29, 1057-1066.

366 B.-R. Koo, I.-K. Park and H.-J. Ahn, J. Alloys Compd., 2014, 603, 52-56.

367 C.-J. Li, B. Wang and J.-N. Wang, J. Nanosci. Nanotechnol., 2012, 12, 2522-2528.

368 C.-J. Li and J.-N. Wang, Mater. Lett., 2010, 64, 586-588.

369 G.-F. Liu, Z.-D. Zhang, F. Dang, C.-B. Cheng, C.-X. Hou and S.-D. Liu, J. Magn. Magn. Mater., 2016, 412, 55-62.

370 F. Bi, X. Dong, J. Wang and G. Liu, J. Mater. Sci., 2015, 50, 1679-1687.

371 X. Xi, Q. Ma, M. Yang, X. Dong, J. Wang, W. Yu and G. Liu, J. Mater. Sci.: Mater. Electron., 2014, 25, 4024-4032.

372 X. Xu, Q. Wang, H. C. Choi and Y. H. Kim, J. Membr. Sci., 2010, 348, 231-237.

373 T.-I. Yang and S.-H. Chang, Nanotechnology, 2017, 28, 055601.

374 V. Guarino, G. Ausanio, V. Iannotti, L. Ambrosio and L. Lanotte, eXPRESS Polym. Lett., 2018, 12, 318-329.

375 R. Brito-Pereira, D. M. Correia, C. Ribeiro, A. Francesko, I. Etxebarria, L. Perez-Alvarez, J. L. Vilas, P. Martins and S. Lanceros-Mendez, Composites, Part B, 2018, 141, 70-75.

376 I. Munaweera, A. Aliev and K. J. Balkus Jr, ACS Appl. Mater. Interfaces, 2014, 6, 244-251.

377 O. Nakhaei, N. Shahtahmassebi, M. R. Roknabadi and M. Behdani, Appl. Phys. A: Mater. Sci. Process., 2016, 122, 537.

378 K. Nasouri and A. M. Shoushtari, Compos. Sci. Technol., 2017, 145, 46-54.

379 K. Nasouri, A. M. Shoushtari and M. R. M. Mojtahedi, J. Polym. Res., 2016, 23, 71.

380 K. Nasouri, A. M. Shoushtari and M. R. M. Mojtahedi, Polym. Compos., 2017, 38, 2026-2034.

381 M. Chowdhury and G. Stylios, J. Mater. Sci., 2011, 46, 3378-3386.

382 S. B. Lee, S. J. Hong, J. W. Yi, S. K. Lee, Y. H. Choa and J. B. Kim, Met. Mater. Int., 2012, 18, 165-170.

383 Z. Zhu, Y. Xu, B. Qi, G. Zeng, P. Wu, G. Liu, W. Wang, F. Cui and Y. Sun, Environ. Sci.: Nano, 2017, 4, 302-306. 
384 Z.-d. Zhang, H. Wang, C. Qin, S. Chen, X. Ji, K. Sun, M. Chen, R.-h. Fan and X. Han, Mater. Des., 2016, 89, 543-548.

385 N. Cai, M. Chen, M. Liu, J. Wang, L. Shen, J. Wang, X. Feng and F. Yu, J. Mol. Liq., 2019, 289, 111060.

386 X. Meng and S. Dong, J. Alloys Compd., 2019, 810, 151806. 387 K.-Y. A. Lin, J.-T. Lin, X.-Y. Lu, C. Hung and Y.-F. Lin, J. Colloid Interface Sci., 2017, 505, 728-735.

388 H.-Y. Mi, X. Jing, H. Xie, H.-X. Huang and L.-S. Turng, Chem. Eng. J., 2018, 337, 541-551.

389 N. A. M. Barakat, B. Kim, S. J. Park, Y. Jo, M.-H. Jung and H. Y. Kim, J. Mater. Chem., 2009, 19, 7371-7378.

390 N. A. M. Barakat, B. Kim, C. Yi, Y. Jo, M.-H. Jung, K. H. Chu and H. Y. Kim, J. Phys. Chem. C, 2009, 113, 19452-19457.

391 J. Yu, D.-H. Nam, Y.-J. Lee and J. Y. Chang, J. Microelectron. Electron. Packag., 2016, 23, 57-63.

392 S.-R. Huang, K.-F. Lin, C.-F. Lee and W.-Y. Chiu, J. Polym. Sci., Part A: Polym. Chem., 2014, 52, 848-856.

393 D. Li, L. Luo, Z. Pang, L. Ding, Q. Wang, H. Ke, F. Huang and Q. Wei, ACS Appl. Mater. Interfaces, 2014, 6, 5144-5151.

394 T. Ren, Y. Si, J. Yang, B. Ding, X. Yang, F. Hong and J. Yu, J. Mater. Chem., 2012, 22, 15919-15927.

395 R. K. Sadasivam, S. Mohiyuddin and G. Packirisamy, ACS Omega, 2017, 2, 6556-6569.

396 X. Huang, Y. Chen, J. Yu, J. Zhang, T. Sang, G. Tao and H. Zhu, J. Mater. Sci.: Mater. Electron., 2015, 26, 3474-3478.

397 Y. Yuan, Y. Feng, X. Zhao, M. Yang, H. Lu, J. Li, Y. Du, Y. Li and X. He, Ceram. Int., 2018, 44, 6673-6680.

398 Y. Si, T. Ren, Y. Li, B. Ding and J. Yu, Carbon, 2012, 50, 5176-5185.

399 J. Wu, N. Wang, Y. Zhao and L. Jiang, Nanoscale, 2015, 7, 2625-2632.

400 Z. Ying, C. Z. Jing, Z. Jin, M. Z. Yong, F. Lin and J. Lei, ChemPhysChem, 2006, 7, 336-341.

401 R. Guo, T. Jiao, R. Xing, Y. Chen, W. Guo, J. Zhou, L. Zhang and Q. Peng, Nanomaterials, 2017, 7, 317.

402 N. A. M. Barakat, J. Mater. Sci., 2012, 47, 6237-6245.

403 F. Mou, J.-g. Guan, W. Shi, Z. Sun and S. Wang, Langmuir, 2010, 26, 15580-15585.

404 W. W. Pan, Q. F. Liu, R. Han, X. Chi and J. B. Wang, Appl. Phys. A: Mater. Sci. Process., 2013, 113, 755-761.

405 G. George and S. Anandhan, RSC Adv., 2014, 4, 62009-62020.

406 H. K. Kim, W. Honda, B. S. Kim and I. S. Kim, J. Mater. Sci., 2013, 48, 1111-1116.

407 A. Garcia-Marquez, S. Glatzel, A. Kraupner, K. Kiefer, K. Siemensmeyer and C. Giordano, Chem. - Eur. J., 2018, 24, 4895-4901.

408 J. Zhu, S. Wei, D. Rutman, N. Haldolaarachchige, D. R. Young and Z. Guo, Polymer, 2011, 52, 2947-2955.

409 N. A. M. Barakat, M. F. Abadir, M. S. Akhtar, M. El-Newehy, Y.-S. Shin and H. Y. Kim, Mater. Lett., 2012, 85, 120-123.

410 A. Baranowska-Korczyc, A. Reszka, K. Sobczak, B. Sikora, P. Dziawa, M. Aleszkiewicz, L. Klopotowski, W. Paszkowicz, P. Dluzewski, B. J. Kowalski, T. A. Kowalewski, M. Sawicki, D. Elbaum and K. Fronc, J. Sol-Gel Sci. Technol., 2012, 61, 494-500.
411 X. Huang and S. W. Or, Mater. Lett., 2019, 238, 271-274.

412 R. Zhang, H. Wu, D. D. Lin and W. Pan, J. Am. Ceram. Soc., 2010, 93, 605-608.

413 P. Mohanapriya and N. V. Jaya, J. Nanosci. Nanotechnol., 2015, 15, 2226-2233.

414 X. Y. Li, J. N. Wang, L. L. Zhang and C. J. Li, J. Mater. Sci., 2012, 47, 465-472.

415 G. G. Philip, A. Senthamizhan, T. S. Natarajan, G. Chandrasekaran and H. A. Therese, Ceram. Int., 2015, 41, 13361-13365.

416 J. Xiang, G. Z. Zhou, X. Q. Shen, Y. Q. Chu and Y. T. Guo, J. Sol-Gel Sci. Technol., 2012, 62, 186-192.

417 Z. Zhu, C. Ji, L. Zhong, S. Liu, F. Cui, H. Sun and W. Wang, J. Mater. Chem. A, 2017, 5, 18071-18080.

418 Y. Hou, Y. Zhang, X. Du, Y. Yang, C. Deng, Z. Yang, L. Zheng and L. Cheng, RSC Adv., 2018, 8, 33574-33582.

419 N. A. M. Barakat, K. A. Khalil, I. H. Mahmoud, M. A. Kanjwal, F. A. Sheikh and H. Y. Kim, J. Phys. Chem. C, 2010, 114, 15589-15593.

420 N. A. M. Barakat, K. A. Khalil and H. Y. Kim, Mater. Res. Bull., 2012, 47, 2140-2147.

421 K. R. Sapkota, P. Gyawali, A. Forbes, I. L. Pegg and J. Philip, J. Appl. Phys., 2012, 111, 123906.

422 J. Lee, T.-Y. Hwang, M. K. Kang, G. Lee, H.-B. Cho, J. Kim and Y.-H. Choa, Appl. Surf. Sci., 2019, 471, 273-276.

423 N. A. M. Barakat, A. A. Elzatahry and K. A. Khalil, Mater. Res. Bull., 2014, 49, 503-508.

424 H. P. Li, X. L. Qin, W. Zhang and W. Pan, J. Am. Ceram. Soc., 2012, 95, 217-222.

425 C. J. Li and G. R. Xu, Mater. Sci. Eng., B, 2011, 176, 552-558.

426 P. Moradipour, L. Rajabi and F. Dabirian, J. Aust. Ceram. Soc., 2018, 54, 23-32.

427 Y. Luo, S. Nartker, M. Wiederoder, H. Miller, D. Hochhalter, L. T. Drzal and E. C. Alocilja, IEEE Trans. Nanotechnol., 2012, 11, 676-681.

428 W. Sun, X. Lu, Y. Xue, Y. Tong and C. Wang, Macromol. Mater. Eng., 2014, 299, 361-367.

429 W. Pan, Z. Ma, J. Liu, Q. Liu and J. Wang, Mater. Lett., 2011, 65, 3269-3271.

430 S. Nilmoung, P. Kidkhunthod, S. Pinitsoontorn, S. Rujirawat, R. Yimnirun and S. Maensiri, Appl. Phys. A: Mater. Sci. Process., 2015, 119, 141-154.

431 J. D. Starr, M. A. K. Budi and J. S. Andrew, J. Am. Ceram. Soc., 2015, 98, 12-19.

432 J. Fu, J. Zhang, Y. Peng, J. Zhao, G. Tan, N. J. Mellors, E. Xie and W. Han, Nanoscale, 2012, 4, 3932-3936.

433 F. Bi, X. Dong, J. Wang and G. Liu, New J. Chem., 2015, 39, 3444-3451.

434 Z. Zhang, G. Yang, J. Wei, H. Bian, J. Gao, J. Li and T. Wang, J. Cryst. Grow., 2016, 445, 42-46.

435 P. D. Prasad and J. Hemalatha, Mater. Res. Express, 2019, 6, 094007.

436 M. J. Bauer, X. Wen, P. Tiwari, D. P. Arnold and J. S. Andrew, Microsyst. Nanoeng., 2018, 4, 37.

437 S.-H. Xie, J. Li, Y. Qiao, Y. Liu, L. Lan, Y. Zhou and S. Tan, Appl. Phys. Lett., 2008, 92, 062901. 
438 L. N. Pan, D. R. Cao, P. P. Jing, J. B. Wang and Q. F. Liu, Nanoscale Res. Lett., 2015, 10, 131.

439 R. Lu, M. Xu, B. Fu, Y. Zhang, C. Zhou, Y. Zeng, S. Yang, X. Song and X. Zhou, ChemistrySelect, 2016, 1, 1510-1514.

440 J. Dai, C. Cheng, Z. Li and W. Feng, Mater. Res. Express, 2019, 6, 086116.

441 E. Santala, M. Kemell, M. Leskela and M. Ritala, Nanotechnology, 2009, 20, 035602.

442 J. Zhang, J. Fu, G. Tan, F. Li, C. Luo, J. Zhao, E. Xie, D. Xue, H. Zhang, N. J. Mellors and Y. Peng, Nanoscale, 2012, 4, 2754-2759.

443 D. Li, T. Herricks and Y. N. Xia, Appl. Phys. Lett., 2003, 83, 4586-4588.

444 J. Zhang, S. Zhu, J. Ming, L. Qiao, F. Li, A. Karim, Y. Peng and J. Fu, Nanoscale, 2019, 11, 13824-13831.

445 J. Zhang, R. Kurosawa, H. Suematsu, T. Nakayama and S. S. Kim, Met. Mater. Int., 2012, 18, 505-508.

446 X. K. Zhang, J. Xiang, Z. P. Wu, L. Gong, X. Chen, G. G. Guan, Y. Wang and K. Y. Zhang, J. Alloys Compd., 2018, 764, 691-700.

447 Y. M. Ren, H. Y. Zhang, H. Z. An, Y. Zhao, J. Feng, L. L. Xue, T. Z. Luan and Z. J. Fan, J. Colloid Interface Sci., 2018, 526, 347-355.

448 H.-R. Jung, K. N. Kim and W.-J. Lee, Korean J. Chem. Eng., 2019, 36, 807-815.

449 P. Wang, T. Dong, M. Li and P. Yang, J. Nanosci. Nanotechnol., 2019, 19, 4474-4480.

450 J. Yan, S. Gao, C. Wang, B. Chai, J. Li, G. Song and S. Chen, Mater. Lett., 2016, 184, 43-46.

451 X. Huang, J. Zhang, S. Xiao, T. Sang and G. Chen, Mater. Lett., 2014, 124, 126-128.

452 C. Wang, X. Tan, J. Yan, B. Chai, J. Li and S. Chen, Appl. Surf. Sci., 2017, 396, 780-790.

453 J. Xie, Q. Wu and D. Zhao, Carbon, 2012, 50, 800-807.

454 M. Arias, V. M. Pantojas, O. Perales and W. Otano, J. Magn. Magn. Mater., 2011, 323, 2109-2114.

455 X. G. Huang, J. Zhang, S. R. Xiao and G. S. Chen, J. Am. Ceram. Soc., 2014, 97, 1363-1366.

456 J. Fu, J. Zhang, Y. Peng, C. Zhao, Y. He, Z. Zhang, X. Pan, N. J. Mellors and E. Xie, Nanoscale, 2013, 5, 12551-12557.

457 Z. Hou, J. Xiang, X. Zhang, L. Gong, J. Mi, X. Shen and K. Zhang, J. Mater. Sci.: Mater. Electron., 2018, 29, 12258-12268.

458 J.-H. Nam, Y.-H. Joo, J.-H. Lee, J. H. Chang, J. H. Cho, M. P. Chun and B. I. Kim, J. Magn. Magn. Mater., 2009, 321, 1389-1392.

459 N. Ghazi, H. M. Chenari and F. E. Ghodsi, J. Magn. Magn. Mater., 2018, 468, 132-140.

460 M. Li, H.-Y. Bai, Z.-L. Da, X. Yan, C. Chen, J.-H. Jiang, W.-Q. Fan and W.-D. Shi, Cryst. Res. Technol., 2015, 50, 244-249.

461 C. J. Li, J. N. Wang, B. Wang, J. R. Gong and Z. Lin, J. Nanosci. Nanotechnol., 2012, 12, 2496-2502.

462 J.-M. Li and X.-L. Zeng, Appl. Phys. Lett., 2017, 110, 083107. 463 A. Karaphun, S. Kaewmala, N. Meethong, S. Hunpratub and E. Swatsitang, J. Supercond. Novel Magn., 2018, 31, 1909-1916.
464 F. Song, X. Shen, M. Liu and J. Xiang, J. Solid State Chem., 2012, 185, 31-36.

465 F. Song, X. Shen, M. Liu and J. Xiang, J. Nanosci. Nanotechnol., 2011, 11, 6979-6985.

466 M. Q. Liu, F. Z. Song, X. Q. Shen and Y. W. Zhu, J. Sol-Gel Sci. Technol., 2010, 56, 39-46.

467 F.-Z. Mou, J.-G. Guan, Z.-G. Sun, X.-A. Fan and G.-X. Tong, J. Solid State Chem., 2010, 183, 736-743.

468 J. Liu, C. Gong and G. Fan, J. Sol-Gel Sci. Technol., 2012, 61, 185-191.

469 J. Zhang, J. Fu, F. Li, E. Xie, D. Xue, N. J. Mellors and Y. Peng, ACS Nano, 2012, 6, 2273-2280.

470 J. Xiang, Z. Hou, X. Zhang, L. Gong, Z. Wu and J. Mi, J. Alloys Compd., 2018, 737, 412-420.

471 J. S. Im, J. G. Kim, S.-H. Lee and Y.-S. Lee, Mater. Chem. Phys., 2010, 124, 434-438.

472 B. Li, C. Wang, W. Zhang, C. Hang, J. Fei and H. Wang, Mater. Lett., 2013, 91, 55-58.

473 D. Q. Zhang, J. Y. Cheng, J. X. Chai, J. J. Deng, R. Ren, Y. Su, H. Wang, C. Q. Ma, C. S. Lee, W. J. Zhang, G. P. Zheng and M. S. Cao, J. Alloys Compd., 2018, 740, 1067-1076.

474 X. Zhou, J. Xue, D. Zhou, Z. Wang, Y. Bai, X. Wu, X. Liu and J. Meng, ACS Appl. Mater. Interfaces, 2010, 2, 2689-2693.

475 J. Zheng, K. Du, D. Xiao, Z.-Y. Zhou, W.-G. Wei, J.-J. Chen, L.-F. Yin and J. Shen, Chin. Phys. Lett., 2016, 33, 097501.

476 W. Ponhan, V. Amornkitbamrung and S. Maensiri, J. Alloys Compd., 2014, 606, 182-188.

477 M. Q. Liu, X. Q. Shen, F. Z. Song, J. Xiang and R. J. Liu, J. Sol-Gel Sci. Technol., 2011, 59, 553-560.

478 J. Dai, Y. Dai, Z. Wang and H. Gao, J. Exp. Nanosci., 2015, 10, 249-257.

479 P. Mohanapriya, R. Pradeepkumar, N. V. Jaya and T. S. Natarajan, Appl. Phys. Lett., 2014, 105, 022406.

480 M. Liu, H. Liu, S. Sun, X. Li, Y. Zhou, Z. Hou and J. Lin, Langmuir, 2014, 30, 1176-1182.

481 Y. T. Wei, L. Zhong, D. Li, Q. L. Ma and X. T. Dong, Opt. Mater., 2019, 95, 109261.

482 D. Li, Q. L. Ma, Y. Song, X. Xi, X. T. Dong, W. S. Yu, J. X. Wang and G. X. Liu, RSC Adv., 2016, 6, 113045.

483 D. Li, Q. L. Ma, X. Xi, X. T. Dong, W. S. Yu, J. X. Wang and G. X. Liu, Chem. Eng. J., 2017, 309, 230-239.

484 J. Chen, Y. Song, D. Li, Q. Ma, X. Dong, W. Yu, X. Wang, Y. Yang, J. Wang and G. Liu, J. Lumin., 2019, 206, 509-517.

485 R. Tao, C. Shao, X. Li, X. Li, S. Liu, S. Yang, C. Zhao and Y. Liu, J. Colloid Interface Sci., 2018, 529, 404-414.

486 M. Sobhan, Q. Xu, Q. Yang, F. Anariba and P. Wu, Appl. Phys. Lett., 2014, 104, 051606.

487 S. H. Xie, J. Y. Li, R. Proksch, Y. M. Liu, Y. C. Zhou, Y. Y. Liu, Y. Ou, L. N. Lan and Y. Qiao, Appl. Phys. Lett., 2008, 93, 222904.

488 S. You, C. Liu, H. Liu, X. Yu, S. Li, W. Liu, S. Guo and X. Zhao, Mater. Lett., 2014, 130, 157-159.

489 K. Prashanthi and T. Thundat, Scanning, 2014, 36, 224-230. 490 Y. W. Zhao, H. Q. Fan, G. C. Liu, Z. Y. Liu and X. H. Ren, J. Alloys Compd., 2016, 675, 441-447.

491 E. A. Duarte, P. A. Quintero, M. W. Meisel and J. C. Nino, Phys. C, 2013, 495, 109-113. 
492 F. C. Lu, K. Yin, K. X. Fu, Y. N. Wang, J. Ren and Q. Xie, Ceram. Int., 2017, 43, 16101-16106.

493 B. Li, C. Wang, W. Liu, M. Ye and N. Wang, Mater. Lett., 2013, 90, 45-48.

494 T. Yang, J. Zheng, Q. Cheng, Y.-Y. Hu and C. K. Chan, ACS Appl. Mater. Interfaces, 2017, 9, 21773-21780.
495 X. Li, F. Guo, S. Y. Wang, X. Wang, X. L. Xu, J. Gao and W. F. Liu, Appl. Phys. Lett., 2015, 107, 062903.

496 D. Baiyila, X. Wang, X. Li, B. Sharileaodu, X. Li, L. Xu, Z. Liu, L. Duan and J. Liu, J. Mater. Chem. A, 2014, 2, 12304-12310.

497 V. D. M. Schiefferdecker, G. M. O. Barra, S. D. A. S. Ramoa and C. Merlini, Front. Mater., 2019, 6, 193. 